\title{
The Relationship of the Various MRI parameters and their contribution with Clinical and Cognitive Disability in Multiple Sclerosis
}

\author{
Ph.D. Thesis
}

Eszter Tóth M.D.

Clinical and Experimental Neuroscience Program, Doctoral School of Clinical Medicine Department of Neurology

Faculty of Medicine Albert Szent-Györgyi Clinical Center University of Szeged

Supervisors: Zsigmond Tamás Kincses M.D., Ph.D., D.Sc László Vécsei M.D., Ph.D., D.Sc.

Department of Neurology, Faculty of Medicine Albert Szent-Györgyi Clinical Center

University of Szeged 


\section{Original Publications directly related to the thesis:}

I. Gray Matter Atrophy Is Primarily Related to Demyelination of Lesions in Multiple Sclerosis: A Diffusion Tensor Imaging MRI Study.

Tóth E, Szabó N, Csete G, Király A, Faragó P, Spisák T, Bencsik K, Vécsei L, Kincses ZT.

Front Neuroanat. 2017 Mar 29;11:23. doi: 10.3389/fnana.2017.00023. eCollection 2017.

PMID: 28424595 IF: 3.152

II. The Contribution of Various MRI Parameters to Clinical and Cognitive Disability in Multiple Sclerosis

Eszter Tóth, Péter Faragó, András Király, Nikoletta Szabó, Dániel Veréb, Krisztián Kocsis, Bálint Kincses, Dániel Sandi, Krisztina Bencsik, László Vécsei and Zsigmond Tamás Kincses

Front. Neurol., 23 January 2019 | https://doi.org/10.3389/fneur.2018.01172 IF: 3.508

\section{Cumulative impact factor of the publications directly related to the thesis: $\mathbf{6 , 6 6}$}

\section{Original Publications not directly related to the thesis:}

I. Király A, Szabó N, Párdutz Á, Tóth E, Tajti J, Csete G, Faragó P, Bodnár P, Szok D, Tuka B, Pálinkás É, Ertsey C, Vécsei L, Kincses ZT.

Macro- and microstructural alterations of the subcortical structures in episodic cluster headache.

Cephalalgia. 2018 Apr;38(4):662-673. doi: 10.1177/0333102417703762.

Epub 2017 Apr 20. PubMed PMID: 28425325. IF: 3.882

II. Faragó P, Tuka B, Tóth E, Szabó N, Király A, Csete G, Szok D, Tajti J, Párdutz Á, Vécsei L, Kincses ZT.

Interictal brain activity differs in migraine with and without aura: resting state fMRI study.

J Headache Pain. 2017 Dec;18(1):8. doi: 10.1186/s10194-016-0716-8. Epub 2017 Jan 25. PubMed PMID: 28124204; PubMed Central PMCID: PMC5267588. IF: 3.403

III. Faragó P, Szabó N, Tóth E, Tuka B, Király A, Csete G, Párdutz Á, Szok D, Tajti J, Ertsey C, Vécsei L, Kincses ZT.

Ipsilateral Alteration of Resting State Activity Suggests That Cortical Dysfunction Contributes to the Pathogenesis of Cluster Headache.

Brain Topogr. 2017 Mar;30(2):281-289. doi:10.1007/s10548-016-0535-x. Epub 2016 Nov 4. PubMed PMID: 27815646. IF: 2.703

IV. Tóth E, Bencsik K, Vörös E, Fricska-Nagy Z, Füvesi J, Rajda C, Csomor A, Palkó A, Vécsei L, Kincses ZT.

The role of MRI in measuring the effectivity of disease modifying treatments I. Ideggyogy Sz. 2018 Mar 30;71(3-04):77-80. doi:10.18071/isz.71.0077. Review. Hungarian. PubMed PMID: 29889465. IF: 0.252

V. Kincses Z, Tóth E, Fricska-Nagy Z, Füvesi J, Rajda C, Bencsik K, Vörös E, Csomor A, Palkó A, Vécsei L.

The role of MRI in measuring the effectivity of disease modifying treatments II. 
Ideggyogy Sz. 2018 Mar 30;71(3-04):81-88. doi: 10.18071/isz.71.0081. Review. Hungarian. PubMed PMID: 29889466. IF: 0.252

VI. Tuka B, Szabó N, Tóth E, Kincses ZT, Párdutz Á, Szok D, Körtési T, Bagoly T, Helyes Z, Edvinsson L, Vécsei L, Tajti J.

Release of PACAP-38 in episodic cluster headache patients - an exploratory study. J Headache Pain. 2016 Dec;17(1):69. doi: 10.1186/s10194-016-0660-7. Epub 2016 Jul 30. PubMed PMID: 27475101; PubMed Central PMCID: PMC4967416. IF: 3.58

VII. Király A, Szabó N, Tóth E, Csete G, Faragó P, Kocsis K, Must A, Vécsei L, Kincses ZT.

Male brain ages faster: the age and gender dependence of subcortical volumes. Brain Imaging Behav. 2016 Sep;10(3):901-10. doi: 10.1007/s11682-015-9468-3. PubMed PMID: 26572143. IF: 3.985

VIII. Hoř́nek D, Štěpán-Buksakowska I, Szabó N, Erickson BJ, Tóth E, Šulc V, Beneš V, Vrána J, Hort J, Nimsky C, Mohapl M, Roček M, Vécsei L, Kincses ZT.

Difference in white matter microstructure in differential diagnosis of normal pressure hydrocephalus and Alzheimer's disease.

Clin Neurol Neurosurg. 2016 Jan;140:52-9. doi: 10.1016/j.clineuro.2015.11.010. Epub 2015 Nov 19. PubMed PMID: 26646649. IF: 1.381

IX. Kincses ZT, Tóth E, Bankó N, Veréb D, Szabó N, Csete G, Faragó P, Király A,Bencsik K, Vécsei L. Grey matter atrophy in patients suffering from multiple sclerosis. Ideggyogy Sz. 2014 Sep 30;67(9-10):293-300. Review. PubMed PMID:25518257. IF: 0.386

X. Szabó N, Faragó P, Király A, Veréb D, Csete G, Tóth E, Kocsis K, Kincses B, Tuka B, Párdutz Á, Szok D, Tajti J, Vécsei L, Kincses ZT.

Evidence for Plastic Processes in Migraine with Aura: A Diffusion Weighted MRI Study. Front Neuroanat.2018 Jan 17;11:138. doi: 10.3389/fnana.2017.00138. eCollection 2017. PubMed PMID: 29387002; PubMed Central PMCID: PMC5776127. IF: $\mathbf{3 . 1 5 2}$

XI. Veréb D, Szabó N, Tuka B, Tajti J, Király A, Faragó P, Kocsis K, Tóth E, Kincses B, Bagoly T, Helyes Z, Vécsei L, Kincses ZT.

Correlation of neurochemical and imaging markers in migraine: PACAP38 and DTI measures.

Neurology. 2018 Sep 18;91(12):e1166-e1174. doi:

10.1212/WNL.0000000000006201. Epub 2018 Aug 22. PubMed PMID: 30135251.

IF: 7.609

XII. Szabó N, Kincses ZT, Párdutz Á, Tóth E, Szok D, Csete G, Vécsei L.

White matter disintegration in cluster headache.

J Headache Pain. 2013 Jul 24;14:64. doi: 10.1186/1129-2377-14-64. PubMed PMID: 23883140; PubMed Central PMCID: PMC3728007. IF: 3.281

XIII. Csete G, Szabó N, Rokszin A, Tóth E, Braunitzer G, Benedek G, Vécsei L, Kincses ZT. 
An investigation of the white matter microstructure in motion detection using diffusion MRI. Brain Res. 2014 Jun 27;1570:35-42. doi: 10.1016/j.brainres.2014.05.006. Epub 2014 May 14. PubMed PMID: 24833063. IF: 2.036

XIV. Štěpán-Buksakowska I, Szabó N, Hořínek D, Tóth E, Hort J, Warner J, Charvát F, Vécsei L, Roček M, Kincses ZT.

Cortical and subcortical atrophy in Alzheimer disease: parallel atrophy of thalamus and hippocampus.

Alzheimer Dis Assoc Disord. 2014 Jan-Mar;28(1):65-72.

doi: 10.1097/WAD.0b013e318299d3d6. PubMed PMID: 23751371. IF: 2.44

XV. Tuka B, Helyes Z, Markovics A, Bagoly T, Szolcsányi J, Szabó N, Tóth E, Kincses ZT, Vécsei L, Tajti J.

Alterations in PACAP-38-like immunoreactivity in the plasma during ictal and interictal periods of migraine patients.

Cephalalgia. 2013 Oct;33(13):1085-95. doi: 10.1177/0333102413483931. Epub 2013 Apr 18. PubMed PMID: 23598374. IF: 4.121

XVI. Kincses ZT, Hořínek D, Szabó N, Tóth E, Csete G, Stěpán-Buksakowska I, Hort J, Vécsei L. The pattern of diffusion parameter changes in Alzheimer's disease, identified by means of linked independent component analysis.

J Alzheimers Dis. 2013;36(1):119-28. doi: 10.3233/JAD-122431. PubMed PMID: 23542867. IF: $\mathbf{3 . 6 1 2}$

XVII. Kincses ZT, Szabó N, Tóth E, Zádori D, Faragó P, Németh D, Janacsek K, Babos M, Klivényi P, Vécsei L.

Diffusion MRI measured white matter microstructure as a biomarker of neurodegeneration in preclinical Huntington's disease.

Ideggyogy Sz. 2013 Nov 30;66(11-12):399-405. PubMed PMID: 24555239. IF: 0.343

XVIII. Király A, Kincses ZT, Szabó N, Tóth E, Csete G, Faragó P, Vécsei L.

Gray matter atrophy in presymptomatic Huntington's patients. Ideggyogy Sz. $2016 \mathrm{Jul}$ 30;69(7-8):261-267. doi: 10.18071/isz.69.0261. PubMed PMID: 29465891. IF:0.322

Cumulative impact factor of the publications not directly related to the thesis: $\mathbf{4 6 . 6 9 7}$

Total impact factor: $\mathbf{5 3 . 3 5 7}$ 


\section{TABLE OF CONTENTS}

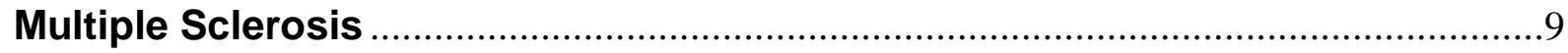

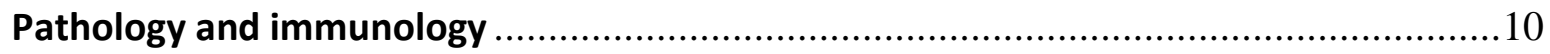

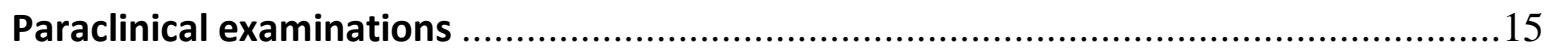

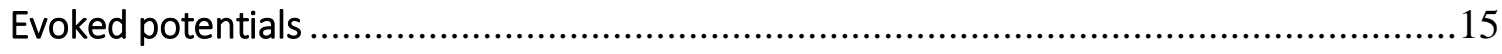

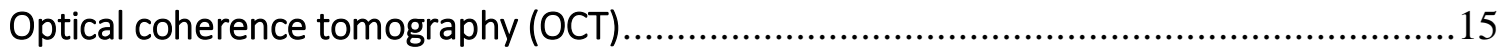

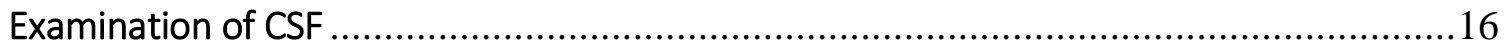

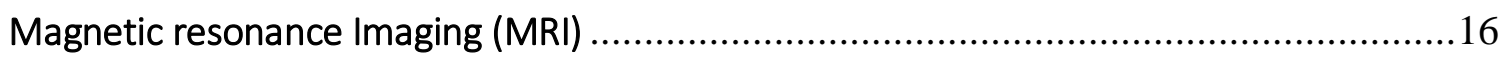

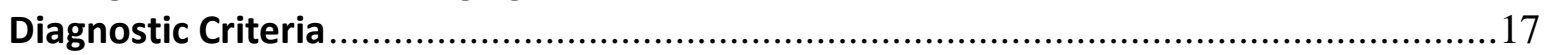

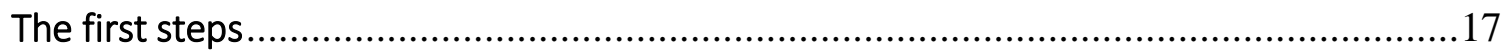

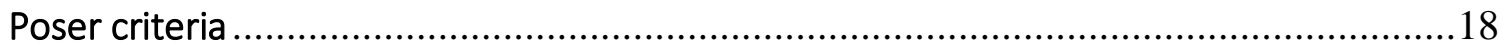

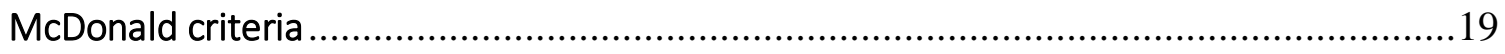

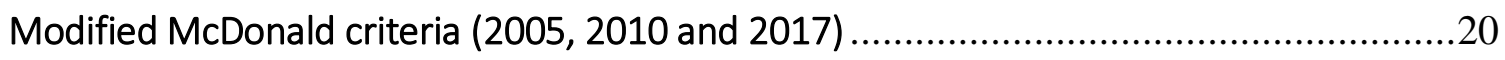

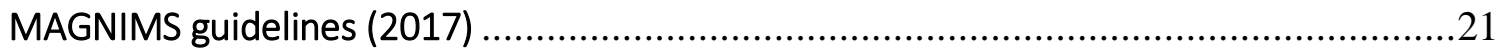

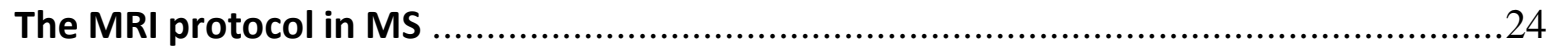

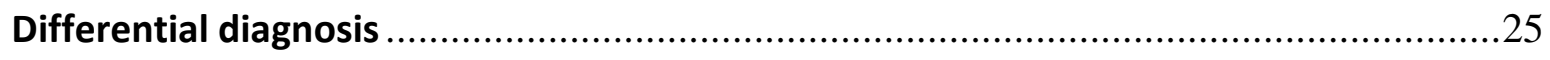

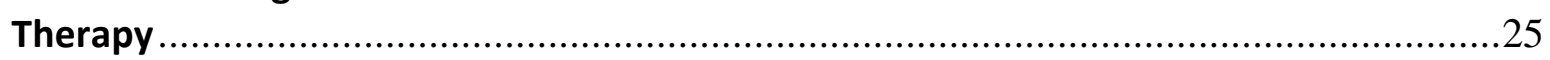

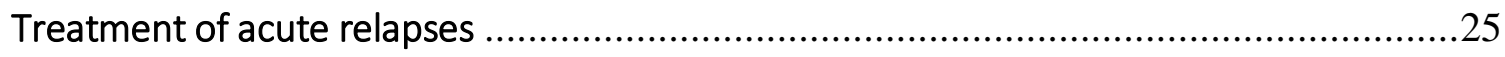

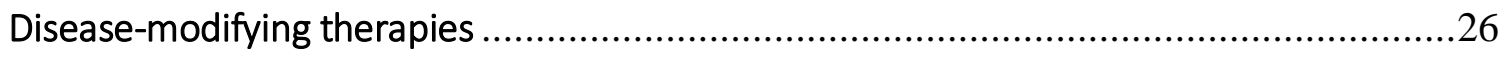

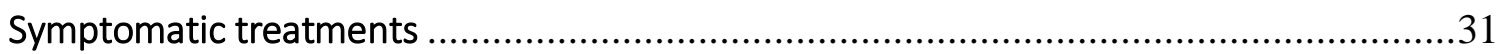

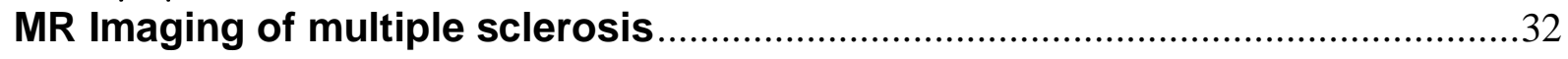

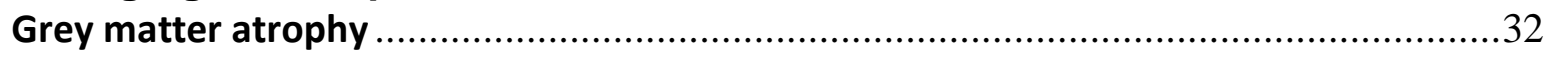

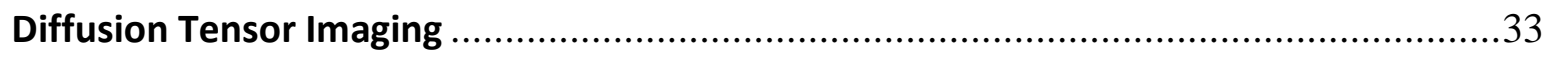

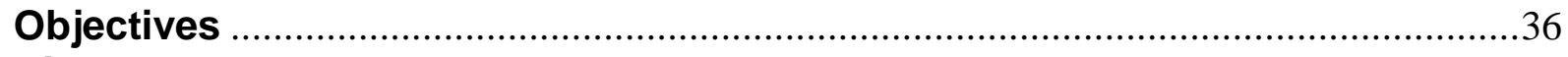

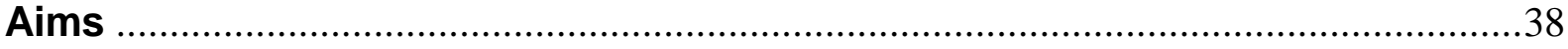

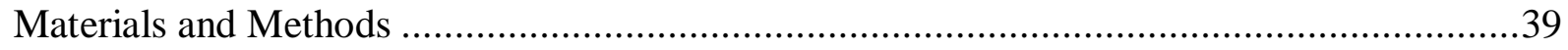

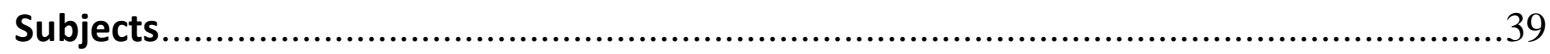

Cognitive assessment of the patients .................................................................... 40

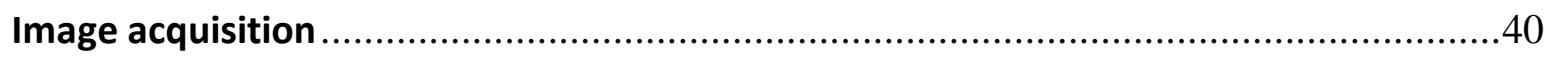

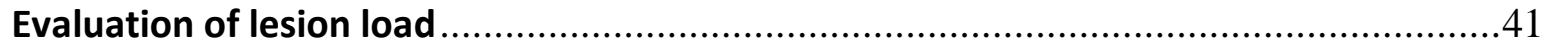

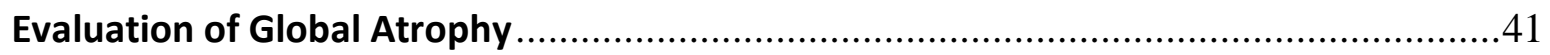

Volumetric analysis of the subcortical structures ................................................... 41

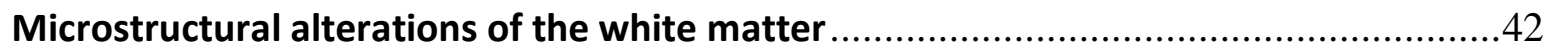

Analysis of the connection between the MR parameters and clinical and cognitive status and between Brain Atrophy and the Compartmental Diffusion Metrics .......................43

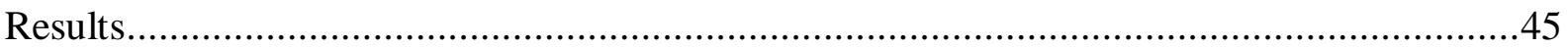

Clinical, cognitive and imaging parameters of the patients .......................................45

Lesion Probability Distribution.........................................................................49

The Connection between the Brain Atrophy and the Compartmental White Matter

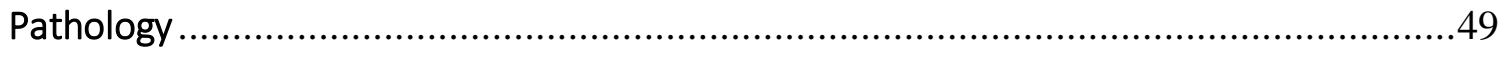

The imaging parameters influencing clinical and cognitive functions...........................51

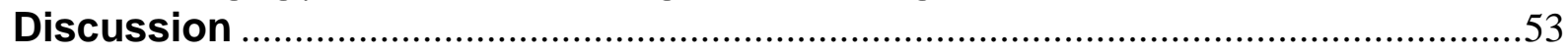

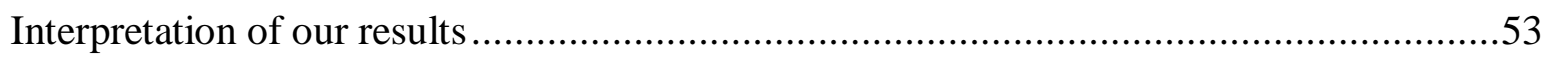

The pathological background of the diffusion parameter and its connection with cortical

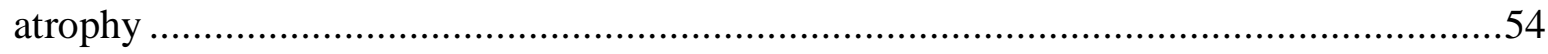

The imaging parameters influencing clinical and cognitive functions ..........................55

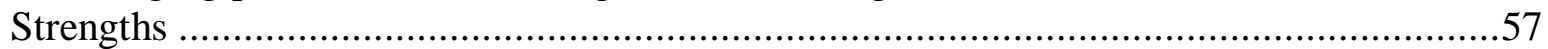




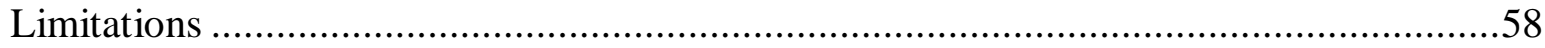

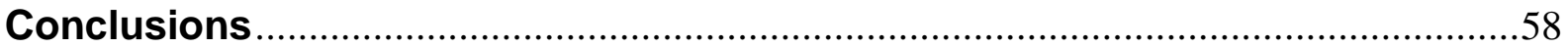

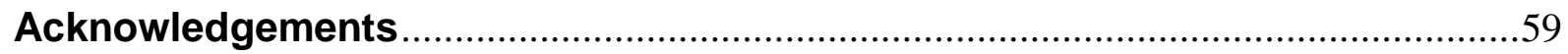

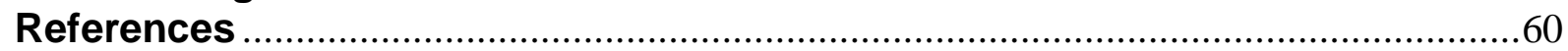


List of abbreviations:

AD - axial diffusivity

ADEM - Acute disseminated encephalomyelitis

ALT - alanine aminotransferase

BAEP - brainstem auditory evoked potential

BICAMS - Brief International Cognitive Assessment for MS

$\mathrm{BP}$ - blood pressure

BVMT - Brief visuospatial memory test

CADASIL - Cerebral Autosomal Dominant Arteriopathy with Subcortical Infarcts and

Leukoencephalopathy

$\mathrm{CC}$ - corpus callosum

CIS - clinically isolated syndrome

CNS - central nervous system

CSF - cerebrospinal fluid

CVLT - California verbal learning test

DIS - dissemination in space

DIT - dissemination in time

DMT - disease modifying therapy

DTI - Diffusion Tensor Imaging

EBV - Epstein Bar Virus

ECTRIMS - European Comittee for Treatment and Research in Multiple Sclerosis/

EDSS - Expanded Disability Status Scale

FA - fractional anisotropy

FBC - full blood count

FDT - FMRIB's Diffusion Toolbox

FLAIR - sagittal fluid-attenuated inversion recovery

FNIRT - FMRIB's linear image registration tool

FSL - FMRIB Software Library

Gd - Gadolinium

GI - gastrointestinal

GLM - general linear model

GM- grey matter

HTLV - Human T-lymphotropic virus

IL - interleukin

INF - interferon

IVIg - Intravenous immunglobulin

LFTs - urea and electrolytes

LL - lesion load

MAGNIMS - European Magnetic Imaging in MS

MD - mean diffusivity

MHC - Major histocompatibility complex

MRI - magnetic resonance imaging

MS - multiple sclerosis

MTR - magnetization transfer ratio

NABs - neutralizing antibodies

NAWM - normal appearing white matter

NEDA - No evidence of disease activity

NMO - Neuromyelitis optica

OCB - oligoclonal band

OCT - optical coherence tomography 
PBV - partial brain volume

pGM - periferial gray matter

PLS - Partial Least Square

PPMS - primary progressive multiple sclerosis

PRMS - progressive relapsing multiple sclerosis

PV - periventricular

$\mathrm{RD}$ - radial diffusivity

RIS - radiologically isolated syndrome

RNFL - retinal fiber layer

ROI - regions-of-interest

RRMS - relapsing-temitting multiple sclerosis

SDMT - symbol digit modalities test

SLE - Systemic lupus erythematosus

SPE - Serum protein electrophoresis

SPMS - secondary progressive multiple sclerosis

SSEP - Somatosensory evoked potential

STIR - short-tau inversion recovery

TBSS - Tract-Based Spatial Statistics

TFCE - Threshold-Free Cluster Enhancing

TFTs - thyroid function test

U\&E - urea and electrolytes

ULN - Upper Limit of Normal

UVB - ultraviolet-B

VBM - voxel-based morphometry

VCSF - ventricular cerebrospinal fluid

VEP - visual evoked potential

VIP - Variable Importance in the Projection

$\mathrm{WM}$ - white matter 


\section{Multiple Sclerosis}

\section{Epidemiology, etiology}

The worldwide incidence of multiple sclerosis is increasing. In 2001 it was estimated to be 3.6/100000 person-years in women and 2.0/100.000 person-years in men(1). The prevalence of MS has an uneven distribution worldwide, as it varies from high levels in temperate areas, such as North America and Europe (> 100/100,000), to low rates in tropical areas, like Eastern Asia and sub-Saharan Africa (2/100,000 population) (2). The general prevalence of MS in Csongrád County was 89.8/100,000, 46.6/100,000 in males and 128.6/100,000 in females in 2013 (3).

The exact underlying factors in the development of MS are still not clear. However, some predisposing factors are already known, such as smoking, EBV infection, sunshine (UVB) exposure and also the level of vitamin D (4). According to previous studies, while symptomatic EBV infection doubles the risk of developing MS (5), being EBV negative protects from the disease $(6,7)$. The mechanism through which the infection escalates the risk of MS is still a matter of dispute. Earlier studies claimed a theory of molecular mimicry (8), while more recent papers suggest a role of EBV-induced B-cell immortalization and/or transformation (9). Previous studies have proven the association between the low risk of MS and the early-age sun exposure, (10-12). According to Van de Mei et al. (10) the protective effect of sun exposure is the most significant between the ages of 6 and 15 years. Consuming dietary sources of vitamin D, cod liver oil and fish in childhood and adolescence are also associated with low MS risk (12). According to the available evidence, it is suggested that the serum level of vitamin D is associated with the risk of MS and it also affects the disease activity (13).

Although nowadays the disease is more common in females (3:1 (F:M)) (14), (3) in studies from the early 1900s the sex ratio was almost equal. This change can be explained, for example, by the increased number of women who started smoking after the Second World War (15). The observation that only the use of smoked (16), but not oral or snuffed (17), tobacco can be associated with the development of MS suggests that these agents cause posttranslational alterations via antigen presentation in the lungs.

According to migration studies, environmental factors trump genetic background, as adult migrants coming from low-risk countries to Europe have a low risk of developing MS, while their children, born in Europe, have a high risk (18).

There is an assumption about the genetic background of MS, although only about one in eight patients has a family history of MS (19). According to a twin study, while in the UK and Canada 
the concordance in female monozygotic twins is approximately $30 \%$, in southern Europe it is only $8.5 \%$ (20). The primary genetic risk associated with MS is HLA-DRB1*15. The odds ratio of MS in heterozygotes for HLA-DRB1*15:01 is >3 and in homozygotes >6 (21), yet the underlying mechanism remains unknown. Genome-wide association studies have identified more than 150 single nucleotide polymorphisms associated with MS tendency (22), principally in the immune function regulatory regions, however, the odds ratios were quite small. Identified functional variants include those within IL7R (23), IL2RA (24), TNFR1 (25), BAFF (26) and CYP2R1 (27).

\section{Pathology and immunology}

The original description of the MS pathology by Charcot, refers to 'sclerosed plaques' that effect the periventricular area, pons, cerebellum, spinal cord and even the grey matter (28). The typical pathological findings in MS are demyelinating plaques caused by perivenular inflammatory lesions (29) containing T-lymphocytes, mainly MHC class I restricted CD8+ Tcells and also a smaller number of B-cells and plasma cells (30). This inflammatory process leads to damage of oligodendrocytes and the development of demyelination. Although in the early stage of the disease axons are relatively spared, later in a more progressive phase, irreversible axonal damage develops (31). The classical 'active lesion', characterized by profound lymphocytic inflammation, appears predominantly in RRMS, while in progressive MS lesions tend to have an inactive core encircled by a narrow margin of activated microglia and macrophages (32). In progressive MS, the inflammatory lesions, while similar to those in RRMS, contain more B-cells and plasma cells (33). In SPMS, higher levels of demyelination are observed, while in PPMS reduced axonal density in the NAWM of the spinal cord can be seen (34).

\section{Clinical symptoms}

The diagnosis of MS is based on the clinical appearance, MRI examinations, the exclusion of other possible diagnoses, and sometimes other paraclinical tests (35), such as the examination of CSF, or evoked potentials (36-39). MS is characterized by clinical episodes (so-called "attacks" or "relapses") of neurological dysfunction. During the relapsing-remitting phase of the disease, between the relapses, the clinical condition of the patients is stable (40). Clinical disability is determined by the Expanded Disability Status Scale (EDSS) (41) (Table 1.). EDSS is based on the measurement of impairment of 8 functional systems (pyramidal, cerebellar, 
brain stem, sensory, bowel and bladder, visual and cerebral (or mental)), the ability to walk and mobility. The EDSS scale ranges from 0 to 10 in 0.5 unit increments.

\begin{tabular}{|c|c|}
\hline \multicolumn{2}{|r|}{ Kurtzke Expanded Disability Status Scale } \\
\hline 0 & Normal neurological examination \\
\hline 1.0 & No disability, minimal signs in one FS \\
\hline 1.5 & No disability, minimal signs in more than one FS \\
\hline 2.0 & Minimal disability in one FS \\
\hline 2.5 & Mild disability in one FS or minimal disability in two FS \\
\hline 3.0 & Moderate disability in one FS, or mild disability in three or four FS. Fully ambulatory \\
\hline 3.5 & $\begin{array}{l}\text { Fully ambulatory but with moderate disability in one FS and more than minimal disability in } \\
\text { several others }\end{array}$ \\
\hline 4.0 & $\begin{array}{l}\text { Fully ambulatory without aid, self-sufficient, up and about some } 12 \text { hours a day despite relatively } \\
\text { severe disability; able to walk without aid or rest some } 500 \text { meters }\end{array}$ \\
\hline 4.5 & $\begin{array}{l}\text { Fully ambulatory without aid, up and about much of the day, able to work a full day, may } \\
\text { otherwise have some limitation of full activity or require minimal assistance; characterized by } \\
\text { relatively severe disability; able to walk without aid or rest some } 300 \text { meters. }\end{array}$ \\
\hline 5.0 & $\begin{array}{l}\text { Ambulatory without aid or rest for about } 200 \text { meters; disability severe enough to impair full daily } \\
\text { activities (work a full day without special provisions) }\end{array}$ \\
\hline 5.5 & $\begin{array}{l}\text { Ambulatory without aid or rest for about } 100 \text { meters; disability severe enough to preclude full } \\
\text { daily activities }\end{array}$ \\
\hline 6.0 & $\begin{array}{l}\text { Intermittent or unilateral constant assistance (cane, crutch, brace) required to walk about } 100 \\
\text { meters with or without resting }\end{array}$ \\
\hline 6.5 & $\begin{array}{l}\text { Constant bilateral assistance (canes, crutches, braces) required to walk about } 20 \text { meters without } \\
\text { resting }\end{array}$ \\
\hline 7.0 & $\begin{array}{l}\text { Unable to walk beyond approximately five meters even with aid, essentially restricted to } \\
\text { wheelchair; wheels self in standard wheelchair and transfers alone; up and about in wheelchair } \\
\text { some } 12 \text { hours a day }\end{array}$ \\
\hline 7.5 & $\begin{array}{l}\text { Unable to take more than a few steps; restricted to wheelchair; may need aid in transfer; wheels } \\
\text { self but cannot carry on in standard wheelchair a full day; May require motorized wheelchair }\end{array}$ \\
\hline 8.0 & $\begin{array}{l}\text { Essentially restricted to bed or chair or perambulated in wheelchair, but may be out of bed itself } \\
\text { much of the day; retains many self-care functions; generally has effective use of arms }\end{array}$ \\
\hline 8.5 & $\begin{array}{l}\text { Essentially restricted to bed much of day; has some effective use of arms retains some self care } \\
\text { functions }\end{array}$ \\
\hline 9.0 & Confined to bed; can still communicate and eat. \\
\hline 9.5 & Totally helpless bed patient; unable to communicate effectively or eat/swallow \\
\hline 10 & Death due to MS \\
\hline
\end{tabular}

Table 1. Expanded Disability Status Scale

\section{$\underline{\text { Usual clinical presentations }}$}

\section{Optic neuritis}

Around $20 \%$ of the MS cases start with acute demyelinating optic neuritis and almost half of the patients are affected by it during their lifetimes (42). Patients often complain of blurring or loss of vision, eye pain (43), the decline of color vision, the appearance of a "blind spot"or "blurry spot".

Myelitis 
Transverse myelitis is characterised by deprivation of sensory, motor, bladder and bowel functions due to the inflammatory-mediated injury of tracts in the spinal cord. In MS partial myelitis occurs, which affects some, but not all of these spinal tracts $(44,45)$.

\section{Brain stem syndromes}

In MS, the brain stem is often damaged and can cause a wide variety of symptoms, such as internuclear ophthalmoplegia, double vision, vertigo, dysarthria, dysphagia, and hypoglossus paresis, facial weakness, myokymia, or facial sensory impairment, dysmetria, ataxia, dysdiadochokinesia. In rare cases, hearing loss and pendular nystagmus can also occur.

\section{Motor symptoms}

Up to $89 \%$ of patients suffer from weakness during their disease (46). It is usually caused by the impairment of the corticospinal tract and often associated with spasticity and hyperreflexia.

\section{Sensory impairment}

Sensory impairment appears in $87 \%$ of the patients (46), who commonly mention paresthesias and numbness. 54\% of MS patients also complain of pain and other unpleasant sensations (47), which have mainly neuropathic characteristics such as burning, sharp or electrical sensations. In up to one-third of the patients Lhermitte's symptom occurs, which is described as an electrical-shock-like feeling running down the spine (48). It is localised in the posterior column in the cervical or upper thoracic spinal cord.

\section{Imbalance}

MS patients commonly complain of uncoordination or being off-balance, which can originate from cerebellar (dysdiadochokinesia, tremor, dysmetria, eye movement abnormalities or gait ataxia,), vestibular, or sensory dysfunction (sensory ataxia), and also spasticity, or weakness.

\section{Cognitive impairment}

Cognitive decline affects around $40-70 \%$ of MS patients (49) (50) and can even lead to dementia (51). Information processing speed, long-term verbal and visuo-spatial memory and executive functions are the most commonly affected domains (49).

\section{Depression}

Although around $30-45 \%$ of MS patients suffer from major depression, the underlying cause is still unclear (52-54). In some cases, injury to the frontotemporal networks is suggested, while in others it is simply a comorbid condition (55).

\section{Fatigue}

Fatigue is one of the most common symptoms in MS, affecting around $83 \%$ of patients in a large survey (47) (56). It can persist even in the remission phase, and often worsens during relapses. The background of fatigue may be related to chronic CNS inflammation (57). It is 
always very important to differentiate between fatigue and other, alternative causes, such as depression, anemia, hypothyroidism, or sleeping disorders.

\section{Bladder and bowel dysfunction}

Since the impairment of the lower urinary tract and the neurogenic bladder can often cause disability for MS patients, its importance can not be underestimated (58-60) "Overactive" bladder, detrusor hyperreflexia, is one of the most common manifestations $(58,61)$, causing symptoms of urinary urgency, increased frequency, and incontinence. Another possibility is bladder underactivity, which appears with symptoms of urinary frequency, incomplete emptying, and detrusor-sphincter dyssynergia (61), which can lead to incomplete emptying, intermittent urinary stream, and urinary hesitancy. Mixtures of these neurogenic bladder dysfunctions often appear in MS (62) and can cause recurrent urinary tract infections.

Bowel impairment in MS is less common than bladder dysfunction and it usually appears in the form of constipation. Bowel incontinence can appear in cases of severe spinal cord injury (63, 64).

About one-third of the patients complain of sexual dysfunction. In men erectile dysfunction, while in women loss of libido and fatigue are the main problems $(47,61,64,65)$.

\section{Heat sensitivity}

It is well known that heat, hot weather, hot baths or overwhelming exercise, characteristically cause worsening of MS symptoms. According to Uthoff's phenomenon, heat sensitivity is based on the slower conduction of demyelinated nerves at higher temperatures (66).

\section{Headache}

Around two-thirds of MS patients mention headaches, which mostly have the characteristics of migraine (67). The early diagnosis of migraine in MS patients is important to differentiate between the symptoms of migraine and a possible relapse in MS (68). According to an earlier study, migraine is not only more common in women with MS, but having migraine may cause a slightly increased risk of MS (69).

\section{Pseudorelapse}

Infections, most commonly urinary tract infection (70), or other stress factors can cause the temporary worsening of MS symptoms (71).

\section{Clinical course of the disease}

In 1996, the US National Multiple Sclerosis Society (NMSS) Advisory Committee on Clinical Trials in Multiple Sclerosis defined the 4 clinical subtypes of multiple sclerosis (40): relapsingremitting $(\mathrm{RR})$, secondary progressive $(\mathrm{SP})$, primary progressive $(\mathrm{PP})$ and progressive relapsing 
(PR). These descriptions were limited to relapsing (RR, SP, and PR) and progressive (PP, SP, and PR) forms, according to the differentiation, whether the course of the disease was predominantly relapsing or progressing (72) (Table 2.).

Relapsing-Remitting Disease (RRMS)

The relapsing-remitting MS spectrum now includes CIS as well, which can be active or inactive. When a clinical or radiological episode ( $\mathrm{Gd}+$ or new/enlarging $\mathrm{T} 2$ lesions) follows the CIS, it is considered to be active, whether or not it fulfills the criteria for relapsing-remitting MS. RRMS can also be characterized as active or inactive within a specific time frame, which should be no longer than 1 year.

Progressive Disease

Primary or secondary progressive disase can be classified into 4 subgroups based on the level of disability:

- Active and with progression (patient with worsening clinical disability and relapses)

- Active but without progression (relapse within a specific timeframe, but without clinical worsening)

- Not active but with progression (clinical worsening, without relapses)

- Not active and without progression (stable disease) (72).

\begin{tabular}{|l|l|l|}
\hline MS subtype & & Disease Activity \\
\hline Relapsing & CIS & Active \\
& Not Active \\
\hline & RRMS & \\
\hline Progressive & & $\begin{array}{l}\text { Active with progression } \\
\text { Active without progression } \\
\text { Not active with progression } \\
\end{array}$ \\
& PPMS & $\begin{array}{l}\text { Not active without } \\
\text { progression (stable disease) }\end{array}$ \\
\hline
\end{tabular}

Table 2. Disease Courses according to Lublin et al., 2014

In October 2012 the Committee recommended changes to the course descriptions and also installed new disease courses.

Clinically isolated syndrome (CIS).

It was described as the first clinical presentation of disease, showing inflammatory demyelination characteristics, similar to MS, although not fulfilling the criteria of dissemination in time (73).

Radiologically isolated syndrome (RIS). 
RIS is a more complicated situation, where incidental imaging suggests inflammatory demyelination in the absence of clinical signs or symptoms (74-76).

Secondary Progressive Multiple Sclerosis (SPMS).

In most cases, this disease course is only diagnosed retrospectively by increased worsening after an originally relapsing disease course, with or without acute exacerbations. There is no exact point, clinical, pathological, immunological or imaging, when it can be declared that RRMS has converted to SPMS, rather the process is gradual.

Primary Progressive Multiple Sclerosis (PPMS).

Although some earlier studies suggested that PPMS is a confinable, less inflammatory form of MS (77), others, based on imaging, clinical and genetic data declare that it is rather a part of the spectrum of progressive MS phenotypes $(78,79)$. According to natural history cohort studies, the rate of the worsening is similar both in SPMS and PPMS $(80,81)$, however, PPMS should remain separate, due to the lack of exacerbations before the clinical progression.

\section{Paraclinical examinations}

\section{Evoked potentials}

Evoked potential measurements can detect the malfunction of the afferent and efferent pathways, thus offering extra verification of dissemintation in space and confirming demyelination, thus supporting the diagnosis of MS (35).

Visual evoked potential (VEP) is the most common electrophysiological test used in MS. During a full-field VEP, the patient has to focus on an alternating checkerboard pattern. The examination measures the cortical responses with occipital scalp electrodes. The delay of the latency of the main wave (P100) of VEP suggests demyelination in the optic pathway. Somatosensory evoked potential (SSEP) can measure the demyelination in the central sensory pathways, thus it is used to assess sensory myelopathy.

Motor evoked potential can measure the integrity of the motor pathways by stimulating the motor cortex with transcranial magnetic stimulation.

\section{Optical coherence tomography (OCT)}

The retinal fiber layer (RNFL) contains axons of retinal ganglion cells, which together create the optic nerve. RNFL thinning is a common phenomenon in MS (82), especially in the temporal peripapillary nerve fiber region (83-86). It can be detected with direct fundoscopy (87) and can be quantified by retinal optical coherence tomography. The axon loss in the retina manifests in MS from an early stage and becomes more significant during the progression of the disease (84). 


\section{Examination of CSF}

The examination of cerebrospinal blood fluid (CSF) can help exclude alternative diagnoses, and verify intrathecal inflammation. The presence of oligoclonal bands (OCB) in CSF, but not in the serum, is the most sensitive test of CSF in MS, which occurs in over $95 \%$ of the patients $(88,89)$. OCBs are IgGs unique to the CSF, and once detected, persist unrestrictedly (90). The increase of the IgG index, a calculated quotient of IgG and albumin amount in CSF and serum, refers to intrathecal IgG synthesis and also suggests intrathecal inflammation, but it is less sensitive for assessing MS than OCBs $(89,91-93)$. The CSF white blood cell count (usually composed of lymphocytes and monocytes) and the total protein is usually normal or mildly elevated in MS. Counts of more than 50 (x $10^{6} / \mathrm{L}$ ) white blood cells in the CSF are abnormal in MS (89).

\section{Magnetic resonance Imaging (MRI)}

Conventional MRI is a sensitive technique to detect T2 hyperintense MS lesions, and is the diagnostic cornerstone of the disease (94). Although MS lesions have no concrete and certain localisations, they primarily appear in the periventricular WM. Lesions also have a predilection for the corpus callosum, brain stem, subcortical regions, U-fibers and optic nerves. The lesions tend to have an ovoid shape with the major axes perpendicular to the ventricular surface (95). Initially, lesions are usually thin and have linear appearence (Dawson's fingers), due to the inflammatory alterations around the long axis of the medullary veins, appearing as dilated perivenular space in the MRI (96). Histopathologically, such perivascular inflammation can cause erosion of the blood-brain barrier, myelin degradation, and formation of new lesions (97). Demyelinating lesions contain T-lymphocytes, and also a smaller number of B-cells and plasma cells (98), which lead to the damage of oligodendrocytes and the development of demyelination. The focal demyelinating lesions next to the corpus callosum can be best detected by sagittal fluid-attenuated inversion recovery (FLAIR) imaging. Besides the white matter lesions, lesions in the gray matter can also appear in MS. Usually they are small, with an intermediately high intensity and a less serious degree of inflammation (99). Optic neuritis, can be detected by longecho short-tau inversion recovery (STIR) imaging, or a fat-suppression technique combined with contrast-enhanced imaging $(100,101)$.

In T1-weighted imaging, MS lesions in the acute phase appear isointense compared to the surrounding, while in the chronic phase, or in case of serious inflammatory oedema, they can be hypointense (black holes). In the acute inflammatory stage, the lesion may degrade the blood-brain barrier, causing gadolinium enhancement $(102,103)$, which may last from days to 
weeks $(104,105)$. The classical 'active lesion' is characterized by profound lymphocytic inflammation. Enhancing lesions can vary in size and shape. Initially they appear as homogeneous enhancing nodules and later progress to ringlike enhancements. Lesions in the chronic phase usually appear as isointense or hypointense in T1-weighted images and can be detected for many years in T2- weighted images.

Brain atrophy, presumably a net accumulative disease burden, is also a significant MR hallmark of MS (106), which can occur in every stage of the disease, even in the very early phase (107). According to earlier studies, despite the remarkably higher inflammatory activity in RRMS compared to SPMS (108), the brain atrophy rate is independent of the disease subtype (109, 110). It usually appears in the form of enlarged ventricles and reduced volume of CC (111). There is a short-term brain volume fluctuation (even a small increase), which can be observed mainly in RRMS (112). Steroid treatment can attenuate inflammation and may also cause shortterm changes in brain volume (113). Recently, numerous quantitative methods have been

developed for the precise measurement of global and regional brain tissue loss (114). Atrophy is seen in all stages in a progressive manner, including patients with early MS (107), emphasizing the need for earlier involvement of neuroprotective intervention. Earlier studies estimated the rate of brain atrophy around 0.6-1.0\% annually in MS (115-117), while in 2015 DeStefano determined the pathological brain volume loss as higher than $0.4 \%$ brain volume change annually in MS (118). The underlying mechanism of brain atrophy in MS is not completely clarified. Several studies have examined the phenomenon with various results, but there are two main hypotheses that either the atrophy appears secondarily due to axon damage, or it is a parallel process with demyelination.

\section{Diagnostic Criteria}

\section{The first steps}

The first clinical symptoms described as typical for MS by Jean-Martin Charcot in 1868 were the triad of nystagmus, intention tremor, and scanning speech (119). However, later it turned out, that on the one hand, these symptoms develop in a relatively later stage of the disease and on the other hand, they appear in several other neurological disorders as well $(120,121)$. In 1906, Marburg declared that MS can be diagnosed by the simultaneous presence of pyramidal signs, lack of plantar reflex and the Uhthoff's phenomenon. Allison and Milliar created the first clinical classification of MS in 1954, which recognized that the clinical symptoms appear in different areas of the CNS at different time points. They classified patients into groups of early, 
possible and probable MS (76). Schumacher, who in 1965 created the first modern diagnostic criteria of MS, also used the above mentioned classification (122).

Schumacher's criteria for clinically definite MS:

a) objective neurological symptoms during physical examination;

b) at least two symptoms allude to different regions of CNS during the physical examination or documented in the medical history;

c) the presence of symptoms connected to white matter lesions;

d) at least 2 relapses, with symptoms lasting at least $24 \mathrm{~h}$, and at least 1 month between the relapses or the deterioriation of symptoms during 6 months;

e) the age of the patient is between 10 and 50 years;

f) the probability of alternative disorders with similar symptoms are lower.

In 1967 Rose modified Schumacher's criteria by removing the age restriction (123).

\section{Poser criteria}

In 1983 a new diagnostic criteria for MS was created by Poser et al. for clinical trials (38) based on Schumacher's criteria. It identified 5 alternate diagnoses: clinically definite, or probable MS, laboratory-supported definite or probable MS and not MS (38). According to Poser et al., only patients belonging to the first four group should be screened (38). Relapse or neurological worsening was considered the primary clinical attribute of the disease, which was defined as an acute or subacute development of neurological symptoms "typical for MS", These symptoms must have persisted for minimum 24 hours and should have been independent of any infection. Poser defined symptoms "typical for MS"' such as disturbances of consciousness, headaches, or psychiatric symptoms. According to Poser criteria, the diagnosis of clinically definite MS could be set if the patient had minimum two relapses (at least 30 days had to elapse between the two episodes) and, according to the clinical examination, at least two structures of the CNS were impaired. The diagnosis of laboratory-supported definite MS was declared if there was at least one relapse and, if according to the clinical examination, only one area of the CNS was impaired, but laboratory tests (such as evoked potentials, CSF or MRI) strengthened the diagnosis. Among the laboratory tests, examination of the CSF had a significant role, as the calculation of the IgG index and the detection of oligoclonal bands in the CSF became accessible (124). Irregularity in evoked potential corresponded as silent damage to the CNS. VEP can show impairment of the optic nerve, BAEP suggests damage to the brain stem and SSEP indicaes damage to the sensory pathways in the spinal cord and brainstem. However, at 
the time of the Poser criteria, while there was no standard definition of MS MRI lesions, their presence could still support the diagnosis $(125,126)$.

\section{In between}

Since Poser, several criteria have been proposed to determine those MRI characteristics that best define multiple sclerosis (127). In 1988, both Paty (128) and Fazekas (129) defined their own MRI criteria for diagnosis of MS. According to Paty's criteria, the MRI is abnormal if $\geq 4$ lesions appear, or in the case of 3 lesions, if one of them is located in the periventricular region. The Fazekas' criteria demanded minimum 3 lesions and 2 out of the following characteristics: 1) size of $6 \mathrm{~mm}$ or larger, 2) location adjacent to the lateral ventricles, or 3) location in the infratentorial area.

The Barkhof criteria in 1997 (125) required the following: 1) one Gd-enhancing lesion or $\geq 9$ T2-weighted lesions 2) $\geq 3$ lesions in the periventricular region 3) $\geq 1$ juxtacortical lesion, and 4) $\geq 1$ infratentorial lesion.

\section{McDonald criteria}

After 1996, with the development of MRI and the promotion of interferon-beta, the first diseasemodifying drug in Europe, the MS diagnostic criteria underwent a significant and continuous transformation (130). In 2001, the McDonald criteria were developed, which had several important differences from the Poser criteria (39). The classification of the patients changed to $M S$ when the clinical course was typical for MS, and all the criteria were fulfilled. Possible $M S$ was diagnosed,whenthe McDonald criteria were not fulfilled $(131,132)$ and not $M S$, when the diagnosis was excluded (39).

The definition of relapse was also modified, as the 30 days gap was counted from the start of the first neurological worsening, unlike in the Poser's criteria, which recommended 'early recovery'. The role of MRI techniques also became more significant. In those cases when the clinical proof was insufficient, an MRI scan became mandatory to declare DIT or DIS. Radiological DIS could be stated if three of the following were fullfilled: $\geq 1$ one Gd+ lesion or 9 T2 hyperintense lesions, $\geq 1$ infratentorial lesion, $\geq 1$ juxtacortical lesion, $\geq 3$ periventricular lesions (39). Radiological DIT was proven if there was a gadolinium-enhancing lesion in the brain in the MRI scan performed $\geq 3$ months after the onset of first clinical symptoms (should not be the one responsible for the clinical symptoms), or in case of the presence of new T2 hyperintensive lesion or a Gd-enhancing lesion in the second MRI scan performed not sooner than 3 months. Although the diagnosis of the relapsing-remitting form of MS (RRMS) could still be stated only after the second relapse, the McDonald criteria for MS could be met before it. In 
the medical literature, this group of patients is determined as 'McDonald MS'. It incorporates patients with only one multifocal relapse, with two relapses, but only a single neurological symptom and also with CIS $(73,126,133)$. Parallel to the increasing significance of MRI techniques the importance of the other laboratory tests decreased. The examination of the CSF was only suggested if the MRI could not prove DIS on its own. Also, VEP was recommended only in those cases when damage to the optic nerve was suspected.

\section{Modified McDonald criteria (2005, 2010 and 2017)}

The Panel on MS Diagnosis (Panel) modified the McDonald criteria three times (2005, 2010 and 2017) $(131,134)(135)$ to accelerate and ease the diagnostic process (Table 3). The Panel highlighted that since the McDonald criteria was developed for patients who have characteristic clinical symptoms and was tested on a Western adult population, it should be used only as the support and not the diagnostic cornerstone of MS. According to the Panel, in case of children, adults from any other ethnic group and patients with non-characteristic symptoms or clinical course, the McDonald criteria is not usable and examinations of their diseases should be carried out instead.

According to the modification in 2005, if an MRI performed 3 months after the first relapse presented even one gadolinium-enhanced lesion or in case of a new T2 lesion in the MRI done 30 days after the first clinical symptoms, the diagnosis of DIT could be stated (37). For DIS, three of the following should be fullfilled: $\geq 1$ one $\mathrm{Gd}+$ lesion or $9 \mathrm{~T} 2$ hyperintense lesions, $\geq 1$ infratentorial lesion, $\geq 1$ juxtacortical lesion, $\geq 3$ periventricular lesions. Spinal cord lesions were also included in the criteria and were treated as equivalent to an infratentorial lesion. The lesions in the spinal cord, together with the brain lesions, could meet the required number of lesions and a gadolinium-enhancing lesion in the spinal cord could also fulfill the radiological criteria for DIT. However, spinal cord MRI scans were only recommended if new clinical symptoms appeared which suggested spinal cord damage (125).

In the second modification of the criteria in 2010, based on a MAGNIMS (European Magnetic Imaging in MS) study, the standards for radiological DIS were changed. According to the new guideline, at least two MS typical lesions should be present in at least two out of the four locations typical of MS (periventricular, subcortical, infratentorial and spinal cord) in the MRI, exluding lesions in symptomatic areas, in the case of patients with brainstem or spinal cord syndromes (36). The criteria of DIT also changed, thus the coexistence of gadoliniumenhancing and non-enhancing lesions (both in the brain or the spinal cord) was considered sufficient proof (36). A new T2 and/or Gd+ lesion(s) on follow-up MRI, with reference to a 
baseline scan can still prove DIT, independently of the time of the baseline MRI. According to the new guideline, it is possible to introduce a disease-modifying therapy at the time when the first clinical symptoms of MS emerge.

In 2017, the Panel again recommended revisions to the McDonald criteria (136). In CIS, in case either clinical or MRI criteria of DIS are fullilled, with the presence of oligoclonal bands in the CSF, the diagnosis of MS can be made (137). From 2017, symptomatic and also asymptomatic lesions in MRI can be used for the determination of DIS and DIT, except lesions in the optic nerve, in the case of optic neuritis. It was recommended that cortical lesions, in addition to juxtacortical lesions, can also be used to fulfil MRI criteria for DIS. At the time of diagnosis, a temporary disease course (RRMS, PPMS, SPMS) should be defined and also the activity and progressivity of the course, based on the previous year. This should be re-evaluated periodically based on accumulated data.

\section{MAGNIMS guidelines (2017)}

Since 2011, improvements in MRI technology (high and ultra-high-field scanners), new pathophysiological mechanisms, and thus new data about MS, have become available. Therefore, in 2016, the MAGNIMS made further improvements on the 2010 modified McDonald criteria and summarised them in a stand alone panel (135).

\section{Recommeneded modifications:}

- Defining DIS $\geq 3$ lesions are required, involving the periventricular region.

- Lesions in the optic nerve are added to the DIS criteria.

- Intra-, leuko and juxtacortical lesions should be combined into the term „,cortical/juxtacortical lesions”.

- For fullfilling the criteria of DIS and DIT, no discrimination is needed between symptomatic and asymptomatic MRI lesions $(138,139)$.

- While the role of spinal cord imaging is only limited in DIT, for defining DIS MRI imaging of the whole spinal cord is recommended (140-143).

- For PPMS and relapse-onset MS identical DIS criteria should be used. CSF should be taken into account in cases of clinically uncertain PPMS cases (144).

- In children $\geq 11$ years, without ADEM-like appearence, the same MRI criteria for DIS and DIT should be used as in adults $(145,146)$.

- In the case of RIS the same criteria in DIS and DIT should be used, as in MS.

- Once other diseases, such NMOSD, are excluded, MRI criteria for MS can be applied equally well in patients from Asia or Latin America as well $(147,148)$. 
Additional classifications and summary statements

- The criteria of DIT remained unchanged.

- Non-enhancing black holes can not be used as an alternative criterion for DIT in adults.

- In the case of atypical MRI presentation, differential diagnoses, such as acquired and inherited WM diseases should be considered.

- Although the evidence for high - or ultra-high-field scanners accelerating the diagnosis of MS is still limited, the detection of MS characteristic lesions can be improved by them. 


\begin{tabular}{|c|c|c|c|c|c|c|c|}
\hline \multicolumn{2}{|c|}{ McDonald criteria (2000) } & \multicolumn{2}{|c|}{ Modified McDonald Criteria (2005) } & \multicolumn{2}{|c|}{ Modified McDonald Criteria (2010) } & \multicolumn{2}{|c|}{ Modified McDonald Criteria (2017) } \\
\hline DIS & DIT & DIS & DIT & DIS & DIT & DIS & DIT \\
\hline $\begin{array}{l}\text { 3 out of the } 4 \\
\text { conditions: } \\
\text { 1. } \geq 1 \text { Gd- } \\
\text { enhancing } \\
\text { lesion/ } \geq 9 \text { T2 } \\
\text { hyperintensive } \\
\text { lesions } \\
\text { 2. } \geq 1 \\
\text { infratentorial } \\
\text { lesion } \\
\text { 3. } \geq 1 \\
\text { subcortical } \\
\text { lesion } \\
4 . \geq 3 \\
\text { periventricular } \\
\text { lesions }\end{array}$ & $\begin{array}{l}\text { a) The presence of } \geq \\
1 \text { Gd-enhancing } \\
\text { lesion in the brain in } \\
\text { the MRI scan } \\
\text { performed } \geq 3 \text { months } \\
\text { after the onset of first } \\
\text { clinical symptoms } \\
\text { (should not be the one } \\
\text { responsible for the } \\
\text { clinical symptoms). } \\
\text { b) The presence of } \\
\text { new T2 } \\
\text { hyperintensive lesion } \\
\text { or a Gd-enhancing } \\
\text { lesion in the second } \\
\text { MRI scan performed } \\
\text { not sooner than } 3 \\
\text { months } \\
\text { after the first. }\end{array}$ & $\begin{array}{l}3 \text { out of the } 4 \\
\text { conditions: } \\
\text { 1. } \geq 1 \text { Gd- } \\
\text { enhancing } \\
\text { lesion/ } \geq 9 \mathrm{~T} 2 \\
\text { hyperintensive } \\
\text { lesions } \\
2 . \geq 1 \\
\text { infratentorial } \\
\text { lesion } \\
3 . \geq 1 \text { subcortical } \\
\text { lesion } \\
4 . \geq 3 \\
\text { periventricular } \\
\text { lesions }\end{array}$ & $\begin{array}{l}\text { a) The presence of } \geq 1 \\
\text { Gd-enhancing lesion } \\
\text { in a MRI scan } \\
\text { performed } \geq 3 \text { months } \\
\text { after the onset of first } \\
\text { clinical symptoms } \\
\text { (should not be the one } \\
\text { responsible for the } \\
\text { clinical symptoms). } \\
\text { b) The presence of a } \\
\text { new T2 hyperintensive } \\
\text { lesion in the next MRI } \\
\text { scan if the previous } \\
\text { one was done at least } \\
30 \text { days after the } \\
\text { onset of first clinical } \\
\text { symptoms. }\end{array}$ & $\begin{array}{l}\text { 'Dissemination in } \\
\text { space' may be } \\
\text { demonstrated } \\
\text { by the presence of at } \\
\text { least } 1 \mathrm{~T} 2 \\
\text { hyperintensive } \\
\text { lesion in } 2 \text { out of } 4 \\
\text { typical locations: } \\
\text { - periventricular } \\
\text { - subcortical } \\
\text { - infratentorial } \\
\text { - in the spinal cord }\end{array}$ & $\begin{array}{l}\text { a) A new T2 } \\
\text { hyperintensive } \\
\text { lesion/ a Gd- } \\
\text { enhancing lesion in } \\
\text { the next MRI scan. } \\
\text { The time of the } \\
\text { previous MRI scan } \\
\text { is not important. } \\
\text { b) By the presence } \\
\text { of both Gd- } \\
\text { enhancing and non- } \\
\text { enhancing lesions } \\
\text { in the first MRI } \\
\text { scan. The time of } \\
\text { the MRI scan is not } \\
\text { important. }\end{array}$ & $\begin{array}{l}\text { 'Dissemination in } \\
\text { space' may be } \\
\text { demonstrated } \\
\text { by the presence of at } \\
\text { least } 1 \mathrm{~T} 2 \\
\text { hyperintensive } \\
\text { lesion in at least } 2 \\
\text { out of } 4 \text { typical } \\
\text { locations } \\
\text { (periventricular must } \\
\text { be involved): } \\
\text { - periventricular } \\
\text { - subcortical } \\
\text { - infratentorial } \\
\text { - in the spinal cord } \\
\text { No discrimination is } \\
\text { needed between } \\
\text { symptomatic and } \\
\text { asymptomatic MRI } \\
\text { lesions! }\end{array}$ & $\begin{array}{l}\text { a) A new T2 } \\
\text { hyperintensive } \\
\text { lesion/ a Gd- } \\
\text { enhancing lesion in } \\
\text { the next MRI scan. } \\
\text { The time of the } \\
\text { previous MRI scan is } \\
\text { not important. } \\
\text { b) By the presence of } \\
\text { both Gd-enhancing } \\
\text { and non-enhancing } \\
\text { lesions in the first } \\
\text { MRI scan. The time } \\
\text { of the MRI scan is } \\
\text { not important. } \\
\text { No discrimination is } \\
\text { needed between } \\
\text { symptomatic and } \\
\text { asymptomatic MRI } \\
\text { lesions! }\end{array}$ \\
\hline
\end{tabular}

Table 3 Evolution of the McDonald criteria 


\section{The MRI protocol in MS}

Based on the international guidelines, in 2017 our team published a recommendation for the MRI protocol to be used in MS patients to diagnose the disease and to evaluate therapeutic efficacy $(149,150)$.

When?

- 6 months after the beginning of the disease-modifying therapy (baseline)

- 1 year after the beginning of therapy

- Yearly in the first 2-3 years of treatment

- 3 years after the beginning of therapy, in every 2 years, in case of stable clinical condition

- In case of a relapse (before the steroid treatment)

- In case of symptoms not related to MS

What kind of MRI sequences?

\section{$\underline{\text { Brain }}$}

The MRI scans should be made on at least $1.5 \mathrm{~T}$. The direction of the axial scans should be subcallosal for comparability.

- 3D inversion recovery-prepared T1-weighted, spoiled gradient-echo sequence with $1 \times 1 \times 1 \mathrm{~mm}$ resolution before the application of the contrast material - for volumetry analyses.

- Axial 2D spin-echo based T1-weighted sequences, with 1x1x3mm resolution - for the identification of black holes.

- Sagittal 3D FLAIR sequences with 1x1x1mm resolution - for the identification of periventricular, juxtacortical lesions, parallel to the corpus callosum.

- fast/turbo spin-echo axial PD/T2-weighted sequence with 1x1x3mm resolution - for the identification of infratentorial lesions.

- 3D FLASH (non-inversion recovery-prepared) post-contrast sequences with $1 \times 1 \times 1 \mathrm{~mm}$ resolution, at least 5 minutes after the application of the contrast matter for the identification of the contrast-enhancing lesions.

The above-mentioned sequences can be complemented if it is necessary:

- Axial diffusion-weighted sequences with $<5 \mathrm{~mm}$ slice thickness - for detecting not-MS pathology, or early signs of PML. 
- Orbital images: coronal STIR or fat-surpressing T2 sequences, and also post-contrast fat-surpressing T1 sequences with at least $2 \mathrm{~mm}$ slice thickness - for verifying optical neuritis and exclusion of alternate diagnoses (sarcoidosis, NMO).

- 2D or 3D Dual inversion recovery sequence - for identification of cortical lesions.

$\underline{\text { Spinal cord }}$

- Sagittal fast dual echo (T2 and PD) sequences with at least 3x1x1mm resolution.

- Sagittal short-tau inversion recovery (STIR) T2-weighted sequences.

- Sagittal post-contrast T1-weighted spin-echo sequences.

- Axial T2 fast spin-echo and axial post-contrast T1-weighted spin-echo sequences with $5 \mathrm{~mm}$ slice thickness, corresponding with the identified lesions.

\section{Differential diagnosis}

The exclusion of other alternate diagnoses is a demanding part of the diagnosis of the disease. These include, but are not limited to: ADEM, neuromyelitis optica, small vessel ischaemic white matter disease, and stroke, antiphospholipid antibody syndrome, SLE, Sjögren's syndrome, Behcet's disease, sarcoidosis, CNS lymphoma, Susac syndrome, CADASIL, Lyme disease, neurosyphilis, HTLV-infection, and Vitamin $\mathrm{B}_{12}$ deficiency.

\section{Therapy}

The treatment of MS is a complex process, including MS-specific disease-modifying therapies, symptomatic therapies and handling symptoms that develop due to the neurological dysfunctions. On the other hand, it is also important to pay attention to the comorbidities that occur during the disease course.

\section{Treatment of acute relapses}

\section{- Steroid treatment}

Today IV methylprednisolone is the first line, most commonly used therapy of relapse in MS (151). It is used in 500mg -1 gr dosages for 3 to 5 days, followed (or not) by an oral administration in lower dosage. The main mechanism of action of systemic corticosteroids is the induction of T-cell apoptosis and reduction of lymphocyte infiltration into the CNS. As a result, the overall proportion of T-regulatory cells decreases, while the proportions of CD39-expressing T-regulatory cells and monocytes increase (152). In the past 30 years several studies examined the differences of high-dose oral and IV methylprednisolone in clinical or imaging outcomes. Berkovich (153), Le Page (154) and even the Cochrane Database of Systematic Reviews found that in most trials the effect of the oral 
methylprednisolone is comparable to that of the IV administration. In case of short-term steroid treatment, steroid side effects are quite rare (153). The most common adverse effects in short-term use are weight loss, anxiety, GI symptoms, headache and oedema. Hyperglycaemia, hirsutism and hypertension are less frequently reported (153). Severe psychiatric disorder, acute psychosis, insomnia, infections, and aseptic necrosis of the hip are also frequently reported adverse effects $(153,155,156)$. In at least $50 \%$ of patients with long-term corticosteroid treatment osteoporosis develops (153). Steroid resistance is also a known problem, which is caused by the downregulation of glucocorticoid receptor expression. With concomitant medications (eg. GI prophylaxis, potassium complementation), and additional monitoring (eg. the level of blood sugar), the side effects of methylprednisolone therapy can be reduced.

\section{- Plasmapheresis}

In cases of acute relapses, MS patients are usually treated with high-dose intravenous corticosteroids, though in some patients steroid refractory relapses occur and thus plasma exchange or immunoadsorption might be needed (157). Plasma exchange removes pathogenic humoral factors, including auto-antibodies that are directed against the myelin sheath (158). Since immunoadsorption eliminates only specific antibodies, sparing other plasma proteins, it is considered to be associated with fewer side effects and lower risks of allergic reactions compared to plasma exchange (159).

\section{- IVIg}

IVIg is a pooled preparation of normal IgG gained from the plasma of thousands of healthy donors (160). Originally it was used for replacement therapy in primary and secondary immunodeficiencies. IVIg has its effects via several nonspecific mechanisms, such as the expansion of regulatory $\mathrm{T}$ cells, the inhibition of activation of macrophages, pathogenic $\mathrm{T}$ cells (Th17 and Th1) and dendritic cells, the modulation of B cell responses and the inhibition of pathogenic autoantibody processing, the suppression of inflammatory cytokine production, the activation of anti-inflammatory cytokines, and the neutralization of pathogenic autoantibodies (161). These data and the relatively low number of side effects make IVIg a promising therapy in RRMS.

\section{Disease-modifying therapies}

As the number and efficacy of disease-modifying therapies rapidly increases, the support for early treatment and prevention of long-term disability has also increased. Immunosuppressants (fingolimod, natalizumab, ocrelizumab) or immunomodulatory treatment (interferon-beta, 
glatiramer acetate) aim to suppress inflammation and also disease activity. The presently available immune reconstitution therapies (alemtuzumab, cladribine) aim to produce long-term immunological processes (Table 4).

The ECTRIMS/EAN guideline on the pharmacological treatment of people with MS was published in 2017, in which questions about treatment efficacy, suboptimal response, response criteria, safety concerns and treatment of MS in pregnancy have been dealt with, and a total of 20 recommendations were proposed (162). 


\begin{tabular}{|c|c|c|c|c|c|}
\hline & $\begin{array}{l}\text { Brand } \\
\text { names }\end{array}$ & $\begin{array}{c}\text { Mechanism of } \\
\text { action }\end{array}$ & Administration & Main side effects & Required monitoring \\
\hline \multicolumn{6}{|c|}{ First line injection therapies } \\
\hline $\begin{array}{c}\text { Interferon-beta } 1 \mathrm{a} \\
\text { and } 1 \mathrm{~b}\end{array}$ & $\begin{array}{l}\text { Avonex, } \\
\text { Betaferon, } \\
\text { Rebif, } \\
\text { Extavita }\end{array}$ & $\begin{array}{c}\text { Immunomodulatory, } \\
\text { pleiotropic immune } \\
\text { effects }\end{array}$ & s.c./i.m. & \multirow{2}{*}{$\begin{array}{c}\text { Injection site reactions, abnormal } \\
\text { LFTs, flu-like symptoms, leukopaenia, } \\
\text { lymphopaenia, }\end{array}$} & \multirow{2}{*}{$\begin{array}{l}\text { Baseline: FBC, SPE, U\&E, TFTs, LFTs, urine } \\
\text { protein. } \\
\text { Follow-up: 1, 3-and 6-month, then every } 6 \text { months } \\
\text { FBC, LFTs and U\&E. } \\
12 \text { monthly TFTs. NABs at } 12 \& 24 \text { months }\end{array}$} \\
\hline $\begin{array}{l}\text { Peg-IFN- } \\
\text { beta-1a }\end{array}$ & Plegridy & $\begin{array}{l}\text { Immunomodulatory, } \\
\text { Pleiotropic immune } \\
\text { effects (pegylated) }\end{array}$ & $\begin{array}{l}\text { Prefilled syringe } \\
\text { 125ug sc/2 weeks }\end{array}$ & & \\
\hline $\begin{array}{l}\text { Glatiramer } \\
\text { acetate }\end{array}$ & Copaxone & $\begin{array}{l}\text { Immunomodulatory, } \\
\text { pleiotropic immune } \\
\text { effects }\end{array}$ & $\begin{array}{l}\text { Prefilled syringe } \\
\text { 20mg sc daily / } \\
40 \mathrm{mg} \mathrm{sc} \mathrm{TIW}\end{array}$ & $\begin{array}{l}\text { Injection site reactions, flushing } \\
\text { reactions, lipoatrophy, }\end{array}$ & None required \\
\hline \multicolumn{6}{|c|}{ Oral immunmodulatory therapies } \\
\hline $\begin{array}{l}\text { Dimethyl } \\
\text { fumarate }\end{array}$ & Tecfidera & $\begin{array}{l}\text { Pleiotropic, NRF2 } \\
\text { activation, } \\
\text { NFK } \beta \text { downregulation }\end{array}$ & $\begin{array}{c}\text { 240mg 2x/day per } \\
\text { os }\end{array}$ & $\begin{array}{c}\text { Flushing and GI symptoms, abnormal } \\
\text { LFTs, proteinuria, lymphopaenia, } \\
\text { PML }\end{array}$ & $\begin{array}{l}\text { Baseline: FBC, LFTs, U\&E, urine protein. } \\
\text { Follow-up: FBC and urine protein every } 3 \text { months } \\
\text { for a year, then every 6-months. }\end{array}$ \\
\hline Teriflunomide & Aubagio & $\begin{array}{l}\text { Dihydroorotate } \\
\text { dehydrogenase } \\
\text { inhibitor, } \\
\text { antiproliferative }\end{array}$ & $\begin{array}{l}7 \text { (only in the } \\
\text { USA) or } 14 \mathrm{mg} \\
\text { daily per os }\end{array}$ & $\begin{array}{c}\text { GI symptoms, hair thinning, abnormal } \\
\text { leukopaenia, LFTs, }\end{array}$ & $\begin{array}{l}\text { Baseline: BP, FBC, LFTs, U\&E, urine protein. } \\
\text { Follow-up: Fortnightly LFTs for } 6 \text { months then } \\
\text { every } 8 \text { weeks. Weekly LFT if ALT 2-3x ULN. } \\
\text { Every } 3 \text { months FBC for } 1 \text { year then every } 6 \\
\text { months. }\end{array}$ \\
\hline \multicolumn{6}{|c|}{ Oral immunosuppressive therapy } \\
\hline Fingolimod & Gilenya & $\begin{array}{c}\text { Selective S1P } \\
\text { modulator, prevents }\end{array}$ & $0.5 \mathrm{mg}$ daily per os & $\begin{array}{c}\text { Bradycardia, hypertension, } \\
\text { lymphopaenia, bronchospasm, } \\
\text { infections, macular oedema, abnormal }\end{array}$ & $\begin{array}{c}\text { Baseline: BP, FBC, LFTs, U\&E, TFTs, serum } \\
\text { Immunoglobulin levels, serology (VZV, hepatitis } \\
\text { B\&C, HIV1\&2, syphilis), TB elispot, ECG. }\end{array}$ \\
\hline
\end{tabular}




\begin{tabular}{|c|c|c|c|c|c|}
\hline & & $\begin{array}{l}\text { lymphocyte-regress } \\
\text { from lymph nodes }\end{array}$ & & $\begin{array}{c}\text { LFTs, basal cell carcinoma, } \\
\text { opportunistic infections (e.g. PML, } \\
\text { cryptococcosis) }\end{array}$ & $\begin{array}{c}\text { Follow-up: every } 3 \text { months FBC, LFTs, U\&E. } \\
\text { TFTs every } 12 \text { months. OCT at } 3 \text { months for } \\
\text { macular oedema. }\end{array}$ \\
\hline \multicolumn{6}{|c|}{ Intravenous immunosuppressive therapies } \\
\hline Natalizumab & Tysabri & $\begin{array}{l}\text { Anti-VLA4, selective } \\
\text { Adhesion molecule } \\
\text { inhibitor }\end{array}$ & $\begin{array}{l}\text { 300mg } \\
\text { IV 4-weekly }\end{array}$ & Infusion reactions, $\mathrm{PML}$ & $\begin{array}{l}\text { Baseline: FBC, U\&E, LFTs, JCV-serology. } \\
\text { Follow-up: LFTs every } 3 \text { months for a year. } \\
\text { NABs at } 12 \text { months. JCV serology every } 6 \text { months. }\end{array}$ \\
\hline Ocrelizumab & Ocrevus & $\begin{array}{l}\text { Anti-CD20, B-cell } \\
\text { depleter }\end{array}$ & $\begin{array}{l}\text { 300mg IV, then 2- } \\
\text { weeks later } 2 \mathrm{nd} \\
\text { dose of } 300 \mathrm{mg} \text { IV. } \\
\text { Subsequent dosing } \\
600 \mathrm{mg} \text { IV every } 6 \\
\text { months }\end{array}$ & $\begin{array}{l}\text { Infusion reactions, possible } \\
\text { hypogammaglobulinemia } \\
\text { with prolonged use, infections }\end{array}$ & $\begin{array}{l}\text { Baseline: FBC, LFTs, U\&E, TFTs, serum } \\
\text { immunoglobulin levels, serology (VZV, hepatitis } \\
\text { B\&C, HIV1\&2, syphilis), TB elispot, cervical } \\
\text { smear. } \\
\text { Follow-up: annual serum immunoglobulin levels }\end{array}$ \\
\hline \multicolumn{6}{|c|}{ Induction/immune reconstitution therapies } \\
\hline Alemtuzumab & Lemtrada & $\begin{array}{l}\text { Anti-CD52, non- } \\
\text { selective immune- } \\
\text { depleter }\end{array}$ & $\begin{array}{l}\text { 12mg IVI x } 5 \text { days } \\
\text { yr-1, } 12 \mathrm{mg} \text { IVI x } 3 \\
\text { days yr-2 }\end{array}$ & $\begin{array}{l}\text { Infusion reactions, leukopaenia,, } \\
\text { infections/opportunistic infections, } \\
\text { secondary autoimmunity (thyroid, } \\
\text { ITP, renal, etc.) }\end{array}$ & $\begin{array}{c}\text { Baseline: FBC, LFTs, U\&E, TFTs, serum } \\
\text { immunoglobulin levels, serology (VZV, hepatitis } \\
\text { B\&C, HIV1\&2, syphilis), TB elispot, cervical } \\
\text { smear. } \\
\text { Follow-up (for } 48 \text { months after last course): } \\
\text { monthly FBC, U\&E and urine analysis, every } 3 \\
\text { months TFTs. }\end{array}$ \\
\hline Cladribine & Mavenclad & $\begin{array}{c}\text { Deoxyadenosine } \\
\text { (purine) analogue, } \\
\text { adenosine deaminase }\end{array}$ & $\begin{array}{l}\text { 10mg tablets: } \\
\text { cumulative dose } \\
\text { of } 3.5 \mathrm{mg} / \mathrm{kg} \text { over }\end{array}$ & $\begin{array}{l}\text { Lymphopaenia, infections (in } \\
\text { particular herpes zoster) }\end{array}$ & Baseline: FBC, LFTs, U\&E, TFTs, serum \\
\hline
\end{tabular}




\begin{tabular}{|c|c|c|c|c|c|}
\hline & & $\begin{array}{l}\text { inhibitor, selective } \mathrm{T} \\
\text { and } \mathrm{B} \text { cell depletion }\end{array}$ & $\begin{array}{c}2 \text { years. Tablets } \\
\text { given for } 4-5 \\
\text { days/month } 1 \& 2 \\
\text { (8-10 days of } \\
\text { treatment per } \\
\text { year) }\end{array}$ & & $\begin{array}{l}\text { Immunoglobulin levels, serology (VZV, hepatitis } \\
\text { B\&C, HIV1\&2, syphilis), TB elispot, pregnancy } \\
\text { test and cervical smear. } \\
\text { Follow-up: FBC } 2 \text { and } 6 \text { months after start of } \\
\text { treatment in each treatment year. }\end{array}$ \\
\hline Mitoxantrone & Novatrone & $\begin{array}{l}\text { Immune depleter } \\
\text { (topoisomerase } \\
\text { inhibitor) }\end{array}$ & $\begin{array}{c}12 \mathrm{mg} / \mathrm{m} 2 \text { IVI } 3 \\
\text { monthly for } 2 \\
\text { years; maximum } \\
\text { dose of } 140 \mathrm{mg} / \mathrm{m} 2\end{array}$ & $\begin{array}{l}\text { Leukopaenia, nausea, vomiting, hair } \\
\text { loss, infections, cardiomyopathy, } \\
\text { amenorrhoea }\end{array}$ & $\begin{array}{l}\text { Baseline: FBC, LFTs, U\&E, TFTs, SPE, serum } \\
\text { Immunoglobulin levels, serology (VZV, hepatitis } \\
\text { B\&C, HIV1\&2, syphilis), TB elispot. Follow-up: } \\
\text { every } 3 \text { months FBC, LFTs U\&E. TFTs } 12 \text { months. }\end{array}$ \\
\hline
\end{tabular}

Table 4: Immunmodulatory treatments in MS (Abbreviations stand for: FBC - full blood count, U\&E - urea and electrolytes, LFTs - urea and electrolytes, TFTs - thyroid

function test, SPE - Serum protein electrophoresis, NABs - neutralizing antibodies, BP - blood pressure, ALT - alanine aminotransferase, ULN - Upper Limit of Normal, 


\section{Measuring therapeutic efficacy}

Since more and more effective DMTs are developed, the actual expectation in MS therapy is to reach no evidence of disease activity (NEDA) (163-165).

At first, NEDA was characterized by clinical parameters (NEDA-1 and 2):

1. no relapses - the appearance of a new neurological symptom, or the worsening of previously stable ones, attending for at least 24 hours, without fever or infection within 7 days of the beginning of the symptoms;

2. no disability progression - an increase of the EDSS score: by 1.5 points, if the initial score was 0 , by 1.0 point, if the initial score was minimum 1.0 , and by 0.5 points, if the initial score was more than 5.0

NEDA-3 added no MRI activity to the criteria - new or augmented T2 lesions and/or gadolinium-enhancing lesions $(166,167)$, while brain volume loss, the marker of neurodegeneration was included in NEDA-4. Accordingly, neurofilament level is the new marker in NEDA-5.

\section{Symptomatic treatments}

This group contains the treatment of those non-MS-specific symptoms that occur due to the damage of the central nervous system. These are for example:

a. bladder dysfunction, which can be treated by anticholinergics, local injection of botulinum toxin $(168,169)$ and intermittent catheterization;

b. neuropathic pain, treated with tricyclic antidepressants, or gabapentin;

c. spasticity, which can be medicated with baclofen;

d. cognitive impairment, which needs complex medical and non-medical management;

e. sleep deprivation due to, for example, anxiety, depression or fatigue.

There are also several symptomatic treatments specially licensed for MS, for example, sativex for spasticity and fampridine for walking difficulties. 


\section{MR Imaging of multiple sclerosis}

Multiple sclerosis is primarily characterised by demyelination, parallel with varying extents of axon loss (170). While the demyelinating lesions are the diagnostic cornerstones of the disease (37), thus the most well-known MRI finding in MS, recent studies highlight that the grey matter and the white matter microstructure are also affected (171).

\section{Grey matter atrophy}

There are several available approaches that can define GM atrophy. The GM volume (cortical with or without subcortical) can be defined

- manually,

- by automatic segmentation of brain tissue types, measuring the gross volume (172-174).

- by measuring cortical thickness.

\section{SIENAX}

Tissue type segmentation enabled the identification of both grey (175-178) and white matter atrophy $(176,179)$.

As the first step, SIENAX segments brain from non-brain tissue and determines the surface of the outer skull using data from a single time-point. After that, the brain and skull images are registered to a standard space pair brain and skull image, normalising for skull size and eliminating the problem of measuring CSF volume. The next step is to apply a probabilistic brain mask derived in standard space to exclude certain structures (eyes/optic nerve) from the brain segmentation. Finally, intensity-based tissue-type segmentation (including partial volume estimation) and a (normalised) brain volume evaluation is carried out (180).

\section{$\underline{\mathrm{VBM}}$}

The most common approach for measuring cortical thickness is the voxel-wise comparison of intensities (probability of tissue types in individual voxels) (voxel-based morphometry - VBM) $(172,181)$.

VBM performs a voxel-wise comparison of the local concentration of GM between two groups. At first the high-resolution images of all subjects are spatially normalized into the same stereotactic space. After that, the GM is segmented from the spatially normalized images and smoothed. The analysis then performs voxel-wise non-parametric statistical tests comparing the smoothed GM images from the two groups. Finally, using the theory of Gaussian random fields, corrections for multiple comparisons are carried out (182).

Its advantage is the ability to identify focal atrophy, however, the inter-subject registration significantly limits the usability of the method. 
Independently of the used methodology, all studies agree on the significant GM atrophy in MS. The earliest MRI study using manual measurements showed significant decrease in gross brain volume in MS patients (183), likewise later studies, applying semiautomatic larger datasets also indicated a decrease $(184,185)$. According to VBM studies, the location of GM atrophy is varied in the cortex. Nevertheless, other studies did not detect GM atrophy in MS patients comparing to the control group $(186,187)$. According to the work of Steenwijk et al., there are ten cortical thickness patterns in multiple sclerosis, which showed a non-random and symmetrical localization, developing according to distinct anatomical patterns. They were ranging from patterns associated with sensory-motor areas to those that overlap with regions associated with the limbic system and the default mode network. Additionally, these atrophy patterns revealed stronger associations with the clinical decline than global cortical atrophy (188).

\section{Diffusion Tensor Imaging}

Diffusion is the movement in the material which is not accompanied by huge molar motions. Dripping a drop of ink into water can serve as an expressive example. At the beginning the ink is located in a concentrated area, but over time it will gradually spread, in a spherically symmetrical way. This movement appears independently from any other molar motion. Fick's first law describes the above mentioned experiment (189). It states that the diffusion flux is directly proportional to the concentration gradient and the diffusion coefficient:

$\mathrm{J}=-\mathrm{D} \nabla \mathrm{C}$,

where $\mathbf{J}$ (vector) is the diffusion flux, $\mathrm{C}$ is the molecular concentraion, and $\mathrm{D}$ is the diffusion coefficient, dependent upon some of the material's attributes, which affect diffusion, such as temperature, microstructural parameters and size of the diffusing material. Despite the fact that in a balanced environment (stable temperature, pressure and consistent concentration distribution) there is no net flux, the microscopic movement of molecules still exists. It was first described by Brown at the beginning of the 1800s. In the early 20th century, Einstein concluded the same (190). Based on a probability conception, he defined the dislocational distribution depending on the difffusion coefficient:

$$
\left(\mathrm{x}^{2}\right)=2 \mathrm{D} \Delta
$$


where $\left(\mathrm{x}^{2}\right)$ is the mean square dislocational distribution in time $(\Delta)$, and D is Fick's diffusion coefficient.

MRI methodology provides a great opportunity for examining diffusion, since geometrical structures blocking microscopic movements have a significant role among the factors affecting diffusion. It is of particular importance in the examination of living tissues, since the size of the structures blocking diffusion are in an order of a magnitude that can not be examined with conventional MRI methods. Using adequate MRI sequences, it becomes possible to measure the microscopic parameters that refer to those structures which define the tissue structure. Cellular elements (membranes) inhibit molecular diffusion, thus the architecture of the tissues can be detected by the diffusion profile of water. The diffusion of water is easier along the major axis of a WM fibre bundle than perpendicularly (191). Magnetic resonance Diffusion Tensor Imaging (DTI) is a sensitive method for detecting water diffusion characteristics (for example the primary diffusion direction and diffusion anisotropy) and therefore can be used to investigate white matter tracts and other local properties of brain tissues (192).

DTI can non-invasively portray the diffusion of water in biological tissues. With multiple measurements the diffusion can be described as an elliptoid, of which the three main axes are identified by singular value decomposition. Diffusion properties, which correlate with the tissue microstructure, can be described with the combination of these three axes.

- $F A\left(\sqrt{\frac{3}{2}} \frac{\sqrt{\left(\lambda_{1}-(\lambda)\right)^{2}+\left(\lambda_{2}-(\lambda)\right)^{2}+\left(\lambda_{3}-(\lambda)\right)^{2}}}{\sqrt{\lambda_{1}^{2}+\lambda_{2}^{2}+\lambda_{3}^{2}}}\right)$ : The variability of diffusion in various directions is described by the diffusion anisotropy and can be quantified by measuring the fractional anisotropy (FA) (193). Its theoretical value ranges from 0 to 1 , increasing from the CSF, though the GM and reaches the highest value in major white matter tracts. FA, as a tract integrity marker can be compared across subjects, as it is a voxel-wise computable scalariform value, independent of the orientation of the local fibres.

- $\operatorname{MD}\left(\lambda_{1}+\lambda_{2}+\lambda_{3}\right) / 3$ : The mean diffusivity, calculated as the mean value of the three diffusion tensors, describes the overall diffusion.

- Axial diffusivity $\left(\lambda_{1}\right)$ : It shows the mean diffusion coefficient of water molecules diffusing parallel to the tract within the voxel of interest.

- Radial diffusivity $\left(\lambda_{2}+\lambda_{3}\right) / 2$ : It refers to the extent of water diffusion perpendicular to the tract.

Cross-subject comparison of DTI parameters is an inherently difficult task, mainly because of misalignment issues. Tract-Based Spatial Statistics (TBSS) provide a useful approach for localised statistical testing of diffusion parameters solving the registration issues. In summary, 
the methods concentrate only on a skeleton of the white matter fibres, which can be identified by the local maxima of the FA. A brief summary of the TBSS approach:

- Refers to a common registration target and uses collinear registration to align the FA images of all subjects. At this point, the alignment is not required to be perfect.

- Produces the mean of the aligned FA images and practices "thinning" (non-maximumsuppression perpendicular to the local tract structure) to produce a skeletonised mean FA image. The mean FA image is thresholded for suppressing low mean FA areas and/or high inter-subject variability.

- By filling the skeleton with FA values from the closest relevant tract centre, it projects each subject's aligned FA image onto the skeleton. This is performed for each skeleton voxel by finding the maximum value perpendicular to the local skeleton structure for the subject's FA image.

- Performs voxel-wise statistics across subjects on the skeleton space FA data (194). 


\section{Objectives}

The identification of a reliable MRI marker and the structural background of clinical and cognitive symptoms in MS are still hot topics. While lesions in the white matter are remarkable MRI markers in MS and counted as one of the diagnostic cornerstones of the disease (135), the lesion load only modestly correlates with clinical and cognitive decline. This phenomenon is known as the clinico-radiological paradox $(195,196)$. Although the Gd-enhancing lesions are slightly more specific MRI markers during the acute phase of the disease, they can rarely be seen on the MRI. It can happen, even in cases of relapse, that no Gd-enhancement appears. Since the Gd-enhancement can only be monitored for 2 or 3 weeks (104), detection is barely possible during a routine MRI.

GM atrophy (cortical with or without subcortical structures) can be detected by several approaches. Manually, by an automatic segmentation of brain tissue types that can measure the whole brain, the GM and WM volume, and by measuring the cortical thickness, which can identify local atrophy. Atrophy is seen to be a progressive process, even from the very beginning of the disease. Earlier studies estimated the rate of brain atrophy at around 0.6-1.0\% annually in MS (115-117), while in 2015 DeStefano determined the pathological annual brain volume loss higher than $0.4 \%$ (118).

GM atrophy has become a remarkable tool to follow-up therapeutic efficacy $(118,171)$ and, unlike WM lesions, is strongly connected to clinico-cognitive functioning (197, 198). Several drug trials used GM atrophy as a marker of treatment efficacy. In a phase III clinical trial, patients showed reduced rates of atrophy (brain parenchymal fraction) in the treatment arm (INF $\beta$-1a )(199), while in a comparative study GA decreased the rate of atrophy more than INF $\beta-1 \mathrm{a}$ (200). According to the SENTINEL study, the combined intramuscular INF $\beta-1 \mathrm{a}$ and natalizumab therapy reduced the atrophy rate compared to the group receiving only INF $\beta-1 \mathrm{a}$ (201). In the TRANSFORMS (a 12 months phase III) study, fingolimod caused remarkable reduction in the brain atrophy rate compared to the im. INF $\beta$ treatment (202).

Diffusion is the movement in the material, which is not accompanied by huge molar motions. It can be non-invasively portray by DTI. Cellular elements (membranes) inhibit molecular diffusion, thus the architecture of the tissues can be detected by the diffusion profile of water. Tract-Based Spatial Statistics (TBSS) and the manual labeling of the regions-of-interest (ROIs) (203) are useful approaches for localised statistical testing of FA (and other diffusion-related) data. While ROIs are very useful when they are defined for each individual subject, the manual drawing process is time-consuming and may result in misalignment. TBSS is a more effective 
process, especially when using a large number of subjects, but individual differences of interest may be lost by registering the FA maps of all subjects to a target.

According to earlier studies, the various models of diffusion parameter changes refer to different pathological changes of the WM. The alterations of AD show axon damage, while RD changes refer to demyelination (204-207). There are contradictory results about the relationship of diffusion metrics with the disability. While some studies found no connection (208), others revealed correlation between the disability and the FA in NAWM (209) or MD in the lesions (210). It is also important to use a high number of diffusion directions, thus the alterations of the demyelination-like diffusion parameters can be shown extensively in the WM skeleton (211).

In our first study we aimed to determine the relationship between cortical atrophy and WM pathology in MS. Within this, we studied whether the pathology of the focal lesions or the diffuse NAWM has a more significant role in the evolution of GM atrophy. Based on Jenha's study (212), we were also interested in the connection between the desintegration of the periventricular WM and the conception of GM atrophy. Our aim was to test two hypotheses. According to the first, GM atrophy is defined by demyelination-like diffusion features that suggest there is a common root in the development of demyelination in WM and GM atrophy (maybe a common pathological process mediated by the CSF). The second hypothesis proposed that GM atrophy is more connected to axon loss-like diffusion pattern, which points to a role of remote axonal transection in GM loss. The accurate mechanism lying under the atrophy is not well-understood yet, however, several formal studies have made an attempt to detect it. The demyelination measured in the GM has a similar magnitude to that of the WM (213). According to former ex-vivo studies, GM demyelination is primarily subpial and usually affects several neighboring gyri in a ribbon form. It was confirmed that this kind of cortical demyelination has consorted with meningeal inflammation. Mediated by the CSF, meningeal inflammation results in a non-targeted general immunopathological reaction, which was found to be accountable for the GM pathology $(214,215)$. The study of Jehna et al. supports the hypothesis about a common pathology in the periventricular WM and the cortex mediated by the CSF. They found a connection between cortical atrophy and the periventricular lesion burden in MS (212). While several studies focused on the role of periventricular lesions, others suggest that different mechanisms also have an effect on the development of cortical atrophy. Wegner et al. declared that the number of leukocortical lesions is almost as high as that of the subpial lesions (216). They also revealed neuronal loss in regions without B-cell follicle-like structures. Remote axonal transections (supposedly relating lesion formation in the WM and demyelination) and 
dying back axonopathy could also cause cortical atrophy $(217,218)$. Charil et al. detected the most remarkable cortical atrophy in MS in association cortices, with widespread cortico-cortical connections (219). These findings support the hypothesis that plastic changes, like a decrease in synaptic density caused by reduced cortical input, can manifest in the form of cortical atrophy. Low levels of N-acetylaspartate, a neuronal viability marker in the NAWM of MS patients detected by MR spectroscopy, are supposed to be a sign of loss or dysfunctional axons $(220,221)$. The ratio of $\mathrm{N}$-acetylaspartate/myo-inositol, the indicator of decreased neuronal integrity and high gliosis, participates in the development of brain volume change (222). Myelin pathology in the NAWM, measured by MTR, was also connected to disability and cerebral atrophy (223).

In our second study, we meant to define the pattern of the MRI parameters best predicting clinical and cognitive disability in patients with MS. Although several studies examined the relationship between various MRI markers and clinical and cognitive decline (224-227), only a few of them paid attention to the importance of the diffusion parameters (228-230). Besides, despite their uncontroversial worth, these studies have their limitations. Some of them applied only low numbers of diffusion directions or used only some of the diffusion parameters. Others did not include all of the separate subcortical structures or the cognitive domains in the analysis. Lesions do not correlate with the clinical symptoms and GM atrophy is nonspecific to the underlying pathology of MS. Fortunately, nowadays novel methods are available that better describe the pathological processes. In our studies, we applied diffusion tensor imaging (DTI) to examine WM pathology. DTI is able to reveal widespread changes in the WM, in the lesions, such as in the NAWM (211). These alterations also show a connection between various clinical and cognitive malfunctions $(226,231)$.

Since MRI parameters are strongly related (211), the conventional linear regression analysis is not an appropriate choice for the statistics. In our studies, we used the model-free partial least square (PLS) approach, which can detect the design of those parameters that best predicts the questionable parameters, besides dealing with the problem of collinearity.

\section{Aims}

In our consecutive studies we aimed to answer two questions:

- the relationship between cortical atrophy and white matter desintegration as measured by DTI, 
- definition of those MRI parameters that best predict the clinical and cognitive disability in multiple sclerosis.

\section{Materials and Methods}

\section{Subjects}

The first and second studies were conducted on 52 and 53 patients, respectively, with a diagnosis of relapsing-remitting multiple sclerosis, and 50 and 53 healthy, age-matched volunteer controls with no history of any neurological or psychiatric diseases. Patients were recruited from the Multiple Sclerosis Outpatient Clinic at the Department of Neurology. The diagnosis was based on the 2005 revision of the McDonald criteria (37). The clinical disability of the patients was measured on the Kurtzke expanded disability status scale (EDSS) (41). All patients were on disease-modifying therapy (Table 5). The cognitive performance of the patients was measured by Brief International Assessment for MS (BICAMS). All patients were in stable clinical condition, no relapses and no EDSS progression had occurred in the preceding six months.

The studies were approved by the ethics committee of the National Institute of Pharmacy and Nutrition and the Regional Human Biomedical Research Ethics Committee and all study participants gave their written informed consent in accordance with the Helsinki Declaration (Ref. No.: 000002/2016/OTIG).

\begin{tabular}{|c|c|c|c|c|}
\hline & \multicolumn{2}{|c|}{ Study 1 } & \multicolumn{2}{c|}{ Study 2 } \\
\hline Patients & 52 & Controls & Patients & Controls \\
\hline $\begin{array}{c}\text { Age (years; } \\
\text { mean } \pm \text { SD) }\end{array}$ & $40.87 \pm 10.31$ & $\begin{array}{c}37.14 \pm 10 \\
.77\end{array}$ & $44.34 \pm 11.51$ & 53 \\
\hline Sex (male) & 13 & 20 & 17 & $36.06 \pm 1$ \\
& $9.69 \pm 7.188$ & N.A. & $13.89 \pm 9.02$ & 16 \\
\hline $\begin{array}{c}\text { Disease duration } \\
\text { (years; mean } \pm \text { SD) }\end{array}$ & $1.66 \pm 1.44$ & N.A. & $1.89 \pm 1.65$ & N.A. A. \\
\hline EDSS score & $\begin{array}{l}\text { Interferon beta: } 25 \\
\text { Glatiramer acetate: } 16\end{array}$ & & Interferon beta: 33 & \\
\hline Fingolimod: 1 & Glatiramer acetate: 20 & \\
\hline
\end{tabular}

Table 5. Clinical and demographic data of the participating subjects. 


\section{Cognitive assessment of the patients}

The Brief International Cognitive Assessment for MS (BICAMS) test is a short form that is a fast, sensitive and specific tool for the determination of the most frequently affected cognitive domains of the patient (232-234). The BICAMS test involves three separate tests: the symbol digit modalities test (SDMT), the first five recall trials of the California verbal learning test II. (CVLT-II) and the first three recall trials of the brief visuospatial memory test revised (BVMTR) (235).

The SDMT measures the information processing speed, in both written and oral versions. This test is carried out using a sheet, containing nine symbols in pseudo-randomized lines. Each symbol is paired with a digit in a key at the top of the sheet. At the beginning there is a short practice time, then patients have 90 seconds to pair as many of the symbols with the digits as they can. The final score is the number of correct responses (236).

The CVLT-II measures verbal learning. The first five recall trials of the test contain 16 words clustered into 4 semantic groups. The examiner reads the list aloud at a speed of around 1 word/second and the patients have to repeat them back in an optional order. For this test, there is no time limit. The final score is the number of correct words recalled during the five trials (237).

The BVMT-R measures visual memory. The examiner shows the patients a sheet with a matrix of six abstract figures for 10 second, then the patients have to reproduce them on a blank sheet as accurately as they can, without a time limit. The final score is the points for the reproduced figures ( 0,1 or 2 according to the accuracy) during the three trials (238).

In our study, we used the validated Hungarian version of the BICAMS test (for details of the validation process see: (233)). For all subtests of BICAMS, the patients' results were compared to the age-matched control group of healthy individuals from our earlier validation study (233). A difference of more than two standard deviations when compared to the control database was considered as abnormal.

\section{Image acquisition}

MR imaging was carried out on a 1.5T GE Signa Excite HDxt MR scanner. 3D spoiled gradient echo (FSPGR: TE: $4.1 \mathrm{~ms}$, TR: $10.276 \mathrm{~ms}$, matrix: 256x256, FOV: 25x25 cm, Flip angle: 15 degrees, in-plane resolution: 1x1 mm, slice thickness: $1 \mathrm{~mm}$ ), FLAIR (TE: $4.1 \mathrm{~ms}$, TR: 10.276 ms, matrix: 256x256, FOV: 25x25 cm, Flip angle: 15 degrees, in-plane resolution: 1x1 mm, slice thickness: $1 \mathrm{~mm}$ ) and 60 direction diffusion-weighted images with 6 non-diffusionweighted reference volumes (TE: 93.8 ms, TR: 16000 ms, matrix: 96x96, FOV: 23x23 cm, Flip 
angle: 90 degrees, in-plane resolution: $2.4 \times 2.4 \mathrm{~mm}$ slice thickness: $2.4 \mathrm{~mm}, \mathrm{~b}: 1000 \mathrm{~s} / \mathrm{mm}^{2}$, NEX: 2, ASSET) were acquired for all subjects.

\section{Evaluation of lesion load}

Lesions were manually segmented on the FLAIR images by ET, and rechecked by ZTK, having considerable experience in MS neuroradiology. FLAIR images were registered to the highresolution T1 images with a 6 degree-of-freedom linear registration (239). High-resolution T1 images were registered to standard space images with a 12 degree-of-freedom affine registration and were refined by non-linear registration implemented in FNIRT (240). Binary lesion masks were transformed to standard space using the transformation matrices and warp fields from the above-mentioned registrations. Standard space masks were thresholded at 0.5 and binarized again in order to avoid the size increment of the mask caused by the trilinear interpolation. Binary masks were summed in order to provide a lesion probability distribution.

\section{Evaluation of Global Atrophy}

We calculated the total brain volume with SIENAX (180), part of FSL $(181,241)$. SIENAX started by extracting brain and skull images from the single whole-head input data (180). We then carried out tissue-type segmentation with partial volume estimation (242) in order to calculate the total volume of brain tissue (including separate estimates of volumes of total gray matter, peripheral gray matter and white matter). We "filled" the area under the binary lesion masks with intensities similar to those in the non-lesioned neighborhood, to reduce the bias caused by the T1 hypointense lesions (243).

\section{Volumetric analysis of the subcortical structures}

Image analysis was carried out using tools of FSL (FMRIB Software Library, http://www.fmrib.ox.ac.uk/fsl) (181). To automatically segment the subcortical structures (244), FIRST, a deformable-model-based segmentation/registration tool was used that uses a Bayesian Appearance Model (FMRIB's Integrated Registration Segmentation Toolkit). For the automatic segmentation of structures, shape and intensity variations of subcortical structures were constructed from a training set of 336 images. With preservation of the cross-subject vertex correspondence, surface meshes were obtained with a deformable model. At each vertex, a sample was taken from the normalized intensities along the surface normal. Then the vertex location and intensity variation were modeled as a multivariate Gaussian distribution. Finally, maximizing the posterior probability of the shape, given the observed intensities, this model 
was fit to new images $(198,245)$. The result of the segmentation was manually checked and corrected if necessary by the first author. The volume of the segmented subcortical structures was normalised to the head size.

\section{Microstructural alterations of the white matter}

Diffusion data were corrected for Eddy currents and movement artefacts by a 12 degree-offreedom affine linear registration to the first non-diffusion-weighted reference image. Diffusion images were processed using FDT (FMRIB's Diffusion Toolbox part of FSL: www.fmrib.ox.ac.uk/fsl/fdt/)). Fractional anisotropy, Mean diffusivity $\left(\left(\lambda_{1}+\lambda_{2}+\lambda_{3}\right) / 3\right)$, Axial diffusivity $\left(\lambda_{1}\right)$ and Radial diffusivity $\left(\left(\lambda_{2}+\lambda_{3}\right) / 2\right)$ to the principal diffusion direction were computed for the whole brain.

The Tract-Based Spatial Statistics (TBSS) method was used to reduce possible errors resulting from misalignment of the images: A non-linear registration tool (FNIRT), which uses a b-spline representation of the registration warp field, aligned all Fractional anisotropy images to a 1x1x1 mm FMRIB58_FA standard space. The data on all patients were brought into the standard space, and a mean fractional anisotropy image was created and then fed into the Fractional anisotropy skeletonization program, thresholded at fractional anisotropy $=0.2$ to create a mean fractional anisotropy skeleton that represented the centers of all tracts common to the group. The aligned fractional anisotropy data on each subject were then projected onto this skeleton, which resulted in the 4D skeletonized fractional anisotropy image. The resulting data were fed into voxel-wise cross-subject statistics.

With the use of non-parametric permutation-based cluster analysis $(5,000$ permutations) as implemented in FSL, modeling and inferring, we accomplished the standard general linear model (GLM) design. The design encoded for group membership. Statistical thresholding was carried out with the Threshold-Free Cluster Enhancing (TFCE) approach ( $p<0.05$ was chosen as a threshold and the results are corrected for multiple comparisons across space).

Also, a voxel-wise alteration of the diffusion parameters, (microstructural integrity index MII), was calculated for each patient (211), by comparing the value of every voxel with the distribution from the normal subjects in the spatially matching voxel (z-score). To identify global white matter damage we calculated the averages of these z-scores: 


$$
\begin{gathered}
\bar{X}_{n}=\frac{{ }_{i=1}^{q} X_{n, i}}{q}, \\
{ }_{n}=\frac{\left.{ }_{i=1}^{q} \bar{X}_{n} X_{n, i}\right)}{q}, \\
Z_{X, n, j}=\frac{X_{n, j} X_{n}}{n},
\end{gathered}
$$

where $\mathrm{X}$ is the measured diffusion parameter (fractional anisotropy, mean diffusivity, axial diffusivity, and radial diffusivity) in the nth voxel in the skeleton. Indices $i$ and $j$ are for controls and patients, respectively.

The average diffusion parameters were calculated for each patient in the following compartments: periventricular lesions, non-periventricular lesions, periventricular normal white matter, and non-periventricular normal white matter.

To define the periventricular space, the ventricles were manually segmented on the $1 \times 1 \times 1$ mm FMRIB58_FA image dilated by three voxels similar to Jehna et al. (2015). The nonperiventricular white matter was defined as the rest of the white matter, periventricular part excluded.

The manually segmented lesions were brought to the diffusion data space with a 6 degree-offreedom linear registration. Through the use of the warp field and the skeleton projections of the Tract-Based Spatial Statistics analysis of the fractional anisotropy images, the lesion mask was brought to the skeleton with the FSL tbss_non_fa algorithm. The mask was finally thresholded at 0.5 and binarized to avoid any size increment arising from the interpolation.

Analysis of the connection between the MR parameters and clinical and cognitive status and between Brain Atrophy and the Compartmental Diffusion Metrics

We used partial least squares (PLS) regression analysis to estimate the contributions of the various MRI parameters (partial brain volume, normalised gray matter and white matter volume, volume of the subcortical structures, lesion load and the diffusion parameters of the lesions and the normal appearing white matter) to the EDSS and the subscores of the BICAMS test. Using this analysis, we also determined the contributions of the calculated compartmental diffusion parameters to the EDSS, gray matter and global brain atrophy. 
If $\mathrm{Y}$ is an $\mathrm{n} \times \mathrm{q}$ matrix of dependent variables over $\mathrm{n}$ observations and $\mathrm{X}$ is an $\mathrm{n} \times \mathrm{p}$ matrix of predictors, PLS successively extracts latent variables (factors and loadings) from X and Y in such a way that covariance between the factors and loadings is maximized. With this approach, PLS reduces the dimensionality of the data by providing a weighted linear combination of $\mathrm{X}$ variables to form orthogonal components that predict the dependent variable. In mathematical terms, partial least squares is a linear decomposition of $\mathrm{X}$ and $\mathrm{Y}$ such that

$$
\begin{aligned}
& \mathrm{X}=\mathrm{TP}^{\mathrm{T}}+\mathrm{E}, \\
& \mathrm{Y}=\mathrm{UQ}^{\mathrm{T}}+\mathrm{F}
\end{aligned}
$$

and the covariance between $\mathrm{T}$ and $\mathrm{U}$ is maximum (246). In the above equations, $\mathrm{T}$ is the $\mathrm{n} \times \mathrm{r} \mathrm{X}$ scores, $\mathrm{U}$ is the $\mathrm{n} \times \mathrm{r} \mathrm{Y}$ scores, $\mathrm{P}$ is the $\mathrm{p} \times \mathrm{r} \mathrm{X}$ loadings, $\mathrm{Q}$ is the $1 \times \mathrm{r} \mathrm{Y}$ loadings, $\mathrm{E}$ and $\mathrm{F}$ are residuals, and $\mathrm{r}$ is the number of extracted latent variables. The statistical inference on the significance of the latent variable was carried out by permutation tests on the singular values of the decomposition. The elements of the dependent variable matrix were randomly permuted 5000 times and the singular value was recalculated to depict a null distribution. The summary of the importance for the $\mathrm{X}$ loadings was calculated by a Variable Importance in the Projection (VIP) score (247). Since the average of squared Variable Importance in the Projection scores is equal to 1, the 'greater than one' rule was used for the selection of the important variables.

During the first analysis, the dependent variable (Y) is the normalized brain or gray matter volume, the predictors $(\mathrm{X})$ are the diffusion parameters in the different compartments (periventricular and non-periventricular $\bar{Z}_{F A}, \bar{Z}_{M D}, \bar{Z}_{A D}$ and $\bar{Z}_{R D}$ ), and the observations are the patients. The $\mathrm{X}$ loadings are the optimum weights of the compartmental diffusion parameters which best predict the peripheral gray matter atrophy.

During the second analysis, the dependent variables $(\mathrm{Y})$ are the subscores of BICAMS or EDSS, the predictors $(\mathrm{X})$ are the various MRI parameters and the observations are the patients. The $\mathrm{X}$ loadings are the optimum weights of the compartmental diffusion parameters which best predict the BICAMS or EDSS.

We performed volumetric comparison across groups and the correlation tests with the Statistical Package for Social Sciences (SPSS 17 for OS X, SPSS Inc., http://www.spss.com). 


\section{Results}

\section{Clinical, cognitive and imaging parameters of the patients}

Despite the comparatively long disease duration, the patients who took part in our studies have only mild to moderate disability as measured by EDSS (Table 1).

In our first study the SIENAX analysis revealed reduction in total brain volume (patients: $718.764 \pm 14.968 \mathrm{~cm} 3$, controls: $791.772 \pm 22.692$; mean $\pm \mathrm{SE}$ ), total WM (patients: 323.237 $\pm 7.246 \mathrm{~cm} 3$, controls: $355.350 \pm 10.929 ;$ mean \pm SE), and total GM (patients: $395.527 \pm 8.050$ cm3, controls: $436.422 \pm 12.011$; mean \pm SE) volume in the MS patients compared to controls (normalized to the premorbid brain volume, the normality of the data was violated in the Kolmogorov-Smirnov test, and hence the non-parametric Mann-Whitney U-test was used: $\mathrm{p}<$ $0.015 ; \mathrm{p}<0.0001$; and $\mathrm{p}<0.009$, respectively; Figure 1).

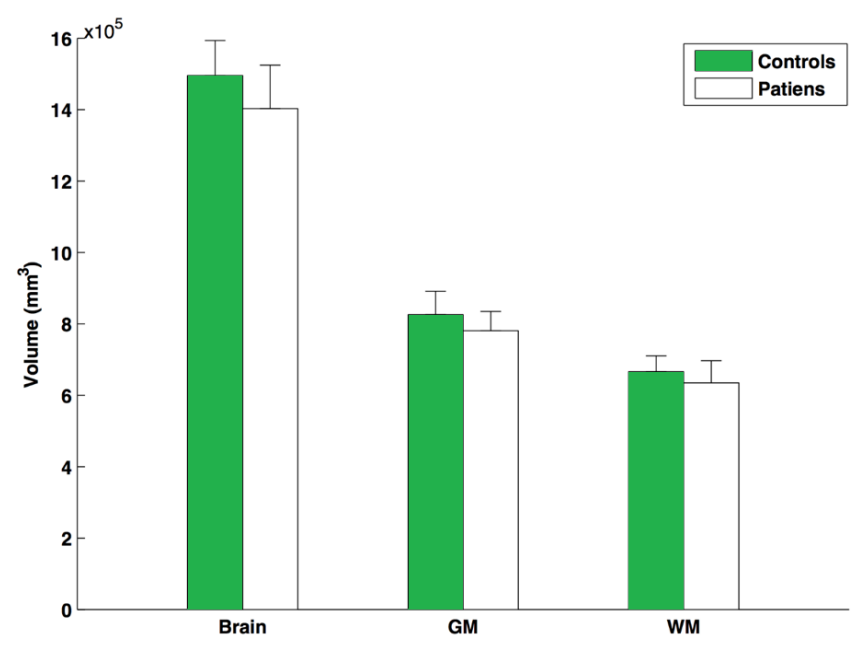

Figure 1. Normalized PBV of controls and patients.

Compared to the healthy controls, TBSS showed significant decrease in the FA ( $<$ 0.0002) of the MS patients: in essentially all the WM fiber bundles, with the exception of the area of the corticospinal tract (Figure 2 second row). The MD was increased $(\mathrm{p}<0.0002)$ in the majority of the WM bundles, but not in the corticospinal tracts or the inferior longitudinal fasciculus (Figure 2 third row, Table 6). The RD also displayed a significant increase $(\mathrm{p}<0.0002)$ in all examined fibers in the skeleton, apart from the corticospinal tracts (Figure 2 fourth row, Table 2). Importantly, the WM, diffusion alterations (FA, MD and RD) were distributed in the NAWM and also in the periventricular WM, where lesions appeared with high probability. In contrast, an increase in $\mathrm{AD}$ was only found in the more central fibers and in the intrathalamic WM $(\mathrm{p}<0.0002)$ in the corpus callosum, the superior longitudinal fasciculus, the superior 
corona radiate, the inferior fronto-occipital fasciculus, the posterior and anterior thalamic radiation, and the internal capsule (Figure 2 fifth row, Table 6).

\begin{tabular}{|l|l|l|l|}
\hline Diffusion parameter & Compartment & Loadings & VIP-scores \\
\hline \multirow{4}{*}{ FA } & Non-PV Lesioned & 5.06 & 0.61 \\
\cline { 2 - 4 } & PV Lesioned & 4.41 & 055 \\
\cline { 2 - 4 } & PV Non-lesioned & 4.44 & 0.93 \\
\cline { 2 - 4 } & Non-PV Non-lesioned & 3.17 & 0.55 \\
\hline \multirow{4}{*}{ MD } & Non-PV Lesioned & -12.28 & $1.17^{*}$ \\
\cline { 2 - 4 } & PV Lesioned & -10.51 & $1.35^{*}$ \\
\cline { 2 - 4 } & PV Non-lesioned & -7.07 & $1.47^{*}$ \\
\cline { 2 - 4 } & Non-PV Non-lesioned & -4.42 & 0.65 \\
\hline \multirow{5}{*}{ RD } & Non-PV Lesioned & -11.32 & $1.18^{*}$ \\
\cline { 2 - 4 } & PV Lesioned & -9.99 & $1.27^{*}$ \\
\cline { 2 - 4 } & PV Non-lesioned & -8.05 & $1.66^{*}$ \\
\cline { 2 - 4 } & Non-PV Non-lesioned & -5.06 & 0.8 \\
\hline & Non-PV Lesioned & -6.39 & 0.59 \\
\cline { 2 - 4 } & PV Lesioned & -6.72 & 0.95 \\
\cline { 2 - 4 } & PV Non-lesioned & -3.48 & 0.78 \\
\cline { 2 - 4 } & Non-PV Non-lesioned & -1.38 & 0.14 \\
\hline
\end{tabular}

Table 6. Loadings and VIP scores that best predict the normalized brain volume. VIP scores $\geq 1$ were considered to indicate a significant contribution $(*)$. 


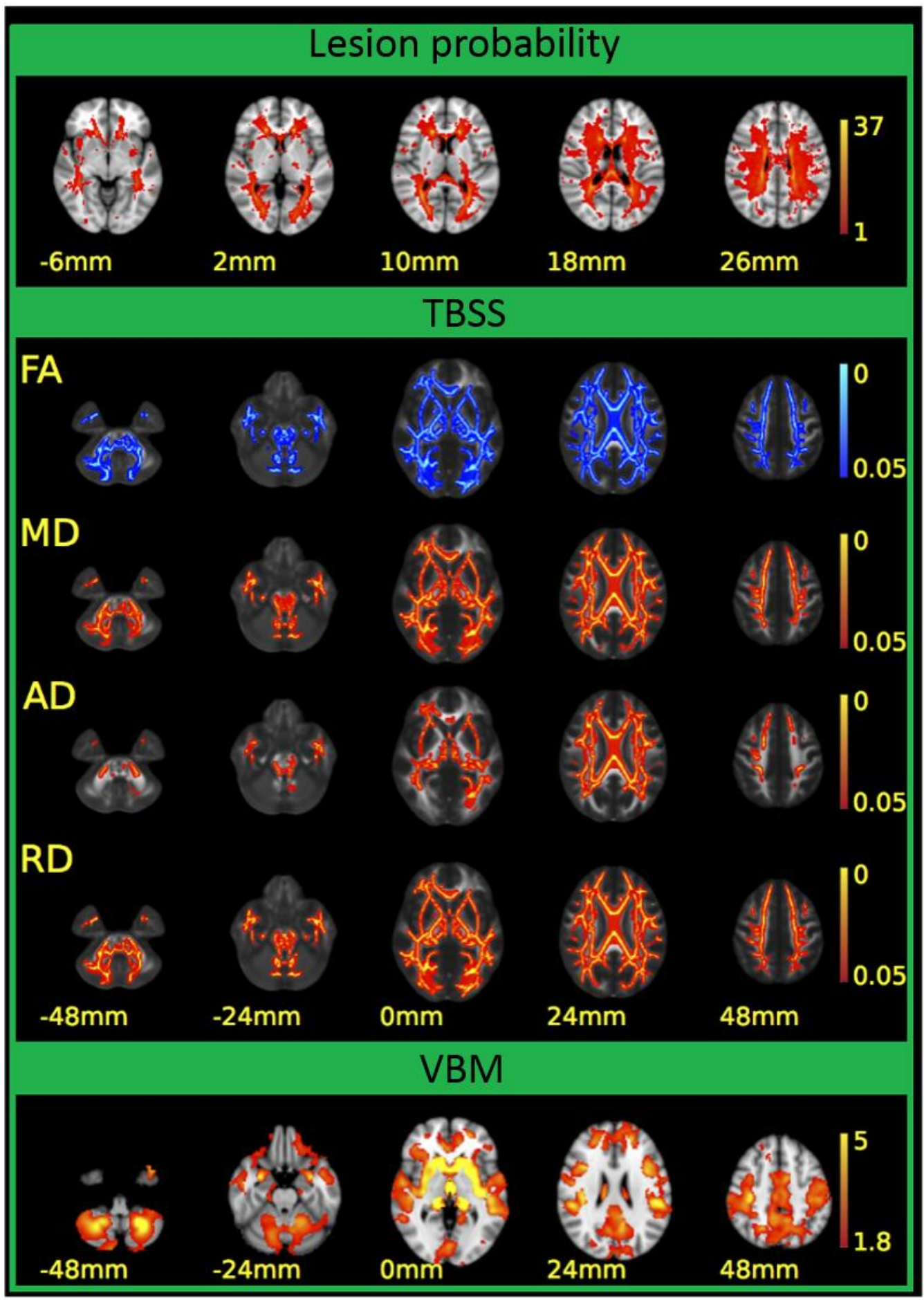

Figure 2. Diffusion parameter alterations and cortical atrophy in MS patients. The first line shows the lesion probability map of the 52 patients, overlaid on the MNI152 standard brain. The colour bar represents the number of patients having a lesion in a certain localization. The $\mathrm{z}$ coordinates of the depicted slices can be seen under the images. The middle section of the Figure shows the results of the TBSS analysis, overlaid on the FMRIB58_FA standard FA template. Significant differences in FA, MD, and AD and RD between patients and controls in the WM skeleton are shown in the consecutive rows. A blue colour represents a decrease, and red-to-yellow colours an increase in the diffusion parameters. For easier visualization, a thickened version of the significant cluster is applied. Colour bars represent $\mathrm{p}$-values (corrected for multiple correlation). The $\mathrm{z}$ coordinates are shown below the images. In the last row, the results of the VBM analysis are depicted, overlaid on the MNI152 standard brain. The significant differences are shown in a red-to-yellow colour scale. The z coordinates are shown under the images. 
In the second study, out of the 53 patients, 18 had cognitive dysfunction on one cognitive test (CVLT: 0, BVMT: 7, SDMT: 9), 8 on two tests (SDMT and BVMT: 7, BVMT and CVLT: 1) and 5 on all three tests.

For the measured MRI parameters (partial brain volume, GM and WM volume, the volume of the subcortical structures and the diffusion parameters of the white matter) see Table 7.

\begin{tabular}{|c|c|c|c|c|}
\hline & & Multiple Sclerosis & Healthy & p-value \\
\hline \multirow{5}{*}{$\begin{array}{l}\text { Global atrophy } \\
(\text { mean } \pm \text { SD })\end{array}$} & $\begin{array}{l}\text { Normalized total } \\
\text { brain volume }\end{array}$ & $\begin{array}{l}1423745.72 \pm 7726 \\
26\end{array}$ & $1492340.43 \pm 65602.53$ & 0.332 \\
\hline & $\begin{array}{l}\text { Normalized GM } \\
\text { volume }\end{array}$ & $\begin{array}{l}784317.27 \pm 51061 \\
79\end{array}$ & $824838.22 \pm 44204.64$ & 0.00003 \\
\hline & $\begin{array}{l}\text { Normalized WM } \\
\text { volume }\end{array}$ & $\begin{array}{l}639428.45 \pm 43973 \\
57\end{array}$ & $667502.21 \pm 36040.49$ & 0.000498 \\
\hline & Normalized pGM & $\begin{array}{l}607231.49 \pm 43383 \\
91\end{array}$ & $642563.77 \pm 35221.91$ & 0.000012 \\
\hline & Normalized VCSF & $\begin{array}{l}48551.20 \pm 20524.2 \\
3\end{array}$ & $33269.52 \pm 11904.28$ & 0.000008 \\
\hline \multirow{12}{*}{$\begin{array}{l}\text { Subcortical Structure } \\
\text { volume } \mathbf{m m}^{3}(\text { mean } \pm \text { SD })\end{array}$} & Left amygdala & $1717.22 \pm 304.80$ & $1755.28 \pm 235.315$ & 0.473 \\
\hline & Left caudatus & $4324.02 \pm 611.32$ & $4683.56 \pm 561.583$ & 0.02 \\
\hline & Left hippocampus & $5019.21 \pm 608.16$ & $5434.64 \pm 690.22$ & 0.001 \\
\hline & Left pallidum & $2303.76 \pm 328.13$ & $2383.04 \pm 187.67$ & 0.130 \\
\hline & Left putamen & $6270.55 \pm 749.85$ & $6802.61 \pm 601.27$ & 0.000106 \\
\hline & Left thalamus & $965.38 \pm 1092.743$ & $10886.14 \pm 837.47$ & 0.00000 \\
\hline & Right amygdale & $1666.32 \pm 264.20$ & $1713.80 \pm 311.28$ & 0.399 \\
\hline & Right caudatus & $4414.96 \pm 705.49$ & $4905.77 \pm 582.28$ & 0.000167 \\
\hline & $\begin{array}{l}\text { Right } \\
\text { hippocampus }\end{array}$ & $5148.92 \pm 551.24$ & $5340.47 \pm 663.50$ & 0.109 \\
\hline & Right pallidum & $2331.54 \pm 250.36$ & $2435.00 \pm 181.80$ & 0.017 \\
\hline & Right putamen & $6248.99 \pm 765.47$ & $6658.91 \pm 628.22$ & 0.003 \\
\hline & Right thalamus & $9380.61 \pm 1092.52$ & $10521.75 \pm 925.85$ & 0.00000 \\
\hline \multirow{8}{*}{$\begin{array}{l}\text { Diffusion parameters \% } \\
(\text { mean } \pm \text { SD) }\end{array}$} & NAWM_FA & $94.46 \pm 5.78$ & & \\
\hline & Lesioned_FA & $89.90 \pm 14.36$ & & \\
\hline & NAWM_AD & $100.85 \pm 2.41$ & & \\
\hline & Lesioned_AD & $105.66 \pm 10.07$ & & \\
\hline & NAWM_MD & $103.84 \pm 5.14$ & & \\
\hline & Lesoined_MD & $112.83 \pm 18.62$ & & \\
\hline & NAWM_RD & $108.06 \pm 9.83$ & & \\
\hline & Lesioned_RD & $123.63 \pm 35.29$ & & \\
\hline Lesions & LL $($ mean \pm SD $)$ & $9698.33 \pm 9754.94$ & & \\
\hline \multirow{3}{*}{$\begin{array}{l}\text { Cognitive scores } \\
(\text { mean } \pm \text { SD })\end{array}$} & BVMT z-score & $-0.67 \pm 1.49$ & & \\
\hline & SDMT z-score & $-1.00 \pm 1.22$ & & \\
\hline & CVLT z-score & $0.28 \pm 0.98$ & & \\
\hline
\end{tabular}

Table 7. MRI parameters and cognitive scores of the subjects. 


\section{Lesion Probability Distribution}

In our first study we determined the distribution of the white matter lesions and their connection with the total brain and gray matter atrophy.

The average native space lesion load was $12.328 \pm 16.100 \mathrm{~cm} 3($ mean \pm SD) and the lesion load normalized to the intracranial volume (v scaling factor) was $17.087 \pm 22.509 \mathrm{~cm} 3$ (mean $\pm \mathrm{SD})$. The normalized lesion volume showed a negative correlation with the normalized GM volume $(\mathrm{R}=-0.32, \mathrm{p}<0.021)$, but there was no correlation with the normalized brain volume. The lesion load did not correlate with the EDSS of the patients either.

The lesions were distributed across widespread WM regions, but the lesion probability was highest in the periventricular WM (Figure 2 first row).

\section{The Connection between the Brain Atrophy and the Compartmental White Matter Pathology}

In our first study our main interest was to the determine those compartmental diffusion parameters (periventricular and non-periventricular $\bar{Z}_{F A}, \bar{Z}_{M D}, \bar{Z}_{A D}$ and $\bar{Z}_{R D}$ ) which best predict brain atrophy.

In the first PLS analysis the normalized GM volume was the dependent variable. Only the first latent variable was evaluated because the second latent variable explained only a small part of the variance of the dependent measure $(<5 \%)$ and the permutation test showed a non-significant latent variable. The permutation test revealed that the first latent variable was significant $(\mathrm{p}<$ 0.001 ) and accounted for $47.3 \%$ of the variation of the dependent variable and $76.5 \%$ of the predictors. The $\mathrm{X}$ loadings and the corresponding Variable Importance in the Projection scores indicated that the MD and RD of the lesioned and non-lesioned periventricular and the nonperiventricular lesioned WM contributed significantly to GM atrophy (Figure 3, Table 8).

Similar results were found in the case of normalized brain volume: only the first latent variable was significant according to the permutation test. The first latent variable accounted for $24.9 \%$ of the variation of the dependent variable and $76.7 \%$ of the predictors. X loadings coding the optimum contrast of the predictors exhibited a similar pattern to that of GM volume. 

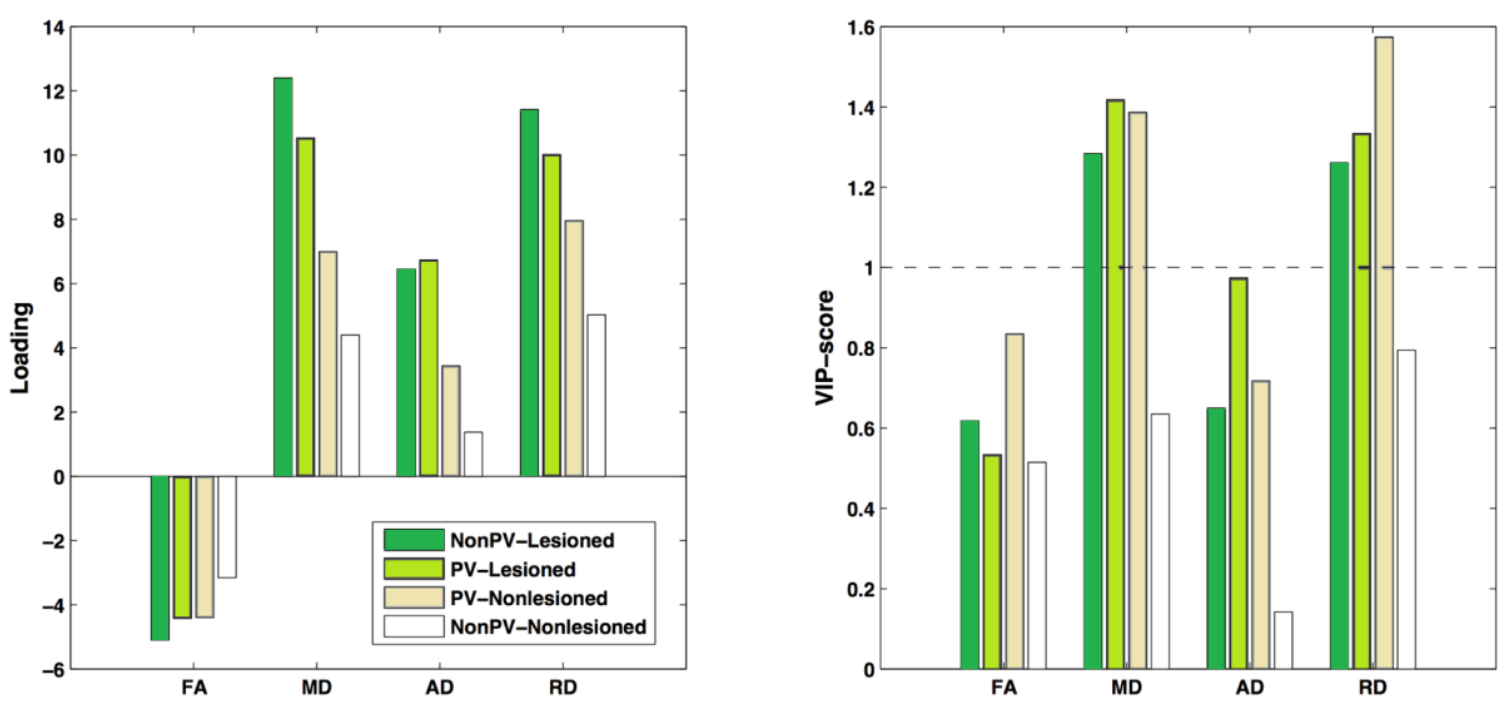

Figure 3. PLS loadings and VIP scores that depict the optimum contrast of the independent variables best predicting the GM volume. These loadings and VIP scores suggest that the diffusion parameters of the lesions and the non-lesioned periventricular WM (PV-WM) predominantly drive GM atrophy. Of the diffusion parameters, mean and radial diffusivity, are connected most significantly to GM atrophy. VIP scores are considered significant if $\geq 1$.

\begin{tabular}{|c|c|c|c|c|}
\hline & Anatomy & $\mathbf{x}$ & $\mathbf{y}$ & $\mathbf{z}$ \\
\hline \multirow{6}{*}{ FA } & Right inferior fronto-occipital fasciculus & 27 & 38 & -2 \\
\hline & Right inferior fronto-occipital fasciculus & 28 & 40 & -2 \\
\hline & Forceps minor & 20 & 45 & -2 \\
\hline & Left inferior fronto-occipital fasciculus & -28 & -82 & -1 \\
\hline & Left inferior fronto-occipital fasciculus & -31 & -70 & -1 \\
\hline & Right Cingulum & 22 & -60 & -1 \\
\hline \multirow{6}{*}{ AD } & Right Inferior fronto-occipital fasciculus & 26 & 23 & 14 \\
\hline & Left Inferior fronto-occipital fasciculus L & -25 & 25 & 14 \\
\hline & Forceps minor & -10 & 26 & 14 \\
\hline & Forceps major & -25 & -72 & 15 \\
\hline & Forceps major & -26 & -67 & 15 \\
\hline & Forceps major & -29 & -62 & 15 \\
\hline \multirow{4}{*}{$\mathbf{R D}$} & Forceps minor & 21 & 21 & 34 \\
\hline & Right inferior fronto-occipital fasciculus & 30 & 37 & -1 \\
\hline & Forceps minor & -8 & 36 & -1 \\
\hline & Right Inferior fronto-occipital fasciculus & 32 & 11 & -1 \\
\hline
\end{tabular}




\begin{tabular}{|c|l|c|c|c|}
\hline \multirow{4}{*}{} & Left Inferior front-occipital fasciculus & -32 & 8 & -1 \\
\cline { 2 - 5 } & Right superior longitudinal fasciculus & 34 & -46 & 21 \\
\hline \multirow{4}{*}{ MD } & Forceps minor & -10 & 33 & 2 \\
\cline { 2 - 5 } & Right superior longitudinal fasciculus & 34 & 2 & 32 \\
\cline { 2 - 5 } & Right Inferior fronto-occipital fasciculus & 32 & 8 & 2 \\
\cline { 2 - 5 } & Right superior longitudinal fasciculus & 34 & -3 & 2 \\
\cline { 2 - 5 } & Left superior longitudinal fasciculus & -30 & 3 & 32 \\
\cline { 2 - 5 } & Left Cingulum & -20 & -45 & 2 \\
\hline
\end{tabular}

Table 8. The local maxima of significant group differences for FA, RD, AD and MD as found by FSL's cluster algorithm. $\mathrm{X}, \mathrm{Y}$ and $\mathrm{Z}$ coordinates are in MNI space. $\mathrm{p}<0.0001$ in all cases. Anatomical localisations are given according to the John Hopkins University white-matter tractography atlas as implemented in fslview (248).

\section{The imaging parameters influencing clinical and cognitive functions}

We examined the MRI markers that best predict clinical disablity.

In the PLS analysis in which the EDSS was the dependent variable, the first latent variable was significant according to the permutation test $(\mathrm{p}<0.001)$. It was responsible for $50.67 \%$ of the variation of the dependent variable and $27.08 \%$ of the predictors.

Age (VIP score: 1.72) and the AD of the NAWM contributed most to clinical disability (VIP score: 1.979) (Figure 5). While far less, the MD of the NAWM (VIP score: 1.169) and the demyelination features of the lesions (VIP $\mathrm{FA}_{1}$ 1.17, VIP $\mathrm{RD}_{1}$ : 1.08) (Figure 5) were still significant contributors.

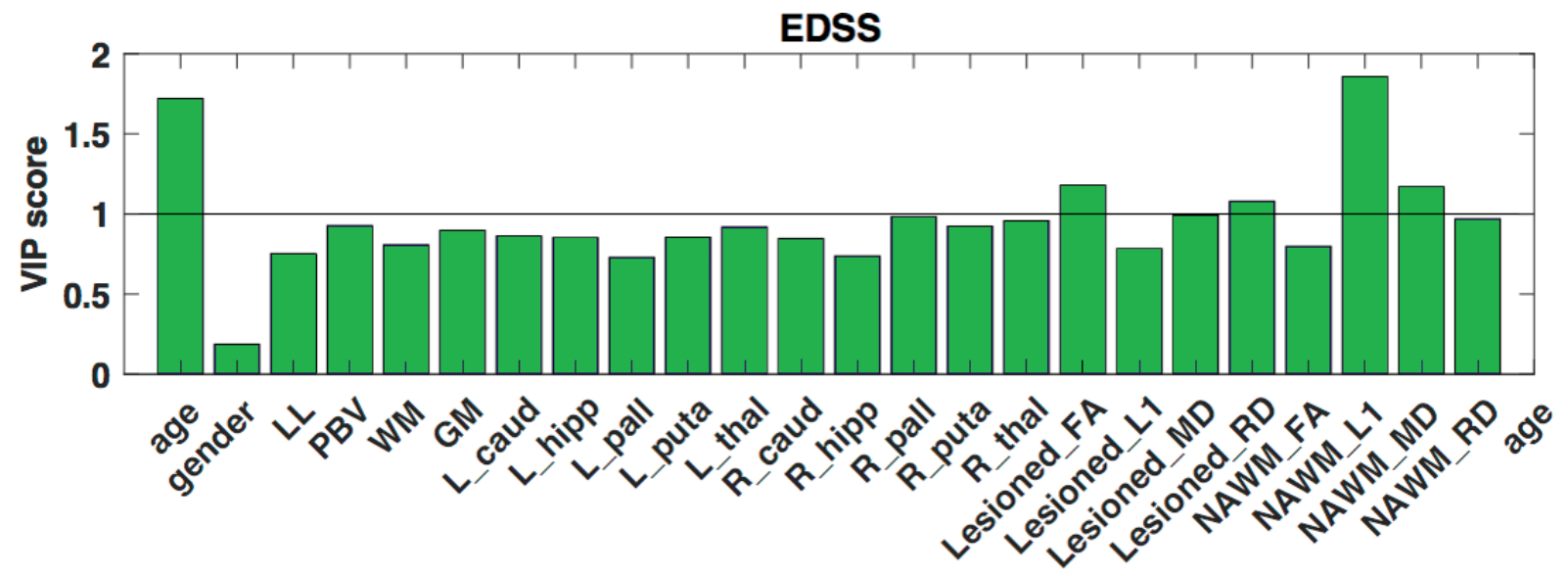

Figure 4. VIP scores of the PLS analysis that depict the optimal contrast of the independent variables predicting clinical disability (EDSS). These VIP scores suggest that principally the AD of the NAWM drives the EDSS. VIP scores $\geq 1$ are identified as significant.

In our second study we primarily focused on the determination of those MRI structures that best predict the alteration of different cognitive domains. In these analyses, the raw scores from the three subtests of the BICAMS test were used as dependent variables. The first latent variable 
was estimated, as the second latent variable was responsible for just a small fraction of the variance of the dependent measure ( $<5 \%$ in case of BVMT and CVLT and $10 \%$ in case of SDMT) and the permutation tests indicated non-significant latent variables. The permutation test showed that the first latent variable was significant $(\mathrm{p}<0.001$ for each subtest) and explained $50.99 \%$ of the variation of the dependent variable and $23.89 \%$ of the predictors in the case of BVMT, as well as $50.93 \%$ of the variation of the dependent variable and $22.24 \%$ of the predictors in the case of CVLT, and $50.67 \%$ of the variation of the dependent variable and $22.43 \%$ of the predictors in the case of SDMT.

Age contributed significantly to all cognitive tests (VIP score: 1.538, 1.127 and 1.296 for BVMT, CVLT, and SDMT respectively). Gender was a significant contributor to CVLT and SDMT (VIP score: 1.356 and 1.345 respectively).

As regarding the visuo-spatial working memory, the most critical contributor was the size of the bilateral hippocampi (VIP scores: 1.183 and 1.2 left and right, respectively) and the demyelination features of the lesions (VIP $\mathrm{FA}_{\mathrm{FA}}$ score: 1.257, VIP $\mathrm{MD}_{\mathrm{MD}}$ score: 1.008, VIP $_{\mathrm{RD}}$ score: 1.158 ) and axon loss diffusion features of NAWM (VIP $\mathrm{FA}_{\mathrm{FA}}$ score: $1.125, \mathrm{VIP}_{\mathrm{L} 1}$ score: 1.232) (Figure 5). Lesion load was also a marginally significant contributor (VIP score: 1.031).

For verbal memory, the best predictor was the size of the right hippocampus (VIP score :1.972), the lesion load (VIP score: 1.274), the partial brain volume (VIP score: 1.119) the total white matter volume (VIP score: 1.008), the total grey matter volume (VIP score: 1.058), the size of the right caudate (VIP score: 1.152) and the FA of the NAWM (VIP score: 1.012) (Figure 5).

In the case of the SDMT test, the most significant contribution was from the demyelinationlike diffusion parameters of the NAWM (fractional anisotropy and radial diffusivity VIP scores: 1.615, 321 respectively) (Figure 5). The FA, mean and radial diffusivity of the lesions (VIP scores: $1.289,1.082$ and 1.271 respectively) and the size of the right hippocampus (VIP score: 1.101) also contributed significantly to performance. 

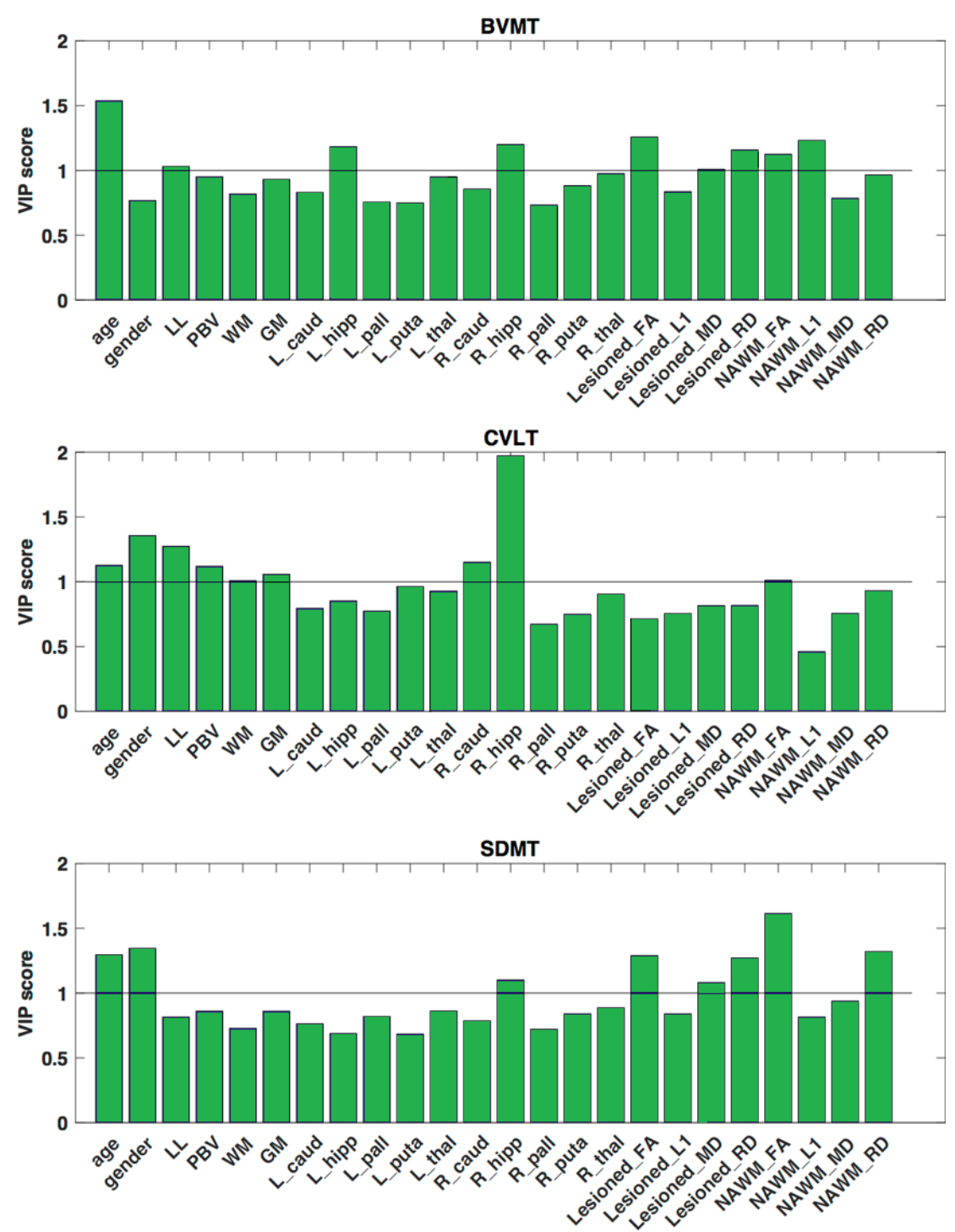

Figure 5. VIP scores of the PLS analysis depicting the optimal contrast of the independent variables predicting cognitive functions. According to these VIP scores, for BVMT the most critical contributor was the size of the bilateral hippocampi, for CVLT the best predictor was the size of the right hippocampus and the total grey matter volume, and in case of the SDMT test the most significant contributions were the diffusion parameters (FA, MD and RD of the NAWM). VIP scores higher than 1 are identified as significant.

\section{Discussion}

\section{Interpretation of our results}

In our MRI studies, we explored the connection between GM atrophy and the microstructure of the WM, and also between the clinical and cognitive disability and various MRI parameters in RRMS patients. We aimed to test two hypotheses about the development of GM atrophy. According to the first one, the connection between GM atrophy and alterations of the axonloss-like diffusion pattern would refer to secondary cortical atrophy caused by remote axonal transection. The second hypothesis declared that if a demyelination-like diffusion pattern in the periventricular white matter is predominantly related to cortical atrophy, it suggests a common 
pathomechanism, primarily suggests a common CSF-mediated process. Our model-free, PLS analysis confirmed the second hypothesis, as the demyelination-like diffusion parameters, the increased $\mathrm{MD}$ and $\mathrm{RD}$ in the lesions and the periventricular non-lesioned $\mathrm{WM}$ were related primarily to GM atrophy. The changes of $\mathrm{AD}$, suggesting axon loss, had a smaller contribution. In the second study it was the AD of the NAWM that best influenced clinical disability. The PLS analysis revealed a complex interaction between cognitive disability and the multiparametric MRI data. The different cognitive domains were predicted by several MRI parameters. The visuo-spatial working memory was affected by the size of the bilateral hippocampi and the demyelination-like diffusion profile of the lesions, and the axon loss of the NAWM. The size of the brain, white and grey matter and the right hippocampus were the best predictors of the verbal memory. The information processing speed was primarily influenced by alterations in the demyelination-like diffusion parameters of the WM.

The pathological background of the diffusion parameter and its connection with cortical atrophy

According to earlier studies, the pattern of diffusion parameter changes refer to pathological changes in the WM. Mouse models of MS $(204,205)$ showed that the alterations of AD and $\mathrm{RD}$ allude to damage of the axons or myelin, respectively. Besides, FA and AD correlated with the total axon number. In a novel mouse model, combining cuprizone-induced demyelination and experimental autoimmune encephalomyelitis, axonal damage and cellular infiltration led to an alteration in $\mathrm{AD}$, while primary demyelination was reflected by changes in $\mathrm{RD}$, but not in AD (204). In transected nerves, decreased FA was revealed, which returned toward normal with axonal regeneration (206). Song et al induced ischaemia in the retina of mice. Three days later they observed a significant decrease in $\mathrm{AD}$, without any alterations in $\mathrm{RD}$, which was consequent with the histological findings of axonal degeneration with lack of demyelination. After two days, parallel with a histological picture of myelin degeneration, increased RD was observed (249). Moreover, in the postmortem human brain myelin content was predicted by alterations of RD, MD and FA before and after fixation (207). According to the above mentioned results, the alterations of diffusion parameters we found in MS patients suggest widespread demyelination in the WM, which is quite similar to the previously presented results (250-258). We also detected widespread demyelination in the NAWM, which was only barely reviewed in former DTI studies. The sensitivity of our investigation was most probably increased by the high number of diffusion directions we applied in our study. More importantly, 
we found a pattern of demyelination-like diffusion parameter alterations in the periventricular WM (lesions and also non-lesioned areas) which best corresponded to the development of GM atrophy. This finding supports the hypothesis of Jehna (212) about a CSF-mediated common process of cortical atrophy and periventricular demyelination. Subpial demyelination and cortical atrophy were associated with meningeal inflammation, infiltration of B-cell folliclelike structures, and CD3+, and CD8+ T-cells $(214,259)$. Besides the demyelination in the cortex, there is a gradient of neuronal and astrocyte loss toward the pial surface and microglia activation in the opposite gradient (214). These findings are concordant with the results of in vitro studies (215) and suggest the role of cytotoxic tissue damage due to a B-and CD8+ Tcell-mediated non-targeted general immunopathological response or microglial activation in the development of the cortical pathology. The spatial location of the abnormalities also strengthens the theory of a common pathomechanism behind the periventricular lesions and cortical demyelination. Subpial lesions are often located around deep sulci, with extended Virchow-Robin space, which contains many immune cells (218). Likewise, the periventricular lesions evolve quite often around the venules and have also been observed in MS-enlarged Virchow-Robin spaces $(96,260)$.

\section{The imaging parameters influencing clinical and cognitive functions}

Recently cognitive decline has become a hot topic in MS research. MS patients are usually more concerned about their cognitive than physical disability, and it influences their quality of life far more (56). According to former results, in patients with cognitive impairment, there is even an accelerated disease progression (261). Thus, investigation into the structural background of cognitive decline can not be underestimated. The BICAMS test, a fast and reliable tool for cognitive measurement, has recently become available, however, the structural brain abnormality measured with this test has not yet been systematically examined.

It has long been known that not only the lesion load but the localisation of the lesions show weak correlation with clinical and cognitive disability $(195,196)$. While the connection between clinical disability and the brain, predominantly the GM, appears to be stronger (176, $184,198,262-264)$, several earlier studies, using voxel-wise morphometry failed to reveal a connection between the disability and the focal GM atrophy (265-270).

According to former papers, the volumetry of the thalamus correlated with information processing speed (271), verbal memory and the attention/executive function (272), while putaminal atrophy was associated with the information processing speed (197). Several 
investigations proved the connection between cognitive decline and hippocampal atrophy (273276). The thinning of different cortical areas appears to be connected to different cognitive domains. Cortical thinning in the insula and the parietal region were connected to verbal and visual memory performance, respectively (277). Left-sided cortical thinning of the anterior cingulate area was associated with decreased verbal fluency, while right-sided was related to reduced figural fluency (278). The thinning of the orbito-frontal cortex was connected to the speed of auditory information processing (279).

There are also contradictory results about the relationship of the diffusion metrics with disability. While Griffin did not find either diffusion parameter alteration in the NAWM or a correlation with disability (208), Ciccarelli revealed a connection between the clinical disability and the FA of the supra and infratentorial NAWM, in particularly FA and MD of the cerebral peduncles (209). Onu et al., in a whole brain TBSS analysis, described widespread differences between MS patients and controls and also found a correlation between FA, EDSS scores, ambulation, and hand function (280). Filippi et al. revealed a modest connection between disability and the MD of lesions (210).

The above-mentioned studies have their limitations, as most of them focus their analyses only on the FA and also the extent of the reported microstructural damage was usually far less. It was previously reported that alterations of $\mathrm{RD}$ and $\mathrm{AD}$ suggest demyelination and axonal loss, respectively $(204,281-284)$. It is also important to use a high number of diffusion directions, thus the alterations of the demyelination-like diffusion parameters can be shown widespread in the WM skeleton (211).

As the summary of the above-mentioned studies shows, there is only a limited number of investigations that examine the pattern of various structural MRI markers contributing to a set of clinically relevant cognitive tests. According to our results, we suggest that the three subtests of the BICAMS are associated with alterations of different brain structures.

Atrophy of the bilateral hippocampi was the most critical contributor to the visuo-spatial working memory. Earlier studies, examining the structural background of visuo-spatial abilities reported controversial results. While Kern et al. found the uncinate fasciculus connecting the mediotemporal structures to the frontal cortex (272) as the best predictor, Koenig and Dineen declared that the visuospatial memory correlated with the diffusion parameters of the fornix, the primary hippocampal efferent $(285,286)$, but not the atrophy of the hippocampus itself (286). Importantly, the structural abnormality of one structure is usually associated with the other, functionally or structurally, connected structures (287). 
The verbal memory test performance was defined by the volume of the total GM and right hippocampus. We should highlight the interesting fact that Dineen, in the study mentioned above did, not find a correlation between hippocampal atrophy and verbal or visuo-spatial memory scores, however, he used a smaller group of MS patients (286). According to the study of Kiy et al., the consolidation scores of the CVLT test were associated with the volume of the right temporal horn, which indirectly measures hippocampal atrophy (288). A recent study discovered that hippocampal viscoelasticity, induced by physical activity, improves the performance on CVLT-II test in MS patients (289). While the CVLT long delay recall was correlated with global brain atrophy (290), the learning score of the CVLT-II was associated with the volume of the thalamus, amygdala, hippocampus and caudate, but not with the lesion load or the brain parenchymal fraction. A linear regression analysis declared the size of the caudate as the best predictor of the verbal learning ability (291).

It is interesting to note the relationship between the laterality of hippocampal atrophy and cognitive decline. The volume of both hippocampi predicted the BVMT similarly, while only the right hippocampus was a significant predictor of the CVLT. This latter finding is especially remarkable since, according to earlier studies, the volume of the right hippocampus is related to the visuospatial memory, while verbal memory is best defined by the left hippocampal volume (292-294).

We should highlight the fact that in our study, out of the three cognitive tests, SDMT showed a connection with the largest area. Yu et al. recently found widespread alterations of the demyelination-like diffusion parameters in the NAWM of MS patients (258), which showed a significant connection with the performance on the SDMT. According to another study the SDMT performance was related to the GM fraction and also the diffusion parameters of the brain parenchyma (228). In this case, similarly to our study, the authors used summary statistics for the diffusion parameters.

\section{Strengths}

According to our earlier study, the pathology can be described better by the pattern of various diffusion measurements than by individual parameters (287). We made a clinically convenient, new whole brain summary of the diffusion measurements, respecting voxel-wise normal variation of the WM microstructure. This is a useful approach in cases of widespread alterations of the diffusion parameters, such as in MS (211).

If a high degree of collinearity is suggested between the predictors (like MRI data), using conventional regression analysis might end in misleading results. We examined the relationship 
between the clinical and cognitive decline and the pattern of diffusion parameters by modelfree PLS analysis, which is able to define the pattern of those parameters that best predict the questionable variable and also manage the problem of collinearity.

\section{Limitations}

While the main strength of our study is that we have detected the independent contribution of various MRI parameters to cognitive and clinical decline and the cortical atrophy in MS, it has to be highlighted that there are several other quantitative MRI markers in the disease, for example, myelin water fraction and magnetisation transfer imaging. The application of more predictors could possibly characterize the dysfunctions more accurately. Additionally, the lack of respecting the spatial distribution of cortical atrophy is a significant weakness of our analysis. Other approaches, such as linked independent component analysis (295) could characterise the focal changes of MRI parameters better. The clinical practicability of this approach is also limited, due to the length of data acquisition and its analysis. However, with the development of MR technology, by establishing the minimum requirements of acquisition parameters (eg. number of diffusion directions) and maintaining analysis approaches, advanced quantitative measurements should become part of the clinical practice too.

\section{Conclusions}

In our studies, we detected widespread diffusion parameter alterations in MS patients that suggested demyelination, both in the high lesion loading periventricular WM and the NAWM. Significant brain, WM and GM atrophy was found in the patients. According to the PLS analysis, the GM atrophy was best predicted by a pattern of demyelination-like diffusion parameters in the periventricular WM. Our findings also showed that the various MRI markers affect the development of the clinical disability and the decline of several cognitive domains. While the pathology of MS is quite diverse, according to our results, even those processes that are spatially distant from each other may have common origins. The CSF is an assumed substance, mediating between such processes, but further investigations are needed to clarify those factors which are accountable for the demyelination in the GM and WM. Our results show that the atrophy of the cortical and subcortical structures and the diffusion measurements of the WM are crucial to understanding the disability progression. Accordingly, these measurements should be taken into account in clinical trials and highlighted in everyday clinical practice. 


\section{Acknowledgements}

I would like to thank Professor László Vécsei M.D. for giving me an opportunity working in the Department of Neurology.

I have to give my greatest gratitude to my advisor, Zsigmond Tamás Kincses M.D. for his help and guidance.

Also, I would like to thank my colleagues and friends, Nikoletta Szabó M.D., Dr. András Király M.D. , Gergő Csete M.D., Dániel Veréb M.D., Bálint Kincses M.D., Bence Bozsik M.D., Rita Maszlag-Török, Bernadett Tuka and Krisztián Kocsis for their help, fun and guide. I would like to thank every fellow worker of the Department of Neurology for their help and support.

Finally, I would also thank my family and my fiancé for their patience and support. 


\section{References}

1. Rosati G. The prevalence of multiple sclerosis in the world: an update. Neurol Sci. 2001;22(2):117-39.

2. Leray E, Moreau T, Fromont A, Edan G. Epidemiology of multiple sclerosis. Rev Neurol (Paris). 2016;172(1):3-13.

3. Zsiros V, Fricska-Nagy Z, Fuvesi J, Kincses ZT, Langane E, Paulik E, et al. Prevalence of multiple sclerosis in Csongrad County, Hungary. Acta Neurol Scand. 2014;130(5):277-82.

4. Ramagopalan SV, Dobson R, Meier UC, Giovannoni G. Multiple sclerosis: risk factors, prodromes, and potential causal pathways. Lancet Neurol. 2010;9(7):727-39.

5. Handel AE, Williamson AJ, Disanto G, Handunnetthi L, Giovannoni G, Ramagopalan SV. An updated meta-analysis of risk of multiple sclerosis following infectious mononucleosis. PLoS One. 2010;5(9).

6. Ascherio A, Munger KL. Environmental risk factors for multiple sclerosis. Part I: the role of infection. Ann Neurol. 2007;61(4):288-99.

7. Pakpoor J, Disanto G, Gerber JE, Dobson R, Meier UC, Giovannoni G, et al. The risk of developing multiple sclerosis in individuals seronegative for Epstein-Barr virus: a meta-analysis. Mult Scler. 2013;19(2):162-6.

8. Lang $\mathrm{HL}$, Jacobsen $\mathrm{H}$, Ikemizu S, Andersson C, Harlos K, Madsen L, et al. A functional and structural basis for TCR cross-reactivity in multiple sclerosis. Nat Immunol. 2002;3(10):940-3.

9. Tracy SI, Kakalacheva K, Lunemann JD, Luzuriaga K, Middeldorp J, Thorley-Lawson DA. Persistence of Epstein-Barr virus in self-reactive memory B cells. J Virol. 2012;86(22):12330-40.

10. van der Mei IA, Ponsonby AL, Dwyer T, Blizzard L, Simmons R, Taylor BV, et al. Past exposure to sun, skin phenotype, and risk of multiple sclerosis: case-control study. Bmj. 2003;327(7410):316.

11. Islam T, Gauderman WJ, Cozen W, Mack TM. Childhood sun exposure influences risk of multiple sclerosis in monozygotic twins. Neurology. 2007;69(4):381-8.

12. Kampman MT, Wilsgaard T, Mellgren SI. Outdoor activities and diet in childhood and adolescence relate to MS risk above the Arctic Circle. J Neurol. 2007;254(4):471-7.

13. Sintzel MB, Rametta M, Reder AT. Vitamin D and Multiple Sclerosis: A Comprehensive Review. Neurol Ther. 2018;7(1):59-85.

14. Orton SM, Herrera BM, Yee IM, Valdar W, Ramagopalan SV, Sadovnick AD, et al. Sex ratio of multiple sclerosis in Canada: a longitudinal study. Lancet Neurol. 2006;5(11):932-6.

15. Palacios N, Alonso A, Bronnum-Hansen $\mathrm{H}$, Ascherio A. Smoking and increased risk of multiple sclerosis: parallel trends in the sex ratio reinforce the evidence. Ann Epidemiol. 2011;21(7):536-42.

16. Handel AE, Williamson AJ, Disanto G, Dobson R, Giovannoni G, Ramagopalan SV. Smoking and multiple sclerosis: an updated meta-analysis. PLoS One. 2011;6(1):e16149.

17. Hedstrom AK, Baarnhielm M, Olsson T, Alfredsson L. Tobacco smoking, but not Swedish snuff use, increases the risk of multiple sclerosis. Neurology. 2009;73(9):696-701.

18. Kurtzke JF. Epidemiology in multiple sclerosis: a pilgrim's progress. Brain. 2013;136(Pt 9):2904-

17.

19. Harirchian MH, Fatehi F, Sarraf $P$, Honarvar NM, Bitarafan S. Worldwide prevalence of familial multiple sclerosis: A systematic review and meta-analysis. Mult Scler Relat Disord. 2018;20:43-7.

20. Ristori G, Cannoni S, Stazi MA, Vanacore N, Cotichini R, Alfo M, et al. Multiple sclerosis in twins from continental Italy and Sardinia: a nationwide study. Ann Neurol. 2006;59(1):27-34.

21. Hollenbach JA, Oksenberg JR. The immunogenetics of multiple sclerosis: A comprehensive review. J Autoimmun. 2015;64:13-25.

22. International Multiple Sclerosis Genetics C, Beecham AH, Patsopoulos NA, Xifara DK, Davis MF, Kemppinen $A$, et al. Analysis of immune-related loci identifies 48 new susceptibility variants for multiple sclerosis. Nat Genet. 2013;45(11):1353-60.

23. Lundmark F, Duvefelt K, lacobaeus E, Kockum I, Wallstrom E, Khademi M, et al. Variation in interleukin 7 receptor alpha chain (IL7R) influences risk of multiple sclerosis. Nat Genet. 2007;39(9):1108-13. 
24. Maier LM, Lowe CE, Cooper J, Downes K, Anderson DE, Severson C, et al. IL2RA genetic heterogeneity in multiple sclerosis and type 1 diabetes susceptibility and soluble interleukin-2 receptor production. PLoS Genet. 2009;5(1):e1000322.

25. Gregory AP, Dendrou CA, Attfield KE, Haghikia A, Xifara DK, Butter F, et al. TNF receptor 1 genetic risk mirrors outcome of anti-TNF therapy in multiple sclerosis. Nature. 2012;488(7412):50811.

26. Steri $\mathrm{M}$, Orru V, Idda ML, Pitzalis M, Pala M, Zara I, et al. Overexpression of the Cytokine BAFF and Autoimmunity Risk. N EngI J Med. 2017;376(17):1615-26.

27. Manousaki D, Dudding T, Haworth S, Hsu YH, Liu CT, Medina-Gomez C, et al. Low-Frequency Synonymous Coding Variation in CYP2R1 Has Large Effects on Vitamin D Levels and Risk of Multiple Sclerosis. Am J Hum Genet. 2017;101(2):227-38.

28. Pearce JM. Historical descriptions of multiple sclerosis. Eur Neurol. 2005;54(1):49-53.

29. Karussis D. The diagnosis of multiple sclerosis and the various related demyelinating syndromes: a critical review. J Autoimmun. 2014;48-49:134-42.

30. Lassmann H. Pathology and disease mechanisms in different stages of multiple sclerosis. J Neurol Sci. 2013;333(1-2):1-4.

31. Trapp BD, Peterson J, Ransohoff RM, Rudick R, Mork S, Bo L. Axonal transection in the lesions of multiple sclerosis. N Engl J Med. 1998;338(5):278-85.

32. Prineas JW, Kwon EE, Cho ES, Sharer LR, Barnett MH, Oleszak EL, et al. Immunopathology of secondary-progressive multiple sclerosis. Ann Neurol. 2001;50(5):646-57.

33. Frischer JM, Bramow S, Dal-Bianco A, Lucchinetti CF, Rauschka H, Schmidbauer M, et al. The relation between inflammation and neurodegeneration in multiple sclerosis brains. Brain. 2009;132(Pt 5):1175-89.

34. Tallantyre EC, Bo L, Al-Rawashdeh O, Owens T, Polman CH, Lowe J, et al. Greater loss of axons in primary progressive multiple sclerosis plaques compared to secondary progressive disease. Brain. 2009;132(Pt 5):1190-9.

35. Gelfand JM. Multiple sclerosis: diagnosis, differential diagnosis, and clinical presentation. Handb Clin Neurol. 2014;122:269-90.

36. Polman CH, Reingold SC, Banwell B, Clanet M, Cohen JA, Filippi M, et al. Diagnostic criteria for multiple sclerosis: 2010 revisions to the McDonald criteria. Ann Neurol. 2011;69(2):292-302.

37. Polman CH, Reingold SC, Edan G, Filippi M, Hartung HP, Kappos L, et al. Diagnostic criteria for multiple sclerosis: 2005 revisions to the "McDonald Criteria". Ann Neurol. 2005;58(6):840-6.

38. Poser CM, Paty DW, Scheinberg L, McDonald WI, Davis FA, Ebers GC, et al. New diagnostic criteria for multiple sclerosis: guidelines for research protocols. Ann Neurol. 1983;13(3):227-31.

39. McDonald WI, Compston A, Edan G, Goodkin D, Hartung HP, Lublin FD, et al. Recommended diagnostic criteria for multiple sclerosis: guidelines from the International Panel on the diagnosis of multiple sclerosis. Ann Neurol. 2001;50(1):121-7.

40. Lublin FD, Reingold SC. Defining the clinical course of multiple sclerosis: results of an international survey. National Multiple Sclerosis Society (USA) Advisory Committee on Clinical Trials of New Agents in Multiple Sclerosis. Neurology. 1996;46(4):907-11.

41. Kurtzke JF. Rating neurologic impairment in multiple sclerosis: an expanded disability status scale (EDSS). Neurology. 1983;33(11):1444-52.

42. Balcer L. Clinical practice. Optic neuritis. N Engl J Med. 2006;354(12):1273-80.

43. The clinical profile of optic neuritis. Experience of the Optic Neuritis Treatment Trial. Optic Neuritis Study Group. Arch Ophthalmol. 1991;109(12):1673-8.

44. Bourre B, Zephir H, Ongagna JC, Cordonnier C, Collongues N, Debette S, et al. Long-term followup of acute partial transverse myelitis. Arch Neurol. 2012;69(3):357-62.

45. Cordonnier C, de Seze J, Breteau G, Ferriby D, Michelin E, Stojkovic T, et al. Prospective study of patients presenting with acute partial transverse myelopathy. J Neurol. 2003;250(12):1447-52.

46. Swingler RJ, Compston DA. The morbidity of multiple sclerosis. Q J Med. 1992;83(300):325-37. 
47. Minden SL, Frankel D, Hadden L, Perloffp J, Srinath KP, Hoaglin DC. The Sonya Slifka Longitudinal Multiple Sclerosis Study: methods and sample characteristics. Mult Scler. 2006;12(1):2438.

48. Kanchandani R, Howe JG. Lhermitte's sign in multiple sclerosis: a clinical survey and review of the literature. J Neurol Neurosurg Psychiatry. 1982;45(4):308-12.

49. Chiaravalloti ND, DeLuca J. Cognitive impairment in multiple sclerosis. Lancet Neurol. 2008;7(12):1139-51.

50. Sandi D, Biernacki T, Szekeres D, Fuvesi J, Kincses ZT, Rozsa C, et al. Prevalence of cognitive impairment among Hungarian patients with relapsing-remitting multiple sclerosis and clinically isolated syndrome. Mult Scler Relat Disord. 2017;17:57-62.

51. Staff NP, Lucchinetti CF, Keegan BM. Multiple sclerosis with predominant, severe cognitive impairment. Arch Neurol. 2009;66(9):1139-43.

52. Beiske AG, Svensson E, Sandanger I, Czujko B, Pedersen ED, Aarseth JH, et al. Depression and anxiety amongst multiple sclerosis patients. Eur J Neurol. 2008;15(3):239-45.

53. Jones KH, Ford DV, Jones PA, John A, Middleton RM, Lockhart-Jones $\mathrm{H}$, et al. A large-scale study of anxiety and depression in people with Multiple Sclerosis: a survey via the web portal of the UK MS Register. PLoS One. 2012;7(7):e41910.

54. Patten SB, Beck CA, Williams JV, Barbui C, Metz LM. Major depression in multiple sclerosis: a population-based perspective. Neurology. 2003;61(11):1524-7.

55. Zorzon M, Zivadinov R, Nasuelli D, Ukmar M, Bratina A, Tommasi MA, et al. Depressive symptoms and MRI changes in multiple sclerosis. Eur J Neurol. 2002;9(5):491-6.

56. Fricska-Nagy Z, Fuvesi J, Rozsa C, Komoly S, Jakab G, Csepany T, et al. The effects of fatigue, depression and the level of disability on the health-related quality of life of glatiramer acetate-treated relapsing-remitting patients with multiple sclerosis in Hungary. Mult Scler Relat Disord. 2016;7:26-32. 57. Krupp LB, Alvarez LA, LaRocca NG, Scheinberg LC. Fatigue in multiple sclerosis. Arch Neurol. 1988;45(4):435-7.

58. de Seze M, Ruffion A, Denys P, Joseph PA, Perrouin-Verbe B, Genulf. The neurogenic bladder in multiple sclerosis: review of the literature and proposal of management guidelines. Mult Scler. 2007;13(7):915-28.

59. Fowler CJ, Panicker JN, Drake M, Harris C, Harrison SC, Kirby M, et al. A UK consensus on the management of the bladder in multiple sclerosis. J Neurol Neurosurg Psychiatry. 2009;80(5):470-7.

60. De Ridder D, Van Der Aa F, Debruyne J, D'Hooghe M B, Dubois B, Guillaume D, et al. Consensus guidelines on the neurologist's role in the management of neurogenic lower urinary tract dysfunction in multiple sclerosis. Clin Neurol Neurosurg. 2013;115(10):2033-40.

61. Litwiller SE, Frohman EM, Zimmern PE. Multiple sclerosis and the urologist. J Urol. 1999;161(3):743-57.

62. Nakipoglu GF, Kaya AZ, Orhan G, Tezen O, Tunc H, Ozgirgin N, et al. Urinary dysfunction in multiple sclerosis. J Clin Neurosci. 2009;16(10):1321-4.

63. Chia YW, Fowler CJ, Kamm MA, Henry MM, Lemieux MC, Swash M. Prevalence of bowel dysfunction in patients with multiple sclerosis and bladder dysfunction. J Neurol. 1995;242(2):105-8.

64. Hennessey A, Robertson NP, Swingler R, Compston DA. Urinary, faecal and sexual dysfunction in patients with multiple sclerosis. J Neurol. 1999;246(11):1027-32.

65. Demirkiran M, Sarica Y, Uguz S, Yerdelen D, Aslan K. Multiple sclerosis patients with and without sexual dysfunction: are there any differences? Mult Scler. 2006;12(2):209-14.

66. Davis FA, Jacobson S. Altered thermal sensitivity in injured and demyelinated nerve. A possible model of temperature effects in multiple sclerosis. J Neurol Neurosurg Psychiatry. 1971;34(5):551-61.

67. Kister I, Caminero AB, Monteith TS, Soliman A, Bacon TE, Bacon JH, et al. Migraine is comorbid with multiple sclerosis and associated with a more symptomatic MS course. J Headache Pain. 2010;11(5):417-25.

68. Gelfand AA, Gelfand JM, Goadsby PJ. Migraine and multiple sclerosis: Epidemiology and approach to treatment. Mult Scler Relat Disord. 2013;2(2):73-9. 
69. Kister I, Munger KL, Herbert J, Ascherio A. Increased risk of multiple sclerosis among women with migraine in the Nurses' Health Study II. Mult Scler. 2012;18(1):90-7.

70. Rakusa M, Murphy O, Mclntyre L, Porter B, Panicker J, Fowler C, et al. Testing for urinary tract colonization before high-dose corticosteroid treatment in acute multiple sclerosis relapses: prospective algorithm validation. Eur J Neurol. 2013;20(3):448-52.

71. Hufschmidt A, Shabarin V, Rauer S, Zimmer T. Neurological symptoms accompanying urinary tract infections. Eur Neurol. 2010;63(3):180-3.

72. Lublin FD, Reingold SC, Cohen JA, Cutter GR, Sorensen PS, Thompson AJ, et al. Defining the clinical course of multiple sclerosis: the 2013 revisions. Neurology. 2014;83(3):278-86.

73. Miller D, Barkhof F, Montalban X, Thompson A, Filippi M. Clinically isolated syndromes suggestive of multiple sclerosis, part I: natural history, pathogenesis, diagnosis, and prognosis. Lancet Neurol. 2005;4(5):281-8.

74. Lebrun C, Bensa C, Debouverie M, Wiertlevski S, Brassat D, de Seze J, et al. Association between clinical conversion to multiple sclerosis in radiologically isolated syndrome and magnetic resonance imaging, cerebrospinal fluid, and visual evoked potential: follow-up of 70 patients. Arch Neurol. 2009;66(7):841-6.

75. Siva A, Saip S, Altintas A, Jacob A, Keegan BM, Kantarci OH. Multiple sclerosis risk in radiologically uncovered asymptomatic possible inflammatory-demyelinating disease. Mult Scler. 2009;15(8):918-27.

76. Okuda DT, Mowry EM, Beheshtian A, Waubant E, Baranzini SE, Goodin DS, et al. Incidental MRI anomalies suggestive of multiple sclerosis: the radiologically isolated syndrome. Neurology. 2009;72(9):800-5.

77. Lassmann $\mathrm{H}$, van Horssen J, Mahad D. Progressive multiple sclerosis: pathology and pathogenesis. Nat Rev Neurol. 2012;8(11):647-56.

78. Lassmann H, Bruck W, Lucchinetti CF. The immunopathology of multiple sclerosis: an overview. Brain Pathol. 2007;17(2):210-8.

79. Okuda DT, Mowry EM, Cree BA, Crabtree EC, Goodin DS, Waubant E, et al. Asymptomatic spinal cord lesions predict disease progression in radiologically isolated syndrome. Neurology. 2011;76(8):686-92.

80. Confavreux C, Vukusic S. Natural history of multiple sclerosis: a unifying concept. Brain. 2006;129(Pt 3):606-16.

81. Ebers GC. Natural history of primary progressive multiple sclerosis. Mult Scler. 2004;10 Suppl 1:S8-13; discussion S-5.

82. Green AJ, McQuaid S, Hauser SL, Allen IV, Lyness R. Ocular pathology in multiple sclerosis: retinal atrophy and inflammation irrespective of disease duration. Brain. 2010;133(Pt 6):1591-601.

83. Fisher JB, Jacobs DA, Markowitz CE, Galetta SL, Volpe NJ, Nano-Schiavi ML, et al. Relation of visual function to retinal nerve fiber layer thickness in multiple sclerosis. Ophthalmology. 2006;113(2):324-32.

84. Gelfand JM, Goodin DS, Boscardin WJ, Nolan R, Cuneo A, Green AJ. Retinal axonal loss begins early in the course of multiple sclerosis and is similar between progressive phenotypes. PLoS One. 2012;7(5):e36847.

85. Henderson AP, Trip SA, Schlottmann PG, Altmann DR, Garway-Heath DF, Plant GT, et al. An investigation of the retinal nerve fibre layer in progressive multiple sclerosis using optical coherence tomography. Brain. 2008;131(Pt 1):277-87.

86. Pulicken M, Gordon-Lipkin E, Balcer L, Frohman E, Cutter G, Calabresi PA. Optical coherence tomography and disease subtype in multiple sclerosis. Neurology. 2007;69(22):2085-92.

87. Frisen L, Hoyt WF. Insidious atrophy of retinal nerve fibers in multiple sclerosis. Funduscopic identification in patients with and without visual complaints. Arch Ophthalmol. 1974;92(2):91-7.

88. Andersson M, Alvarez-Cermeno J, Bernardi G, Cogato I, Fredman P, Frederiksen J, et al. Cerebrospinal fluid in the diagnosis of multiple sclerosis: a consensus report. J Neurol Neurosurg Psychiatry. 1994;57(8):897-902. 
89. Freedman MS, Thompson EJ, Deisenhammer F, Giovannoni G, Grimsley G, Keir G, et al. Recommended standard of cerebrospinal fluid analysis in the diagnosis of multiple sclerosis: a consensus statement. Arch Neurol. 2005;62(6):865-70.

90. Walsh MJ, Tourtellotte WW. Temporal invariance and clonal uniformity of brain and cerebrospinal IgG, IgA, and IgM in multiple sclerosis. J Exp Med. 1986;163(1):41-53.

91. Lefvert AK, Link $\mathrm{H}$. IgG production within the central nervous system: a critical review of proposed formulae. Ann Neurol. 1985;17(1):13-20.

92. Ohman S, Ernerudh J, Forsberg P, Henriksson A, von Schenck H, Vrethem M. Comparison of seven formulae and isoelectrofocusing for determination of intrathecally produced IgG in neurological diseases. Ann Clin Biochem. 1992;29 ( Pt 4):405-10.

93. Reiber $\mathrm{H}$, Ungefehr $\mathrm{S}$, Jacobi $\mathrm{C}$. The intrathecal, polyspecific and oligoclonal immune response in multiple sclerosis. Mult Scler. 1998;4(3):111-7.

94. Ge Y. Multiple sclerosis: the role of MR imaging. AJNR Am J Neuroradiol. 2006;27(6):1165-76.

95. Horowitz AL, Kaplan RD, Grewe G, White RT, Salberg LM. The ovoid lesion: a new MR observation in patients with multiple sclerosis. AJNR Am J Neuroradiol. 1989;10(2):303-5.

96. Ge Y, Law M, Herbert J, Grossman RI. Prominent perivenular spaces in multiple sclerosis as a sign of perivascular inflammation in primary demyelination. AJNR Am J Neuroradiol. 2005;26(9):23169.

97. Adams CW, Abdulla YH, Torres EM, Poston RN. Periventricular lesions in multiple sclerosis: their perivenous origin and relationship to granular ependymitis. Neuropathol Appl Neurobiol. 1987;13(2):141-52.

98. Lassmann H. Multiple sclerosis: lessons from molecular neuropathology. Exp Neurol. 2014;262 Pt A:2-7.

99. Bo L, Vedeler CA, Nyland H, Trapp BD, Mork SJ. Intracortical multiple sclerosis lesions are not associated with increased lymphocyte infiltration. Mult Scler. 2003;9(4):323-31.

100. Onofrj M, Tartaro A, Thomas A, Gambi D, Fulgente T, Delli Pizzi C, et al. Long echo time STIR sequence MRI of optic nerves in optic neuritis. Neuroradiology. 1996;38(1):66-9.

101. Tien RD, Hesselink JR, Szumowski J. MR fat suppression combined with Gd-DTPA enhancement in optic neuritis and perineuritis. J Comput Assist Tomogr. 1991;15(2):223-7.

102. Grossman RI, Braffman BH, Brorson JR, Goldberg HI, Silberberg DH, Gonzalez-Scarano F. Multiple sclerosis: serial study of gadolinium-enhanced MR imaging. Radiology. 1988;169(1):117-22.

103. Kermode AG, Tofts PS, Thompson AJ, MacManus DG, Rudge P, Kendall BE, et al. Heterogeneity of blood-brain barrier changes in multiple sclerosis: an MRI study with gadolinium-DTPA enhancement. Neurology. 1990;40(2):229-35.

104. Guttmann CR, Ahn SS, Hsu L, Kikinis R, Jolesz FA. The evolution of multiple sclerosis lesions on serial MR. AJNR Am J Neuroradiol. 1995;16(7):1481-91.

105. He J, Grossman RI, Ge Y, Mannon L. Enhancing patterns in multiple sclerosis: evolution and persistence. AJNR Am J Neuroradiol. 2001;22(4):664-9.

106. Miller DH, Barkhof F, Frank JA, Parker GJ, Thompson AJ. Measurement of atrophy in multiple sclerosis: pathological basis, methodological aspects and clinical relevance. Brain. 2002;125(Pt 8):1676-95.

107. Brex PA, Jenkins R, Fox NC, Crum WR, O'Riordan JI, Plant GT, et al. Detection of ventricular enlargement in patients at the earliest clinical stage of MS. Neurology. 2000;54(8):1689-91.

108. Miki Y, Grossman RI, Udupa JK, Samarasekera S, van Buchem MA, Cooney BS, et al. Computerassisted quantitation of enhancing lesions in multiple sclerosis: correlation with clinical classification. AJNR Am J Neuroradiol. 1997;18(4):705-10.

109. Ge Y, Grossman RI, Udupa JK, Fulton J, Constantinescu CS, Gonzales-Scarano F, et al. Glatiramer acetate (Copaxone) treatment in relapsing-remitting MS: quantitative MR assessment. Neurology. 2000;54(4):813-7.

110. Kalkers NF, Ameziane N, Bot JC, Minneboo A, Polman CH, Barkhof F. Longitudinal brain volume measurement in multiple sclerosis: rate of brain atrophy is independent of the disease subtype. Arch Neurol. 2002;59(10):1572-6. 
111. Dietemann JL, Beigelman C, Rumbach L, Vouge M, Tajahmady T, Faubert C, et al. Multiple sclerosis and corpus callosum atrophy: relationship of MRI findings to clinical data. Neuroradiology. 1988;30(6):478-80.

112. Leigh R, Ostuni J, Pham D, Goldszal A, Lewis BK, Howard T, et al. Estimating cerebral atrophy in multiple sclerosis patients from various MR pulse sequences. Mult Scler. 2002;8(5):420-9.

113. Rao AB, Richert N, Howard T, Lewis BK, Bash CN, McFarland HF, et al. Methylprednisolone effect on brain volume and enhancing lesions in MS before and during IFNbeta-1b. Neurology. 2002;59(5):688-94.

114. Miller DH, Albert PS, Barkhof F, Francis G, Frank JA, Hodgkinson S, et al. Guidelines for the use of magnetic resonance techniques in monitoring the treatment of multiple sclerosis. US National MS Society Task Force. Ann Neurol. 1996;39(1):6-16.

115. Fox NC, Jenkins R, Leary SM, Stevenson VL, Losseff NA, Crum WR, et al. Progressive cerebral atrophy in MS: a serial study using registered, volumetric MRI. Neurology. 2000;54(4):807-12.

116. Ge Y, Grossman RI, Babb JS, Rabin ML, Mannon L, Kolson DL. Age-related total gray matter and white matter changes in normal adult brain. Part I: volumetric MR imaging analysis. AJNR Am J Neuroradiol. 2002;23(8):1327-33.

117. Xu J, Kobayashi S, Yamaguchi S, lijima K, Okada K, Yamashita K. Gender effects on age-related changes in brain structure. AJNR Am J Neuroradiol. 2000;21(1):112-8.

118. De Stefano N, Stromillo ML, Giorgio A, Bartolozzi ML, Battaglini M, Baldini M, et al. Establishing pathological cut-offs of brain atrophy rates in multiple sclerosis. J Neurol Neurosurg Psychiatry. 2016;87(1):93-9.

119. Rae-Grant AD, Fox RJ, Bethoux F, editors. The history of multiple sclerosis. Multiple Sclerosis and related disorders Clinical guide to diagnosis, medical management and rehabilitation. 2004;Cleveland: DemosMedical; p. 1-11.

120. Ferguson B, Matyszak MK, Esiri MM, Perry VH. Axonal damage in acute multiple sclerosis lesions. Brain. 1997;120 ( Pt 3):393-9.

121. Hirst C, Ingram G, Swingler R, Compston DA, Pickersgill T, Robertson NP. Change in disability in patients with multiple sclerosis: a 20-year prospective population-based analysis. J Neurol Neurosurg Psychiatry. 2008;79(10):1137-43.

122. Schumacher GA, Beebe G, Kibler RF, Kurland LT, Kurtzke JF, McDowell F, et al. Problems of Experimental Trials of Therapy in Multiple Sclerosis: Report by the Panel on the Evaluation of Experimental Trials of Therapy in Multiple Sclerosis. Ann N Y Acad Sci. 1965;122:552-68.

123. Rose AS, Ellison GW, Myers LW, Tourtellotte WW. Criteria for the clinical diagnosis of multiple sclerosis. Neurology. 1976;26(6 PT 2):20-2.

124. Rudick RA. Diagnostic criteria in multiple sclerosis: headed in the right direction but still a ways to go. Ann Neurol. 2011;69(2):234-6.

125. Barkhof F, Filippi M, Miller DH, Scheltens P, Campi A, Polman CH, et al. Comparison of MRI criteria at first presentation to predict conversion to clinically definite multiple sclerosis. Brain. 1997;120 ( Pt 11):2059-69.

126. Josey L, Curley M, Jafari Mousavi F, Taylor BV, Lucas R, Coulthard A. Imaging and diagnostic criteria for Multiple Sclerosis: are we there yet? J Med Imaging Radiat Oncol. 2012;56(6):588-93.

127. Tintore M, Rovira A, Martinez MJ, Rio J, Diaz-Villoslada P, Brieva L, et al. Isolated demyelinating syndromes: comparison of different MR imaging criteria to predict conversion to clinically definite multiple sclerosis. AJNR Am J Neuroradiol. 2000;21(4):702-6.

128. Paty DW, Oger JJ, Kastrukoff LF, Hashimoto SA, Hooge JP, Eisen AA, et al. MRI in the diagnosis of MS: a prospective study with comparison of clinical evaluation, evoked potentials, oligoclonal banding, and CT. Neurology. 1988;38(2):180-5.

129. Fazekas F, Offenbacher H, Fuchs S, Schmidt R, Niederkorn K, Horner S, et al. Criteria for an increased specificity of MRI interpretation in elderly subjects with suspected multiple sclerosis. Neurology. 1988;38(12):1822-5.

130. Przybek J, Gniatkowska I, Mirowska-Guzel D, Czlonkowska A. Evolution of diagnostic criteria for multiple sclerosis. Neurol Neurochir Pol. 2015;49(5):313-21. 
131. Nielsen JM, Uitdehaag BM, Polman CH. Long-term follow-up of suspected though unconfirmed MS. Mult Scler. 2008;14(7):985-7.

132. Poser CM. Revisions to the 2001 McDonald diagnostic criteria. Ann Neurol. 2006;59(4):727-8. 133. Solomon AJ, Klein EP, Bourdette D. "Undiagnosing" multiple sclerosis: the challenge of misdiagnosis in MS. Neurology. 2012;78(24):1986-91.

134. Tur C, Tintore M, Rovira A, Nos C, Rio J, Tellez N, et al. Very early scans for demonstrating dissemination in time in multiple sclerosis. Mult Scler. 2008;14(5):631-5.

135. Filippi M, Rocca MA, Ciccarelli O, De Stefano N, Evangelou N, Kappos L, et al. MRI criteria for the diagnosis of multiple sclerosis: MAGNIMS consensus guidelines. Lancet Neurol. 2016;15(3):292303.

136. Thompson AJ, Banwell BL, Barkhof F, Carroll WM, Coetzee T, Comi G, et al. Diagnosis of multiple sclerosis: 2017 revisions of the McDonald criteria. Lancet Neurol. 2018;17(2):162-73.

137. Arrambide G, Tintore M, Espejo C, Auger C, Castillo M, Rio J, et al. The value of oligoclonal bands in the multiple sclerosis diagnostic criteria. Brain. 2018;141(4):1075-84.

138. Caucheteux N, Maarouf A, Genevray M, Leray E, Deschamps R, Chaunu MP, et al. Criteria improving multiple sclerosis diagnosis at the first MRI. J Neurol. 2015;262(4):979-87.

139. Kang H, Metz LM, Traboulsee AL, Eliasziw M, Zhao GJ, Cheng Y, et al. Application and a proposed modification of the 2010 McDonald criteria for the diagnosis of multiple sclerosis in a Canadian cohort of patients with clinically isolated syndromes. Mult Scler. 2014;20(4):458-63.

140. Bot JC, Barkhof F, Polman CH, Lycklama a Nijeholt GJ, de Groot V, Bergers E, et al. Spinal cord abnormalities in recently diagnosed MS patients: added value of spinal MRI examination. Neurology. 2004;62(2):226-33.

141. Nair G, Absinta M, Reich DS. Optimized T1-MPRAGE sequence for better visualization of spinal cord multiple sclerosis lesions at 3T. AJNR Am J Neuroradiol. 2013;34(11):2215-22.

142. Sombekke MH, Wattjes MP, Balk $L$, Nielsen JM, Vrenken $H$, Uitdehaag BM, et al. Spinal cord lesions in patients with clinically isolated syndrome: a powerful tool in diagnosis and prognosis. Neurology. 2013;80(1):69-75.

143. Weier K, Mazraeh J, Naegelin Y, Thoeni A, Hirsch JG, Fabbro T, et al. Biplanar MRI for the assessment of the spinal cord in multiple sclerosis. Mult Scler. 2012;18(11):1560-9.

144. Kelly SB, Kinsella K, Duggan M, Tubridy N, McGuigan C, Hutchinson M. A proposed modification to the McDonald 2010 criteria for the diagnosis of primary progressive multiple sclerosis. Mult Scler. 2013;19(8):1095-100.

145. Bigi S, Marrie RA, Verhey L, Yeh EA, Banwell B. 2010 McDonald criteria in a pediatric cohort: is positivity at onset associated with a more aggressive multiple sclerosis course? Mult Scler. 2013;19(10):1359-62.

146. Hummel HM, Bruck W, Dreha-Kulaczewski S, Gartner J, Wuerfel J. Pediatric onset multiple sclerosis: McDonald criteria 2010 and the contribution of spinal cord MRI. Mult Scler. 2013;19(10):1330-5.

147. Huh SY, Kim SH, Kim W, Lee SH, Park MS, Ahn SW, et al. Evaluation of McDonald MRI criteria for dissemination in space in Korean patients with clinically isolated syndromes. Mult Scler. 2014;20(4):492-5.

148. Patrucco L, Rojas JI, Miguez JS, Cristiano E. Application of the McDonald 2010 criteria for the diagnosis of multiple sclerosis in an Argentinean cohort of patients with clinically isolated syndromes. Mult Scler. 2013;19(10):1297-301.

149. Kincses Z, Toth E, Fricska-Nagy Z, Fuvesi J, Rajda C, Bencsik K, et al. [The role of MRI in measuring the effectivity of disease modifying treatments II]. Ideggyogy Sz. 2018;71(3-04):81-8.

150. Toth E, Bencsik K, Voros E, Fricska-Nagy Z, Fuvesi J, Rajda C, et al. [The role of MRI in measuring the effectivity of disease modifying treatments I]. Ideggyogy Sz. 2018;71(3-04):77-80.

151. Ontaneda D, Rae-Grant AD. Management of acute exacerbations in multiple sclerosis. Ann Indian Acad Neurol. 2009;12(4):264-72.

152. Waxman SG. Conduction in myelinated, unmyelinated, and demyelinated fibers. Arch Neurol. 1977;34(10):585-9. 
153. Wingerchuk DM, Rodriguez M. Premenstrual multiple sclerosis pseudoexacerbations: Role of body temperature and prevention with aspirin. Arch Neurol. 2006;63(7):1005-8.

154. Buljevac D, Hop WC, Reedeker W, Janssens AC, van der Meche FG, van Doorn PA, et al. Self reported stressful life events and exacerbations in multiple sclerosis: prospective study. BMJ. 2003;327(7416):646.

155. Buljevac D, Flach HZ, Hop WC, Hijdra D, Laman JD, Savelkoul HF, et al. Prospective study on the relationship between infections and multiple sclerosis exacerbations. Brain. 2002;125(Pt 5):952-60.

156. Smith ME, Stone LA, Albert PS, Frank JA, Martin R, Armstrong M, et al. Clinical worsening in multiple sclerosis is associated with increased frequency and area of gadopentetate dimeglumineenhancing magnetic resonance imaging lesions. Ann Neurol. 1993;33(5):480-9.

157. Faissner S, Nikolayczik J, Chan A, Hellwig K, Gold R, Yoon MS, et al. Plasmapheresis and immunoadsorption in patients with steroid refractory multiple sclerosis relapses. I Neurol. 2016;263(6):1092-8.

158. Szczepiorkowski ZM, Winters JL, Bandarenko N, Kim HC, Linenberger ML, Marques MB, et al. Guidelines on the use of therapeutic apheresis in clinical practice--evidence-based approach from the Apheresis Applications Committee of the American Society for Apheresis. J Clin Apher. 2010;25(3):83177.

159. Kohler W, Bucka C, Klingel R. A randomized and controlled study comparing immunoadsorption and plasma exchange in myasthenic crisis. J Clin Apher. 2011;26(6):347-55.

160. Bayry J, Hartung HP, Kaveri SV. IVIg for relapsing-remitting multiple sclerosis: promises and uncertainties. Trends Pharmacol Sci. 2015;36(7):419-21.

161. Buttmann M, Kaveri S, Hartung HP. Polyclonal immunoglobulin G for autoimmune demyelinating nervous system disorders. Trends Pharmacol Sci. 2013;34(8):445-57.

162. Montalban X, Gold R, Thompson AJ, Otero-Romero S, Amato MP, Chandraratna D, et al. ECTRIMS/EAN Guideline on the pharmacological treatment of people with multiple sclerosis. Mult Scler. 2018;24(2):96-120.

163. Matta AP, Nascimento OJ, Ferreira AC, Magalhaes TN, Benevides TP, Kirmse A, et al. No evidence of disease activity in multiple sclerosis patients. Expert Rev Neurother. 2016;16(11):1279-84.

164. Giovannoni G, Turner B, Gnanapavan S, Offiah C, Schmierer K, Marta M. Is it time to target no evident disease activity (NEDA) in multiple sclerosis? Mult Scler Relat Disord. 2015;4(4):329-33.

165. Ziemssen T, Derfuss T, de Stefano N, Giovannoni G, Palavra F, Tomic D, et al. Optimizing treatment success in multiple sclerosis. J Neurol. 2016;263(6):1053-65.

166. Leray E, Yaouanq J, Le Page E, Coustans M, Laplaud D, Oger J, et al. Evidence for a two-stage disability progression in multiple sclerosis. Brain. 2010;133(Pt 7):1900-13.

167. Montalban X, Hauser SL, Kappos L, Arnold DL, Bar-Or A, Comi G, et al. Ocrelizumab versus Placebo in Primary Progressive Multiple Sclerosis. N Engl J Med. 2017;376(3):209-20.

168. Ginsberg D, Gousse A, Keppenne V, Sievert KD, Thompson C, Lam W, et al. Phase 3 efficacy and tolerability study of onabotulinumtoxinA for urinary incontinence from neurogenic detrusor overactivity. J Urol. 2012;187(6):2131-9.

169. Herschorn S, Gajewski J, Ethans K, Corcos J, Carlson K, Bailly G, et al. Efficacy of botulinum toxin A injection for neurogenic detrusor overactivity and urinary incontinence: a randomized, double-blind trial. J Urol. 2011;185(6):2229-35.

170. Keegan BM, Noseworthy JH. Multiple sclerosis. Annu Rev Med. 2002;53:285-302.

171. Kincses ZT, Toth E, Banko N, Vereb D, Szabo N, Csete G, et al. Grey matter atrophy in patients suffering from multiple sclerosis. Ideggyogy Sz. 2014;67(9-10):293-300.

172. Ashburner J, Friston K. Multimodal image coregistration and partitioning--a unified framework. Neuroimage. 1997;6(3):209-17.

173. Nakamura K, Fisher E. Segmentation of brain magnetic resonance images for measurement of gray matter atrophy in multiple sclerosis patients. Neuroimage. 2009;44(3):769-76.

174. Smith SM, De Stefano N, Jenkinson M, Matthews PM. Normalized accurate measurement of longitudinal brain change. J Comput Assist Tomogr. 2001;25(3):466-75. 
175. Chard DT, Griffin CM, Parker GJ, Kapoor R, Thompson AJ, Miller DH. Brain atrophy in clinically early relapsing-remitting multiple sclerosis. Brain. 2002;125(Pt 2):327-37.

176. Tedeschi G, Lavorgna L, Russo P, Prinster A, Dinacci D, Savettieri G, et al. Brain atrophy and lesion load in a large population of patients with multiple sclerosis. Neurology. 2005;65(2):280-5.

177. Sanfilipo MP, Benedict RH, Weinstock-Guttman B, Bakshi R. Gray and white matter brain atrophy and neuropsychological impairment in multiple sclerosis. Neurology. 2006;66(5):685-92.

178. Sastre-Garriga J, Ingle GT, Chard DT, Cercignani M, Ramio-Torrenta L, Miller DH, et al. Grey and white matter volume changes in early primary progressive multiple sclerosis: a longitudinal study. Brain. 2005;128(Pt 6):1454-60.

179. Tiberio M, Chard DT, Altmann DR, Davies G, Griffin CM, Rashid W, et al. Gray and white matter volume changes in early RRMS: a 2-year longitudinal study. Neurology. 2005;64(6):1001-7.

180. Smith SM, Zhang Y, Jenkinson M, Chen J, Matthews PM, Federico A, et al. Accurate, robust, and automated longitudinal and cross-sectional brain change analysis. Neuroimage. 2002;17(1):47989.

181. Smith SM, Jenkinson M, Woolrich MW, Beckmann CF, Behrens TE, Johansen-Berg $\mathrm{H}$, et al. Advances in functional and structural MR image analysis and implementation as FSL. Neuroimage. 2004;23 Suppl 1:S208-19.

182. Ashburner J, Friston KJ. Voxel-based morphometry--the methods. Neuroimage. 2000;11(6 Pt 1):805-21.

183. Filippi M, Mastronardo G, Rocca MA, Pereira C, Comi G. Quantitative volumetric analysis of brain magnetic resonance imaging from patients with multiple sclerosis. J Neurol Sci. 1998;158(2):14853.

184. De Stefano N, Matthews PM, Filippi M, Agosta F, De Luca M, Bartolozzi ML, et al. Evidence of early cortical atrophy in MS: relevance to white matter changes and disability. Neurology. 2003;60(7):1157-62.

185. Bermel RA, Sharma J, Tjoa CW, Puli SR, Bakshi R. A semiautomated measure of whole-brain atrophy in multiple sclerosis. J Neurol Sci. 2003;208(1-2):57-65.

186. Audoin B, Davies GR, Finisku L, Chard DT, Thompson AJ, Miller DH. Localization of grey matter atrophy in early RRMS : A longitudinal study. J Neurol. 2006;253(11):1495-501.

187. Sepulcre J, Sastre-Garriga J, Cercignani M, Ingle GT, Miller DH, Thompson AJ. Regional gray matter atrophy in early primary progressive multiple sclerosis: a voxel-based morphometry study. Arch Neurol. 2006;63(8):1175-80.

188. Steenwijk MD, Geurts JJ, Daams M, Tijms BM, Wink AM, Balk L, et al. Cortical atrophy patterns in multiple sclerosis are non-random and clinically relevant. Brain. 2016;139(Pt 1):115-26.

189. Fick A. Ueber diffusion. Annalen der Physik. 1855;170(1):59-86.

190. Einstein A. Investigation on the theory of the brownian movement. Ann der Physik. 1905.

191. Moseley ME, Cohen Y, Kucharczyk J, Mintorovitch J, Asgari HS, Wendland MF, et al. Diffusionweighted MR imaging of anisotropic water diffusion in cat central nervous system. Radiology. 1990;176(2):439-45.

192. Le Bihan D. Looking into the functional architecture of the brain with diffusion MRI. Nat Rev Neurosci. 2003;4(6):469-80.

193. Basser PJ, Pierpaoli C. Microstructural and physiological features of tissues elucidated by quantitative-diffusion-tensor MRI. J Magn Reson B. 1996;111(3):209-19.

194. Smith SM, Jenkinson M, Johansen-Berg H, Rueckert D, Nichols TE, Mackay CE, et al. Tract-based spatial statistics: voxelwise analysis of multi-subject diffusion data. Neuroimage. 2006;31(4):1487-505.

195. Barkhof $F$. The clinico-radiological paradox in multiple sclerosis revisited. Curr Opin Neurol. 2002;15(3):239-45.

196. Kincses ZT, Ropele S, Jenkinson M, Khalil M, Petrovic K, Loitfelder M, et al. Lesion probability mapping to explain clinical deficits and cognitive performance in multiple sclerosis. Mult Scler. 2011;17(6):681-9. 
197. Batista S, Zivadinov R, Hoogs M, Bergsland N, Heininen-Brown M, Dwyer MG, et al. Basal ganglia, thalamus and neocortical atrophy predicting slowed cognitive processing in multiple sclerosis. J Neurol. 2012;259(1):139-46.

198. Roosendaal SD, Bendfeldt K, Vrenken H, Polman CH, Borgwardt S, Radue EW, et al. Grey matter volume in a large cohort of MS patients: relation to MRI parameters and disability. Mult Scler. 2011;17(9):1098-106.

199. Rudick RA, Fisher E, Lee JC, Simon J, Jacobs L. Use of the brain parenchymal fraction to measure whole brain atrophy in relapsing-remitting MS. Multiple Sclerosis Collaborative Research Group. Neurology. 1999;53(8):1698-704.

200. Khan O, Bao F, Shah M, Caon C, Tselis A, Bailey R, et al. Effect of disease-modifying therapies on brain volume in relapsing-remitting multiple sclerosis: results of a five-year brain MRI study. $J$ Neurol Sci. 2012;312(1-2):7-12.

201. Radue EW, Stuart WH, Calabresi PA, Confavreux C, Galetta SL, Rudick RA, et al. Natalizumab plus interferon beta-1a reduces lesion formation in relapsing multiple sclerosis. J Neurol Sci. 2010;292(1-2):28-35.

202. Cohen JA, Barkhof F, Comi G, Hartung HP, Khatri BO, Montalban X, et al. Oral fingolimod or intramuscular interferon for relapsing multiple sclerosis. N Engl J Med. 2010;362(5):402-15.

203. Poldrack RA. Region of interest analysis for fMRI. Soc Cogn Affect Neurosci. 2007;2(1):67-70.

204. Song SK, Yoshino J, Le TQ, Lin SJ, Sun SW, Cross AH, et al. Demyelination increases radial diffusivity in corpus callosum of mouse brain. Neuroimage. 2005;26(1):132-40.

205. Boretius S, Escher A, Dallenga T, Wrzos C, Tammer R, Bruck W, et al. Assessment of lesion pathology in a new animal model of MS by multiparametric MRI and DTI. Neuroimage. 2012;59(3):2678-88.

206. Lehmann HC, Zhang J, Mori S, Sheikh KA. Diffusion tensor imaging to assess axonal regeneration in peripheral nerves. Exp Neurol. 2010;223(1):238-44.

207. Schmierer K, Wheeler-Kingshott CA, Tozer DJ, Boulby PA, Parkes HG, Yousry TA, et al. Quantitative magnetic resonance of postmortem multiple sclerosis brain before and after fixation. Magn Reson Med. 2008;59(2):268-77.

208. Griffin CM, Chard DT, Ciccarelli O, Kapoor B, Barker GJ, Thompson Al, et al. Diffusion tensor imaging in early relapsing-remitting multiple sclerosis. Mult Scler. 2001;7(5):290-7.

209. Ciccarelli O, Werring DJ, Wheeler-Kingshott CA, Barker GJ, Parker GJ, Thompson AJ, et al. Investigation of MS normal-appearing brain using diffusion tensor MRI with clinical correlations. Neurology. 2001;56(7):926-33.

210. Filippi M, Cercignani M, Inglese M, Horsfield MA, Comi G. Diffusion tensor magnetic resonance imaging in multiple sclerosis. Neurology. 2001;56(3):304-11.

211. Toth E, Szabo N, Csete G, Kiraly A, Farago P, Spisak T, et al. Gray Matter Atrophy Is Primarily Related to Demyelination of Lesions in Multiple Sclerosis: A Diffusion Tensor Imaging MRI Study. Front Neuroanat. 2017;11:23.

212. Jehna M, Pirpamer L, Khalil M, Fuchs S, Ropele S, Langkammer C, et al. Periventricular lesions correlate with cortical thinning in multiple sclerosis. Ann Neurol. 2015;78(4):530-9.

213. Gilmore CP, Donaldson I, Bo L, Owens T, Lowe J, Evangelou N. Regional variations in the extent and pattern of grey matter demyelination in multiple sclerosis: a comparison between the cerebral cortex, cerebellar cortex, deep grey matter nuclei and the spinal cord. J Neurol Neurosurg Psychiatry. 2009;80(2):182-7.

214. Magliozzi R, Howell OW, Reeves C, Roncaroli F, Nicholas R, Serafini B, et al. A Gradient of neuronal loss and meningeal inflammation in multiple sclerosis. Ann Neurol. 2010;68(4):477-93.

215. Lisak RP, Benjamins JA, Nedelkoska L, Barger JL, Ragheb S, Fan B, et al. Secretory products of multiple sclerosis B cells are cytotoxic to oligodendroglia in vitro. J Neuroimmunol. 2012;246(1-2):8595.

216. Wegner C, Esiri MM, Chance SA, Palace J, Matthews PM. Neocortical neuronal, synaptic, and glial loss in multiple sclerosis. Neurology. 2006;67(6):960-7. 
217. Geurts JJ, Calabrese M, Fisher E, Rudick RA. Measurement and clinical effect of grey matter pathology in multiple sclerosis. Lancet Neurol. 2012;11(12):1082-92.

218. Trapp BD, Nave KA. Multiple sclerosis: an immune or neurodegenerative disorder? Annu Rev Neurosci. 2008;31:247-69.

219. Charil A, Dagher A, Lerch JP, Zijdenbos AP, Worsley KJ, Evans AC. Focal cortical atrophy in multiple sclerosis: relation to lesion load and disability. Neuroimage. 2007;34(2):509-17.

220. Fu L, Matthews PM, De Stefano N, Worsley KJ, Narayanan S, Francis GS, et al. Imaging axonal damage of normal-appearing white matter in multiple sclerosis. Brain. 1998;121 ( Pt 1):103-13.

221. Wood ET, Ronen I, Techawiboonwong A, Jones CK, Barker PB, Calabresi P, et al. Investigating axonal damage in multiple sclerosis by diffusion tensor spectroscopy. J Neurosci. 2012;32(19):6665-9.

222. Llufriu S, Kornak J, Ratiney H, Oh J, Brenneman D, Cree BA, et al. Magnetic resonance spectroscopy markers of disease progression in multiple sclerosis. JAMA Neurol. 2014;71(7):840-7.

223. Vrenken H, Pouwels PJ, Ropele S, Knol DL, Geurts JJ, Polman CH, et al. Magnetization transfer ratio measurement in multiple sclerosis normal-appearing brain tissue: limited differences with controls but relationships with clinical and MR measures of disease. Mult Scler. 2007;13(6):708-16.

224. Filippi M, Rocca MA, Benedict RH, DeLuca J, Geurts JJ, Rombouts SA, et al. The contribution of MRI in assessing cognitive impairment in multiple sclerosis. Neurology. 2010;75(23):2121-8.

225. Rocca MA, Amato MP, De Stefano N, Enzinger C, Geurts JJ, Penner IK, et al. Clinical and imaging assessment of cognitive dysfunction in multiple sclerosis. Lancet Neurol. 2015;14(3):302-17.

226. Zhang X, Zhang F, Huang D, Wu L, Ma L, Liu H, et al. Contribution of Gray and White Matter Abnormalities to Cognitive Impairment in Multiple Sclerosis. Int J Mol Sci. 2016;18(1).

227. Riccitelli GC, Pagani E, Rodegher M, Colombo B, Preziosa P, Falini A, et al. Imaging patterns of gray and white matter abnormalities associated with PASAT and SDMT performance in relapsingremitting multiple sclerosis. Mult Scler. 2017:1352458517743091.

228. Benedict RH, Bruce J, Dwyer MG, Weinstock-Guttman B, Tjoa C, Tavazzi E, et al. Diffusionweighted imaging predicts cognitive impairment in multiple sclerosis. Mult Scler. 2007;13(6):722-30.

229. Hulst HE, Gehring K, Uitdehaag BM, Visser LH, Polman CH, Barkhof F, et al. Indicators for cognitive performance and subjective cognitive complaints in multiple sclerosis: a role for advanced MRI? Mult Scler. 2014;20(8):1131-4.

230. Daams M, Steenwijk MD, Schoonheim MM, Wattjes MP, Balk L, Tewarie PK, et al. Multiparametric structural magnetic resonance imaging in relation to cognitive dysfunction in long-standing multiple sclerosis. Mult Scler. 2016;22(5):608-19.

231. Hulst HE, Steenwijk MD, Versteeg A, Pouwels PJ, Vrenken H, Uitdehaag BM, et al. Cognitive impairment in MS: impact of white matter integrity, gray matter volume, and lesions. Neurology. 2013;80(11):1025-32.

232. Langdon DW. Cognition in multiple sclerosis. Curr Opin Neurol. 2011;24(3):244-9.

233. Sandi D, Rudisch T, Fuvesi J, Fricska-Nagy Z, Huszka H, Biernacki T, et al. The Hungarian validation of the Brief International Cognitive Assessment for Multiple Sclerosis (BICAMS) battery and the correlation of cognitive impairment with fatigue and quality of life. Mult Scler Relat Disord. 2015;4(6):499-504.

234. Walker LA, Osman L, Berard JA, Rees LM, Freedman MS, MacLean H, et al. Brief International Cognitive Assessment for Multiple Sclerosis (BICAMS): Canadian contribution to the international validation project. J Neurol Sci. 2016;362:147-52.

235. Langdon DW, Amato MP, Boringa J, Brochet B, Foley F, Fredrikson S, et al. Recommendations for a Brief International Cognitive Assessment for Multiple Sclerosis (BICAMS). Mult Scler. 2012;18(6):891-8.

236. Smith A. Symbol Digit Modalities Test Manual. Western Psychological Services, Los Angeles. 1982.

237. Delis DC, Kramer, J.H., Kaplan, E., Ober, B.A. California Verbal Learning Test. (CVLT-II)second edition. Psychological Corporation, San Antonio, TX. 2000.

238. Benedict RH. The Brief Visuospatial Memory Test Revised (BVMT-R). Psychosocial Assessment Resources Inc, Lutz, FL. 1997. 
239. Jenkinson M, Bannister P, Brady M, Smith S. Improved optimization for the robust and accurate linear registration and motion correction of brain images. Neuroimage. 2002;17(2):825-41.

240. Andersson JLR, Jenkinson M, Smith S. Non-linear Optimisation. Oxford: FMRIB technical report. 2007.

241. Jenkinson M, Beckmann CF, Behrens TE, Woolrich MW, Smith SM. Fsl. Neuroimage. 2012;62(2):782-90.

242. Zhang $Y$, Brady $M$, Smith S. Segmentation of brain MR images through a hidden Markov random field model and the expectation-maximization algorithm. IEEE Trans Med Imaging. 2001;20(1):45-57.

243. Battaglini $M$, Jenkinson $M$, De Stefano N. Evaluating and reducing the impact of white matter lesions on brain volume measurements. Hum Brain Mapp. 2012;33(9):2062-71.

244. Patenaude B, Smith SM, Kennedy DN, Jenkinson M. A Bayesian model of shape and appearance for subcortical brain segmentation. Neuroimage. 2011;56(3):907-22.

245. Zarei M, Patenaude B, Damoiseaux J, Morgese C, Smith S, Matthews PM, et al. Combining shape and connectivity analysis: an MRI study of thalamic degeneration in Alzheimer's disease. Neuroimage. 2010;49(1):1-8.

246. Abdi $\mathrm{H}$, Williams $\mathrm{L}$. Partial least squares methods: partial least squares correlation and partial least square regression. Methods in molecular biology. 2013;930:549-79.

247. Wold S, Johansson E, Cocchi M. PLS - Partial Least Squares Projections to Latent Structures. In: Kubinyi $\mathrm{H}$, editor. 3D QSAR in Drug Design Volume 1: Theory Methods and Applications. 1. Leiden: ESCOM Science Publishers; 1994. p. 523-50.

248. Hua K, Zhang J, Wakana S, Jiang H, Li X, Reich DS, et al. Tract probability maps in stereotaxic spaces: analyses of white matter anatomy and tract-specific quantification. Neuroimage. 2008;39(1):336-47.

249. Song SK, Sun SW, Ju WK, Lin SJ, Cross AH, Neufeld AH. Diffusion tensor imaging detects and differentiates axon and myelin degeneration in mouse optic nerve after retinal ischemia. Neuroimage. 2003;20(3):1714-22.

250. Cifelli A, Arridge M, Jezzard P, Esiri MM, Palace J, Matthews PM. Thalamic neurodegeneration in multiple sclerosis. Ann Neurol. 2002;52(5):650-3.

251. Dineen RA, Vilisaar J, Hlinka J, Bradshaw CM, Morgan PS, Constantinescu CS, et al. Disconnection as a mechanism for cognitive dysfunction in multiple sclerosis. Brain. 2009;132(Pt 1):239-49.

252. Fabiano AJ, Sharma J, Weinstock-Guttman B, Munschauer FE, 3rd, Benedict RH, Zivadinov R, et al. Thalamic involvement in multiple sclerosis: a diffusion-weighted magnetic resonance imaging study. J Neuroimaging. 2003;13(4):307-14.

253. Inglese M, Ge Y, Filippi M, Falini A, Grossman RI, Gonen O. Indirect evidence for early widespread gray matter involvement in relapsing-remitting multiple sclerosis. Neuroimage. 2004;21(4):1825-9.

254. Kern KC, Sarcona J, Montag M, Giesser BS, Sicotte NL. Corpus callosal diffusivity predicts motor impairment in relapsing-remitting multiple sclerosis: a TBSS and tractography study. Neuroimage. 2011;55(3):1169-77.

255. Poonawalla AH, Hasan KM, Gupta RK, Ahn CW, Nelson F, Wolinsky JS, et al. Diffusion-tensor MR imaging of cortical lesions in multiple sclerosis: initial findings. Radiology. 2008;246(3):880-6.

256. Raz E, Cercignani M, Sbardella E, Totaro P, Pozzilli C, Bozzali M, et al. Clinically isolated syndrome suggestive of multiple sclerosis: voxelwise regional investigation of white and gray matter. Radiology. 2010;254(1):227-34.

257. Roosendaal SD, Geurts JJ, Vrenken H, Hulst HE, Cover KS, Castelijns JA, et al. Regional DTI differences in multiple sclerosis patients. Neuroimage. 2009;44(4):1397-403.

258. Yu HJ, Christodoulou C, Bhise V, Greenblatt D, Patel Y, Serafin D, et al. Multiple white matter tract abnormalities underlie cognitive impairment in RRMS. Neuroimage. 2012;59(4):3713-22. 
259. Howell OW, Reeves CA, Nicholas R, Carassiti D, Radotra B, Gentleman SM, et al. Meningeal inflammation is widespread and linked to cortical pathology in multiple sclerosis. Brain. 2011;134(Pt 9):2755-71.

260. Wuerfel J, Haertle M, Waiczies H, Tysiak E, Bechmann I, Wernecke KD, et al. Perivascular spaces--MRI marker of inflammatory activity in the brain? Brain. 2008;131(Pt 9):2332-40.

261. Sander C, Eling P, Hanken K, Klein J, Kastrup A, Hildebrandt H. The Impact of MS-Related Cognitive Fatigue on Future Brain Parenchymal Loss and Relapse: A 17-Month Follow-up Study. Frontiers in neurology. 2016;7:155.

262. Amato MP, Bartolozzi ML, Zipoli V, Portaccio E, Mortilla M, Guidi L, et al. Neocortical volume decrease in relapsing-remitting $M S$ patients with mild cognitive impairment. Neurology. 2004;63(1):89-93.

263. Sanfilipo MP, Benedict RH, Sharma J, Weinstock-Guttman B, Bakshi R. The relationship between whole brain volume and disability in multiple sclerosis: a comparison of normalized gray vs. white matter with misclassification correction. Neuroimage. 2005;26(4):1068-77.

264. Fisniku LK, Chard DT, Jackson JS, Anderson VM, Altmann DR, Miszkiel KA, et al. Gray matter atrophy is related to long-term disability in multiple sclerosis. Ann Neurol. 2008;64(3):247-54.

265. Morgen K, Sammer G, Courtney SM, Wolters T, Melchior H, Blecker CR, et al. Evidence for a direct association between cortical atrophy and cognitive impairment in relapsing-remitting $\mathrm{MS}$. Neurolmage. 2006;30(3):891-8.

266. Prinster A, Quarantelli M, Orefice G, Lanzillo R, Brunetti A, Mollica C, et al. Grey matter loss in relapsing-remitting multiple sclerosis: a voxel-based morphometry study. Neurolmage. 2006;29(3):859-67.

267. Khaleeli Z, Cercignani M, Audoin B, Ciccarelli O, Miller DH, Thompson AJ. Localized grey matter damage in early primary progressive multiple sclerosis contributes to disability. Neurolmage. 2007;37(1):253-61.

268. Cerasa A, Valentino P, Chiriaco C, Pirritano D, Nistico R, Gioia CM, et al. MR imaging and cognitive correlates of relapsing-remitting multiple sclerosis patients with cerebellar symptoms. Journal of neurology. 2013;260(5):1358-66.

269. Sastre-Garriga J, Arevalo MJ, Renom M, Alonso J, Gonzalez I, Galan I, et al. Brain volumetry counterparts of cognitive impairment in patients with multiple sclerosis. Journal of the neurological sciences. 2009;282(1-2):120-4.

270. Ceccarelli A, Jackson JS, Tauhid S, Arora A, Gorky J, Dell'Oglio E, et al. The impact of lesion inpainting and registration methods on voxel-based morphometry in detecting regional cerebral gray matter atrophy in multiple sclerosis. AJNR American journal of neuroradiology. 2012;33(8):1579-85.

271. Koini M, Filippi M, Rocca MA, Yousry T, Ciccarelli O, Tedeschi G, et al. Correlates of Executive Functions in Multiple Sclerosis Based on Structural and Functional MR Imaging: Insights from a Multicenter Study. Radiology. 2016;280(3):869-79.

272. Kern KC, Gold SM, Lee B, Montag M, Horsfall J, O'Connor MF, et al. Thalamic-hippocampalprefrontal disruption in relapsing-remitting multiple sclerosis. Neuroimage Clin. 2015;8:440-7.

273. Sacco R, Bisecco A, Corbo D, Della Corte $M$, d'Ambrosio A, Docimo R, et al. Cognitive impairment and memory disorders in relapsing-remitting multiple sclerosis: the role of white matter, gray matter and hippocampus. Journal of neurology. 2015;262(7):1691-7.

274. Hulst HE, Schoonheim MM, Van Geest Q, Uitdehaag BM, Barkhof F, Geurts JJ. Memory impairment in multiple sclerosis: Relevance of hippocampal activation and hippocampal connectivity. Multiple sclerosis. 2015;21(13):1705-12.

275. Rocca MA, Morelli ME, Amato MP, Moiola L, Ghezzi A, Veggiotti P, et al. Regional hippocampal involvement and cognitive impairment in pediatric multiple sclerosis. Multiple sclerosis. 2016;22(5):628-40.

276. Damjanovic D, Valsasina P, Rocca MA, Stromillo ML, Gallo A, Enzinger C, et al. Hippocampal and Deep Gray Matter Nuclei Atrophy Is Relevant for Explaining Cognitive Impairment in MS: A Multicenter Study. AJNR American journal of neuroradiology. 2017;38(1):18-24. 
277. Tillema JM, Hulst HE, Rocca MA, Vrenken H, Steenwijk MD, Damjanovic D, et al. Regional cortical thinning in multiple sclerosis and its relation with cognitive impairment: A multicenter study. Multiple sclerosis. 2016;22(7):901-9.

278. Geisseler O, Pflugshaupt T, Bezzola L, Reuter K, Weller D, Schuknecht B, et al. Cortical thinning in the anterior cingulate cortex predicts multiple sclerosis patients' fluency performance in a lateralised manner. Neurolmage Clinical. 2016;10:89-95.

279. Sbardella E, Petsas N, Tona F, Prosperini L, Raz E, Pace G, et al. Assessing the correlation between grey and white matter damage with motor and cognitive impairment in multiple sclerosis patients. PLoS One. 2013;8(5):e63250.

280. Onu M, Roceanu A, Sboto-Frankenstein U, Bendic R, Tarta E, Preoteasa F, et al. Diffusion abnormality maps in demyelinating disease: correlations with clinical scores. Eur J Radiol. 2012;81(3):e386-91.

281. Velicu IL, Neagu M, Dobromir M, Luca D, Lupu N, Chiriac H, et al. Structural, Magnetic and Magnetoelastic Behaviour of FeCuNbSiB Thin Films. Sensor Lett. 2012;10(3-4):902-5.

282. Nocentini U, Bozzali M, Spano B, Cercignani M, Serra L, Basile B, et al. Exploration of the relationships between regional grey matter atrophy and cognition in multiple sclerosis. Brain imaging and behavior. 2012.

283. Montalban X, Sastre-Garriga J, Tintore M, Brieva L, Aymerich FX, Rio J, et al. A single-center, randomized, double-blind, placebo-controlled study of interferon beta-1b on primary progressive and transitional multiple sclerosis. Multiple Sclerosis. 2009;15(10):1195-205.

284. Bodini B, Battaglini M, De Stefano N, Barkhof F, Brochet B, Dousset V, et al. Spatial localisation of lesions predicts clinical deterioration in primary progressive multiple sclerosis: a 10-year multicentre study. Multiple Sclerosis. 2009;15(9):S11-S.

285. Koenig KA, Sakaie KE, Lowe MJ, Lin J, Stone L, Bermel RA, et al. High spatial and angular resolution diffusion-weighted imaging reveals forniceal damage related to memory impairment. Magn Reson Imaging. 2013;31(5):695-9.

286. Dineen RA, Bradshaw CM, Constantinescu CS, Auer DP. Extra-hippocampal subcortical limbic involvement predicts episodic recall performance in multiple sclerosis. PLoS One. 2012;7(10):e44942.

287. Kincses ZT, Horinek D, Szabo N, Toth E, Csete G, Stepan-Buksakowska I, et al. The pattern of diffusion parameter changes in Alzheimer's disease, identified by means of linked independent component analysis. J Alzheimers Dis. 2013;36(1):119-28.

288. Kiy G, Lehmann P, Hahn HK, Eling P, Kastrup A, Hildebrandt H. Decreased hippocampal volume, indirectly measured, is associated with depressive symptoms and consolidation deficits in multiple sclerosis. Mult Scler. 2011;17(9):1088-97.

289. Sandroff BM, Johnson CL, Motl RW. Exercise training effects on memory and hippocampal viscoelasticity in multiple sclerosis: a novel application of magnetic resonance elastography. Neuroradiology. 2017;59(1):61-7.

290. Nocentini U, Bozzali M, Spano B, Cercignani M, Serra L, Basile B, et al. Exploration of the relationships between regional grey matter atrophy and cognition in multiple sclerosis. Brain Imaging Behav. 2014;8(3):378-86.

291. Benedict RH, Ramasamy D, Munschauer F, Weinstock-Guttman B, Zivadinov R. Memory impairment in multiple sclerosis: correlation with deep grey matter and mesial temporal atrophy. J Neurol Neurosurg Psychiatry. 2009;80(2):201-6.

292. Ezzati A, Katz MJ, Zammit AR, Lipton ML, Zimmerman ME, Sliwinski MJ, et al. Differential association of left and right hippocampal volumes with verbal episodic and spatial memory in older adults. Neuropsychologia. 2016;93(Pt B):380-5.

293. Travis SG, Huang Y, Fujiwara E, Radomski A, Olsen F, Carter R, et al. High field structural MRI reveals specific episodic memory correlates in the subfields of the hippocampus. Neuropsychologia. 2014;53:233-45.

294. Shi F, Liu B, Zhou Y, Yu C, Jiang T. Hippocampal volume and asymmetry in mild cognitive impairment and Alzheimer's disease: Meta-analyses of MRI studies. Hippocampus. 2009;19(11):105564. 
295. Kincses ZT, Horinek D, Szabo N, Toth E, Csete G, Stepan-Buksakowska I, et al. The Pattern of Diffusion Parameter Changes in Alzheimer's Disease, Identified by Means of Linked Independent Component Analysis. Journal of Alzheimers Disease. 2013;36(1):119-28. 


\title{
Gray Matter Atrophy Is Primarily Related to Demyelination of Lesions in Multiple Sclerosis: A Diffusion Tensor Imaging MRI Study
}

\author{
Eszter Tóth ${ }^{1}$, Nikoletta Szabó ${ }^{1}$, Gergõ Csete ${ }^{1}$, András Király ${ }^{1,2}$, Péter Faragó ${ }^{1,2}$, \\ Tamás Spisák ${ }^{3}$, Krisztina Bencsik ${ }^{1}$, László Vécsei ${ }^{1,4}$ and Zsigmond T. Kincses ${ }^{1 *}$ \\ ${ }^{1}$ Department of Neurology, Albert Szent-Györgyi Clinical Centre, University of Szeged, Szeged, Hungary, ${ }^{2}$ Central European \\ Institute of Technology, Masaryk University, Brno, Czechia, ${ }^{3}$ Department of Nuclear Medicine, University of Debrecen, \\ Debrecen, Hungary, ${ }^{4}$ Neuroscience Research Group of the Hungarian Academy of Sciences and University of Szeged, \\ Szeged, Hungary
}

OPEN ACCESS

Edited by:

Gonzalo Alvarez-Bolado, Heidelberg University, Germany

Reviewed by:

Marisa Koini (nee Loitfelder) Medical University of Graz, Austria

Manuel Menéndez-González, Central University Hospital of Asturias,

Spain

Antonio Giorgio,

University of Siena, Italy

Alexander Emmer,

Martin Luther University of

Halle-Wittenberg, Germany

*Correspondence:

Zsigmond T. Kincses

kincses.zsigmond.tamas@

med.u-szeged.hu

Received: 14 November 2016 Accepted: 07 March 2017 Published: 29 March 2017

Citation:

Tóth E, Szabó N, Csete G, Király A

Faragó P, Spisák T, Bencsik K, Vécsei $L$ and Kincses ZT (2017) Gray Matter Atrophy Is Primarily Related to

Demyelination of Lesions in Multiple Sclerosis: A Diffusion Tensor Imaging MRI Study. Front. Neuroanat. 11:23.

doi: 10.3389/fnana.2017.00023
Objective: Cortical pathology, periventricular demyelination, and lesion formation in multiple sclerosis (MS) are related (Hypothesis 1). Factors in the cerebrospinal fluid close to these compartments could possibly drive the parallel processes. Alternatively, the cortical atrophy could be caused by remote axonal transection (Hypothesis 2). Since MRI can differentiate between demyelination and axon loss, we used this imaging modality to investigate the correlation between the pattern of diffusion parameter changes in the periventricular- and deep white matter and the gray matter atrophy.

Methods: High-resolution T1-weighted, FLAIR, and diffusion MRI images were acquired in 52 RRMS patients and 50 healthy, age-matched controls. We used EDSS to estimate the clinical disability. We used Tract Based Spatial Statistics to compare diffusion parameters (fractional anisotropy, mean, axial, and radial diffusivity) between groups. We evaluated global brain, white, and gray matter atrophy with SIENAX. Averaged, standard diffusion parameters were calculated in four compartment: periventricular lesioned and normal appearing white matter, non-periventricular lesioned and normal appearing white matter. PLS regression was used to identify which diffusion parameter and in which compartment best predicts the brain atrophy and clinical disability.

Results: In our diffusion tensor imaging study compared to controls we found extensive alterations of fractional anisotropy, mean and radial diffusivity and smaller changes of axial diffusivity (maximal $p>0.0002$ ) in patients that suggested demyelination in the lesioned and in the normal appearing white matter. We found significant reduction in total brain, total white, and gray matter (patients: $718.764 \pm 14.968,323.237 \pm 7.246$, $395.527 \pm 8.050 \mathrm{~cm}^{3}$, controls: 791.772 \pm 22.692, $355.350 \pm 10.929,436.422 \pm 12.011 \mathrm{~cm}^{3}$; mean $\left.\pm \mathrm{SE}\right),(p<0.015$; $p<0.0001 ; p<0.009$; respectively) of patients compared to controls. The PLS analysis revealed a combination of demyelination-like diffusion parameters (higher mean and radial diffusivity in patients) in the lesions and in the non-lesioned periventricular white matter, which best predicted the gray matter atrophy $(p<0.001$ ). Similarly, EDSS was best predicted by the radial diffusivity of the lesions and 
the non-lesioned periventricular white matter, but axial diffusivity of the periventricular lesions also contributed significantly $(p<0.0001)$.

Interpretation: Our investigation showed that gray matter atrophy and white matter demyelination are related in MS but white matter axonal loss does not significantly contribute to the gray matter pathology.

Keywords: brain atrophy, demyelination, normal-appearing white matter, periventricular white matter, multiple sclerosis

\section{INTRODUCTION}

Multiple sclerosis is an inflammatory, demyelinating, neurodegenerative disease of the central nervous system. Besides the white matter lesions, which are the diagnostic cornerstones of the disease, increasing attention is being paid to gray matter atrophy, which has recently become a tool for the follow-up of the therapeutic efficacy (Kincses et al., 2014; De Stefano et al., 2016). The importance of the gray matter atrophy lies in the high correlation with the clinicocognitive functioning (Roosendaal et al., 2011; Batista et al., 2012). However, the exact mechanism of the atrophy is not well-understood yet.

The demyelination in the gray matter is comparable in extent to that in the white matter (Gilmore et al., 2009). Ex-vivo studies have shown that the demyelination is mainly subpial (Type III lesions) and presents in the form of ribbons, often affecting several adjacent gyri. This kind of cortical demyelination proved to be associated with meningeal inflammation. Earlier studies found that a non-targeted general immunopathological response arising from this meningeal inflammation and mediated by the cerebrospinal fluid is responsible for the cortical pathology (Magliozzi et al., 2010; Lisak et al., 2012).

Along these lines, Jehna et al. reported a correlation between the increased periventricular lesion burden and the cortical atrophy in multiple sclerosis patients, which strongly supports the concept of a common cerebrospinal fluid-mediated pathology in the cortex and in the periventricular white matter (Jehna et al., 2015).

In contrast, leukocortical lesions (Type I) are almost as abundant as subpial lesions (Wegner et al., 2006), and neuronal loss was detected in regions where no B-cell follicle-like structures were detected. These findings suggest that other mechanisms are also involved in the cortical atrophy. Remote axonal transections (putatively related to lesion formation in the white matter and demyelination) have also been suggested to account for the cortical atrophy. The dying-back axonopathy could ultimately result in atrophy of the cortical gray matter (Trapp and Nave, 2008; Geurts et al., 2012). The reduced cortical input might also lead to plastic changes, such as a reduction in synaptic density, which might also present in the form of cortical atrophy. This hypothesis is strengthened by the findings that most significant cortical atrophy in multiple sclerosis is in association cortices such as the cingulate cortex, which has extensive cortico-cortical connections (Charil et al., 2007).
Magnetic resonance spectroscopy studies demonstrated a low level of $\mathrm{N}$-acetyaspartate-a marker of neuronal viability-in the normal appearing white matter of multiple sclerosis patients, indicating loss or dysfunctional axons (Fu et al., 1998; Wood et al., 2012). It was shown that the $\mathrm{N}$-acetyaspartate/myoinositol ratio-a putative marker of reduced neuronal integrity and increased gliosis-significantly contributes to brain volume change (Llufriu et al., 2014). The myelin pathology in the normal appearing white matter as measured by magnetization transfer ratio was also correlated to the cerebral atrophy and disability (Vrenken et al., 2007).

Based on the above mentioned results we aimed to investigate the contribution of the white matter pathology to the cortical atrophy in multiple sclerosis. Firstly, we explored if the focal lesional pathology or the more diffuse pathology of the normal appearing white matter contributes more to the gray matter atrophy. Secondly, based on Jehna's results (Jehna et al., 2015), we investigated if the periventricular white matter has a special role in the development of gray matter atrophy.

We used diffusion tensor imaging to investigate the white matter pathology. Diffusion tensor imaging describes the diffusion of water in biological tissues non-invasively. The molecular diffusion is hindered by cellular elements (mainly membranes), and hence the diffusion profile of the water can reveal microscopic details about the tissue architecture. Importantly, axon loss and demyelination cause different diffusion profile alterations. The changes in axial diffusivity relates to axon damage, while the alterations of radial diffusivity refer to myelin damage, which in our study we will allude to as demyelination-like diffusion parameters.

Gray matter atrophy defined by demyelination-like diffusion features would support the common origin of white matter demyelination and gray matter atrophy (possibly a common cerebrospinal fluid-mediated pathology of the gray matter and the periventricular white matter; Hypothesis 1). Gray matter atrophy related to an axon loss-like diffusion pattern would suggest the causative factor of remote axonal transection in gray matter atrophy (Hypothesis 2).

The contribution of pattern of diffusion parameters to the gray matter atrophy was investigated by model-free partial least square approach. When the predictors are highly collinear, as it is expected in case of diffusion parameters, the use of conventional regression analysis is not recommended. Partial least squares not only deals with the issue of collinearity, but offers to identify a pattern of parameters that best predicts the variable to be explained. 


\section{MATERIALS AND METHODS}

\section{Subjects}

The study was conducted on 52 patients with a diagnosis of relapsing remitting multiple sclerosis and 50 healthy, agematched volunteer controls with no history of any neurological or psychiatric diseases. Patients were recruited from the Multiple Sclerosis Outpatient Clinic at the Department of Neurology. The diagnosis was based on the 2005 revision of the McDonald criteria (Polman et al., 2005). The clinical disability of the patients, as measured on the Kurtzke expanded disability status scale (EDSS; Kurtzke, 1983), was $1.66 \pm 1.44$. All patients were on disease-modifying therapy (Table 1). All patients were in a stable clinical condition, no relapses and no EDSS progression had occurred in the preceding 6 months.

The study was approved by the ethics committee of the Medical University of Szeged and all study participants gave their written informed consent in accordance with the Declaration of Helsinki (Ref. No. 56/2011).

\section{Image Acquisition}

MR imaging were carried out on a 1.5T GE Signa Excite HDxt MR scanner. 3D spoiled gradient echo (FSPGR: TE: $4.1 \mathrm{~ms}$, TR: $10.276 \mathrm{~ms}$, matrix: $256 \times 256$, FOV: $25 \times 25 \mathrm{~cm}$, Flip angle: $15^{\circ}$, in-plane resolution: $1 \times 1 \mathrm{~mm}$, slice thickness: 1 mm), FLAIR (TE: $4.1 \mathrm{~ms}$, TR: $10.276 \mathrm{~ms}$, matrix: $256 \times 256$, FOV: $25 \times 25 \mathrm{~cm}$, Flip angle: $15^{\circ}$, in-plane resolution: $1 \times 1$ $\mathrm{mm}$, slice thickness: $1 \mathrm{~mm}$ ) and 60 direction diffusion-weighted images with 6 non-diffusion-weighted reference volumes (TE: $93.8 \mathrm{~ms}$, TR: $16000 \mathrm{~ms}$, matrix: $96 \times 96$, FOV: $23 \times 23 \mathrm{~cm}$, Flip angle: $90^{\circ}$, in-plane resolution: $2.4 \times 2.4 \mathrm{~mm}$ slice thickness: $2.4 \mathrm{~mm}$, b: $1000 \mathrm{~s} / \mathrm{mm}^{2}$, NEX: 2, ASSET) were acquired for all subjects.

\section{Lesion Distribution}

Manual lesion segmentation was carried out on the FLAIR images by the first author and supervised by ZTK, who has substantial experience in multiple sclerosis neuroradiology. FLAIR images were registered to the high-resolution T1 images with 6 degree-of-freedom linear registration (Jenkinson et al., 2002). High-resolution T1 images were registered to standard space images with 12 degree-of-freedom affine registration and were refined by non-linear registration implemented in FNIRT (Andersson et al., 2007). Binary lesion masks were transformed

TABLE 1 | Demographic and clinical data on the participating subjects.

\begin{tabular}{lcc}
\hline & Patients & Controls \\
\hline$n$ & 52 & 50 \\
Age (years; mean $\pm S D)$ & $40.87 \pm 10.31$ & $37.14 \pm 10.77$ \\
Sex (male) & 13 & 20 \\
$\begin{array}{l}\text { Disease duration (years; } \\
\text { mean } \pm S D \text { ) }\end{array}$ & $9.69 \pm 7.188$ & N.A. \\
EDSS score & $1.66 \pm 1.44$ & N.A. \\
Therapy & Interferon beta: 25, Glatiramer & \\
& acetate: 16, Fingolimod: 1 &
\end{tabular}

to standard space by using the transformation matrices and warp fields from the above-mentioned registrations. Standard space masks were thresholded at 0.5 and binarized again in order to avoid the size increment of the mask caused by the trilinear interpolation. Binary masks were summed in order to provide a lesion probability distribution.

\section{Diffusion Tensor Analysis}

Diffusion data were corrected for Eddy currents and movement artifacts by 12 degree-of-freedom affine linear registration to the first non-diffusion-weighted reference image. Diffusion images were processed by using FDT (FMRIB's Diffusion Toolbox part of FSL: http://www.fmrib.ox.ac.uk/fsl/fdt/). Fractional anisotropy, mean diffusivity $\left[\left(\lambda_{1}+\lambda_{2}+\lambda_{3}\right) / 3\right)$, axial diffusivity $\left(\lambda_{1}\right)$ and radial diffusivity $\left(\left(\lambda_{2}+\lambda_{3}\right) / 2\right]$ to the principal diffusion direction were computed for the whole brain.

We used the Tract-Based Spatial Statistics (TBSS) method to reduce possible errors resulting from misalignment of the images: A non-linear registration tool (FNIRT), which uses a b-spline representation of the registration warp field, aligned all fractional anisotropy images to a $1 \times 1 \times 1 \mathrm{~mm}$ FMRIB58_FA standard space. We brought the data on all patients into the standard space, and created the mean fractional anisotropy image, which was then fed into the fractional anisotropy skeletonization program, thresholded at fractional anisotropy 0.2 to create a mean fractional anisotropy skeleton that represented the centers of all tracts common to the group. The aligned fractional anisotropy data on each subject was then projected onto this skeleton, which resulted in the $4 \mathrm{D}$ skeletonized fractional anisotropy image. The resulting data was fed into voxel-wise cross-subject statistics.

With the use of a non-parametric permutation-based cluster analysis (5,000 permutation) as implemented in FSL, modeling and inferring, we accomplished the standard general linear model (GLM) design. The design encoded for group membership. Statistical tresholding was carried out with Threshold Free Cluster Enhancing (TFCE) approach $(p<0.05$ was chosen as threshold and the results are corrected for multiple comparisons across space).

\section{Evaluation of Global Atrophy}

We calculated the total brain volume with SIENAX (Smith et al., 2002), part of FSL (Smith et al., 2004; Jenkinson et al., 2012). SIENAX started by extracting brain and skull images from the single whole-head input data (Smith et al., 2002). We then carried out tissue-type segmentation with partial volume estimation (Zhang et al., 2001) in order to calculate the total volume of brain tissue (including separate estimates of volumes of total gray matter, peripheral gray matter and white matter). The area under the binary lesion masks were "filled" with intensities that are similar to those in the non-lesioned neighborhood, to reduce the bias caused by the T1 hypointense lesions (Battaglini et al., 2012).

We performed volumetric comparison across groups and the correlation tests with the Statistical Package for Social Sciences (SPSS 17 for OS X, SPSS Inc., http://www.spss.com). 


\section{Relationship of Brain Atrophy and the Compartmental Diffusion Metrics}

A voxel-wise alteration of the diffusion parameters was calculated for each patient, by comparing the value of every voxel with the distribution from the normal subjects in the spatially matching voxel (z-score). To identify a global white matter damage we calculate the averages of these $\mathrm{z}$-scores:

$$
\begin{aligned}
\bar{X}_{n} & =\frac{\sum_{i=1}^{q} X_{n, i}}{q}, \\
\delta_{n} & =\frac{\sum_{i=1}^{q}\left(\bar{X}_{n}-X_{n, i}\right)}{q}, \\
Z_{X, n, j} & =\frac{X_{n, j}-X_{n}}{\delta_{n}},
\end{aligned}
$$

where $X$ is the measured diffusion parameter (fractional anisotropy, mean diffusivity, axial diffusivity, and radial diffusivity) in the $n^{\text {th }}$ voxel in the skeleton. Indices $i$ and $j$ are for controls and patients, respectively.

The average diffusion parameters were calculated for each patient in the following compartments: periventricular lesions, non-periventricular lesions, periventricular normal white matter, and non-periventricular normal white matter.

To define the periventricular space the ventricles were manually segmented on the $1 \times 1 \times 1 \mathrm{~mm}$ FMRIB58_FA image dilated by three voxels similar to Jehna et al. (2015). The nonperiventricular white matter was defined as the rest of the white matter, periventricular part excluded.

The lesions were projected to the fractional anisotropy skeleton. The manually segmented lesions were brought to the diffusion data space with 6 degree-of-freedom linear registration. Through use of the warp field and the skeleton projections of the TBSS analysis of the fractional anisotropy images, the lesion mask was brought to the skeleton with the FSL tbss_non_fa algorithm. The mask was finally thresholded at 0.5 and binarized to avoid any size increment arising from the interpolation.

We used Partial least square regression analysis to estimate the contributions of the calculated compartmental diffusion parameters to the EDSS, gray matter and global brain atrophy. If $Y$ is an $n \times q$ matrix of dependent variables over $n$ observations and $X$ is an $n \times p$ matrix of predictors, Partial least squares successively extracts latent variables (factors and loadings) from $X$ and $Y$ in such a way that covariance between the factors and loadings is maximized. With this approach, Partial least squares reduces the dimensionality of the data by providing a weighted linear combination of $X$ variables to form orthogonal components that predicts the dependent variable. In mathematical terms, Partial least squares is a linear decomposition of $X$ and $Y$ such that

$$
\begin{aligned}
& X=T P^{T}+E, \\
& Y=U Q^{T}+F
\end{aligned}
$$

and the covariance between $T$ and $U$ is maximum (Abdi and Williams, 2013). In the above equations, $T$ is the $n \times r X$ scores, $U$ is the $n \times r Y$ scores, $P$ is the $p \times r X$ loadings, $Q$ is the $1 \times r Y$ loadings, $E$ and $F$ are residuals, and $r$ is the number of extracted latent variables. The statistical inference on the significance of the latent variable was carried out by permutation tests on the singular values of the decomposition. The elements of the dependent variable matrix were randomly permuted 5,000 times and the singular value was recalculated to depict a null distribution. The summary of the importance for the $X$ loadings was calculated by a Variable Importance in the Projection score (Wold et al., 1994). Since the average of squared Variable Importance in the Projection scores is equal to 1 , the " $>1$ " rule was used for the selection of the important variables.

In the current setting, the dependent variable $(Y)$ is the normalized brain or gray matter volume or EDSS, the predictors $(X)$ are the diffusion parameters in the different compartments (periventricular and non-periventricular $\bar{Z}_{F A}, \bar{Z}_{M D}, \bar{Z}_{A D}$, and $\bar{Z}_{R D}$ ), and the observations are the patients. The $X$ loadings are the optimum weights of the compartmental diffusion parameters which best predict the peripheral gray matter atrophy or EDSS.

\section{RESULTS}

\section{Lesion Probability Distribution}

The average native space lesion load was $12.328 \pm 16.100 \mathrm{~cm}^{3}$ (mean $\pm S D$ ) and the lesion load normalized to the intracranial volume (v scaling factor) was $17.087 \pm 22.509 \mathrm{~cm}^{3}$ (mean \pm $S D)$. The normalized lesion volume showed a negative correlation with the normalized gray matter volume $(R=-0.32, p<0.021)$, but no correlation was found with the normalized brain volume. The lesion load did not correlate with the EDSS of the patients either.

The lesions were distributed across widespread white matter regions, but the lesion probability was highest in the periventricular white matter (Figure 1 first row).

\section{Atrophy and Diffusion Alterations in Multiple Sclerosis}

The SIENAX analysis revealed reduction in total brain volume (patients: $718.764 \pm 14.968 \mathrm{~cm}^{3}$, controls: $791.772 \pm 22.692$; mean \pm SE), total white matter (patients: $323.237 \pm 7.246 \mathrm{~cm}^{3}$, controls: $355.350 \pm 10.929$; mean $\pm \mathrm{SE}$ ), and total gray matter (patients: $395.527 \pm 8.050 \mathrm{~cm}$, controls: $436.422 \pm 12.011$; mean $\pm \mathrm{SE}$ ) volume in the multiple sclerosis patients compared to controls (normalized to the premorbid brain volume, the normality of the data was violated in the Kolmogorov-Smirnov test, and hence the non-parametric Mann-Whitney $U$-test was used: $p<0.015 ; p<0.0001$; and $p<0.009$, respectively; Figure 2).

Relative to the healthy controls, TBSS indicated significant reductions of fractional anisotropy $(p<0.0002)$ in the multiple sclerosis patients: in essentially all the white matter fiber bundles, with the exception of the area of the corticospinal tract (Figure 1 second row). The mean diffusivity was increased $(p<0.0002)$ in the majority of the white matter bundles but not in the corticospinal tracts and the inferior longitudinal fasciculus 


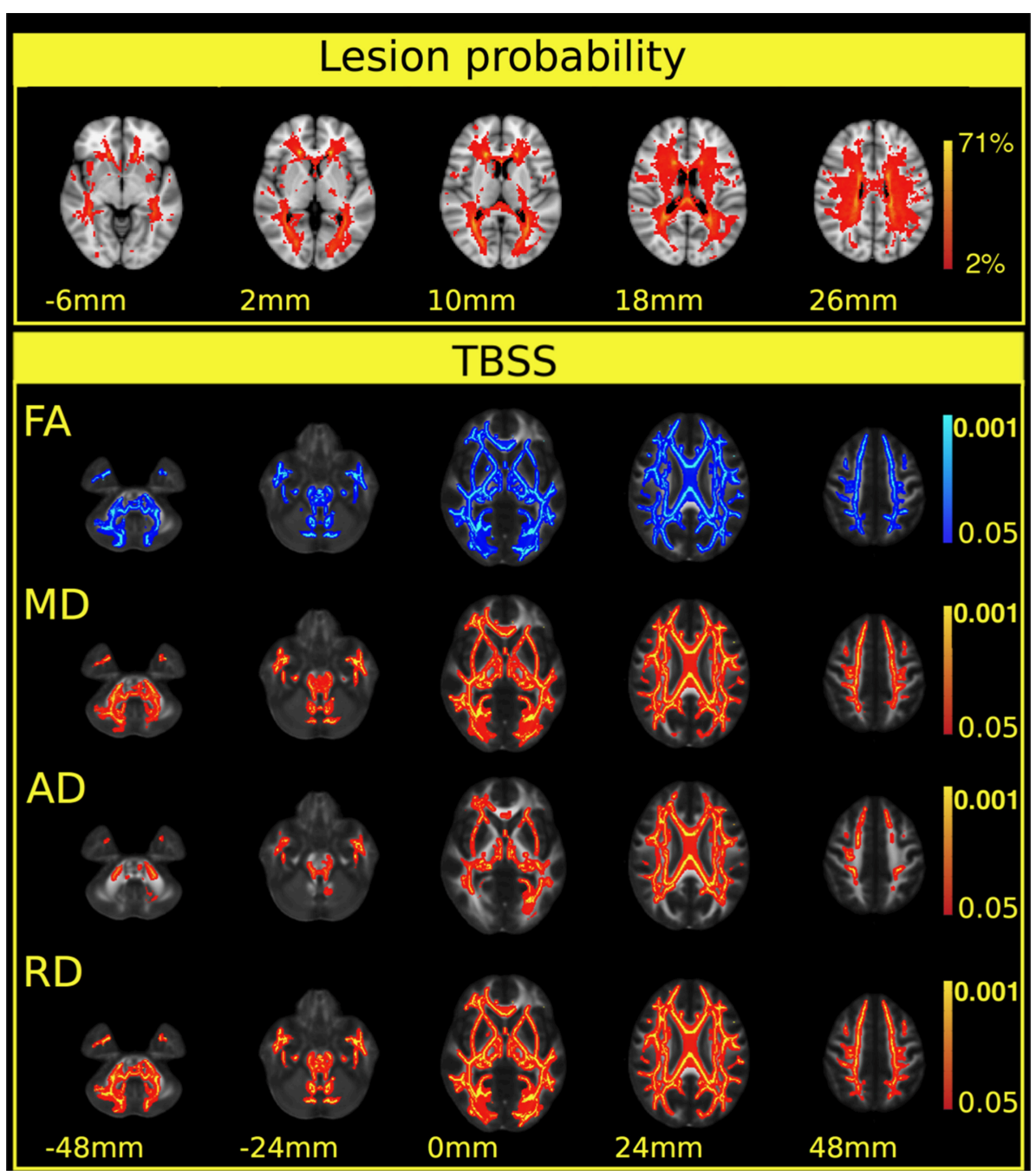

FIGURE 1 | Extensive diffusion parameter changes and cortical atrophy were found in multiple sclerosis patients. The first row depicts the lesion probability map of the 52 patients. The colorbar represents the number of patients having a lesion in a particular localization. The lesion probability map was overlaid on the MN152 standard brain. The z coordinates of the selected slices are shown below the images. The next section of the Figure depicts the results of the TBSS analysis. Significant differences in FA, MD, and axial and radial diffusivity between patients and controls in the white matter skeleton are shown in the consecutive rows. A blue color indicates decrease, and red-to-yellow colors an increase in the given diffusion parameters. A thickened version of the significant cluster is used for easier visualization (red-to-yellow or blue shades). Colorbars represent $p$-values (corrected for multiple correlation). Statistical images are overlaid on the FMRIB58_FA standard FA template and the $z$ coordinates are shown below the images. The $z$-values under the significant corrected $p$-values $(p<0.05)$ are shown. Images are overlaid on the MNI152 standard brain and the z coordinates are shown under the images.

(Figure 1 third row, Table 2). The radial diffusivity also displayed a significant increase $(p<0.0002)$ in all examined fibers in the skeleton, apart from the corticospinal tracts (Figure 1 fourth row, Table 2). Importantly, the white matter, diffusion alterations (fractional anisotropy, mean diffusivity, and radial diffusivity) were distributed in the normal-appearing white matter and also in the periventricular white matter where lesions appeared with high probability.

In contrast, an increase in axial diffusivity was found only in the more central fibers and in the intrathalamic white matter $(p<0.0002)$ in the corpus callosum, the superior longitudinal fasciculus, the superior corona radiate, the inferior fronto-occipital fasciculus, the posterior and anterior thalamic radiation, and the internal capsule (Figure 1 fifth row, Table 2).

\section{The Relationship of Brain Atrophy and the Compartmental White Matter Pathology}

In the first Partial least squares analysis the normalized gray matter volume was used as dependent variable. Only the first latent variable was evaluated, because the second latent variable explained only a small fraction of the variance of the dependent measure $(<5 \%)$ and the permutation test revealed a nonsignificant latent variable. The permutation test indicated that the 


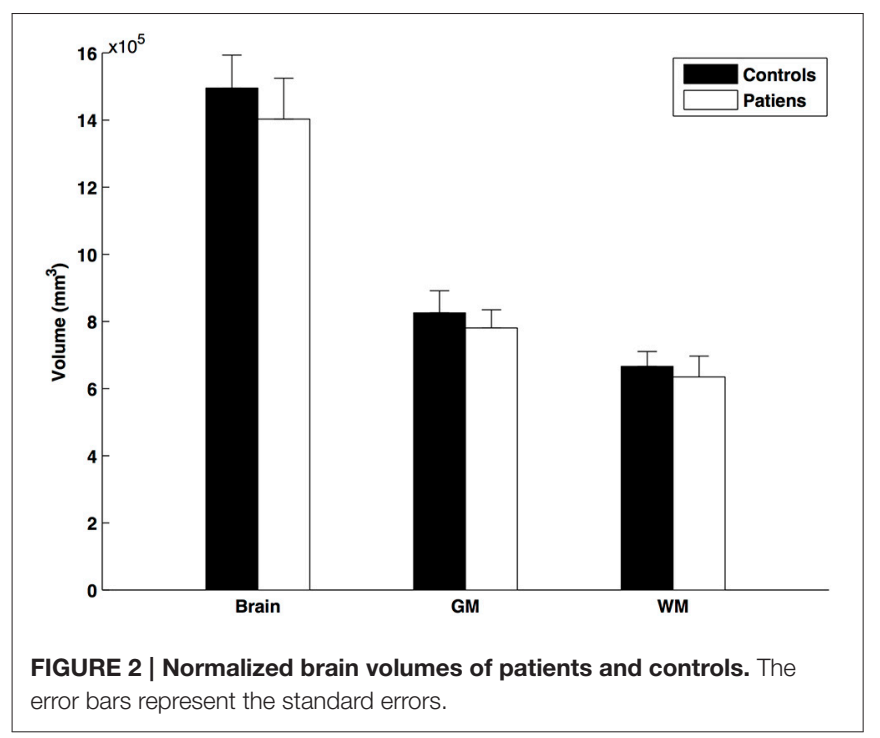

TABLE 2 | The local maxima of significant group differences for AD, RD, and FA as fund by FSL's cluster algorithm.

\begin{tabular}{|c|c|c|c|c|}
\hline & Anatomy & $\mathbf{x}$ & $\mathbf{y}$ & $\mathbf{z}$ \\
\hline \multirow[t]{6}{*}{$A D$} & Right Inferior fronto-occipital fasciculus & 26 & 23 & 14 \\
\hline & Left Inferior fronto-occipital fasciculus L & -25 & 25 & 14 \\
\hline & Forceps minor & -10 & 26 & 14 \\
\hline & Forceps major & -25 & -72 & 15 \\
\hline & Forceps major & -26 & -67 & 15 \\
\hline & Forceps major & -29 & -62 & 15 \\
\hline \multirow[t]{6}{*}{$\mathrm{RD}$} & Forceps minor & 21 & 21 & 34 \\
\hline & Right inferior fronto-occipital fasciculus & 30 & 37 & -1 \\
\hline & Forceps minor & -8 & 36 & -1 \\
\hline & Right Inferior fronto-occipital fasciculus & 32 & 11 & -1 \\
\hline & Left Inferior front-occipital fasciculus & -32 & 8 & -1 \\
\hline & Right superior longitudinal fasciculus & 34 & -46 & 21 \\
\hline \multirow[t]{6}{*}{ MD } & Forceps minor & -10 & 33 & 2 \\
\hline & Right superior longitudinal fasciculus & 34 & 2 & 32 \\
\hline & Right Inferior fronto-occipital fasciculus & 32 & 8 & 2 \\
\hline & Right superior longitudinal fasciculus & 34 & -3 & 2 \\
\hline & Left superior longitudinal fasciculus & -30 & 3 & 32 \\
\hline & Left Cingulum & -20 & -45 & 2 \\
\hline \multirow[t]{6}{*}{ FA } & Right inferior fronto-occipital fasciculus & 27 & 38 & -2 \\
\hline & Right inferior fronto-occipital fasciculus & 28 & 40 & -2 \\
\hline & Forceps minor & 20 & 45 & -2 \\
\hline & Left inferior fronto-occipital fasciculus & -28 & -82 & -1 \\
\hline & Left inferior fronto-occipital fasciculus & -31 & -70 & -1 \\
\hline & Right Cingulum & 22 & -60 & -1 \\
\hline
\end{tabular}

$x, y$, and $z$ coordinates are in MNI space. $p<0.0001$ in all cases. Anatomical localizations are given according to the John Hopkins University white-matter tractography atlas as implemented in fslview (Hua et al., 2008).

first latent variable was significant $(p<0.001)$ and accounted for $47.3 \%$ of the variation of the dependent variable and $76.5 \%$ of the predictors. The $X$ loadings and the corresponding
TABLE 3 | The loadings and VIP scores predicting the normalised brain volume

\begin{tabular}{|c|c|c|c|}
\hline Diffusion parameter & Compartment & Loadings & VIP-scores \\
\hline \multirow[t]{4}{*}{ FA } & Non-PV Lesioned & 5.11 & 0.56 \\
\hline & PV Lesioned & 4.43 & 0.49 \\
\hline & PV Non-lesioned & 4.37 & 0.88 \\
\hline & Non-PV Non-lesioned & 3.14 & 0.50 \\
\hline \multirow[t]{4}{*}{ MD } & Non-PV Lesioned & -12.46 & $1.43^{*}$ \\
\hline & PV Lesioned & -10.54 & $1.25^{\star}$ \\
\hline & PV Non-lesioned & -6.94 & $1.45^{\star}$ \\
\hline & Non-PV Non-lesioned & -4.38 & 0.58 \\
\hline \multirow[t]{4}{*}{$A D$} & Non-PV Lesioned & -6.48 & 0.76 \\
\hline & PV Lesioned & -6.73 & 0.85 \\
\hline & PV Non-lesioned & -3.40 & 0.75 \\
\hline & Non-PV Non-lesioned & -1.37 & 0.15 \\
\hline \multirow[t]{4}{*}{$\mathrm{RD}$} & Non-PV Lesioned & -11.47 & $1.28^{*}$ \\
\hline & PV Lesioned & -10.03 & $1.18^{*}$ \\
\hline & PV Non-lesioned & -7.90 & $1.66^{*}$ \\
\hline & Non-PV Non-lesioned & -5.01 & 0.75 \\
\hline
\end{tabular}

*VIP scores higher than 1 were considered to indicate a significant contribution.

Variable Importance in the Projection scores indicated that the mean diffusivity and radial diffusivity of the lesioned and nonlesioned periventricular and the non-periventricular lesioned white matter contributed significantly to the gray matter atrophy (Figure 3, Table 3).

Similar results were found in the case of the normalized brain volume: only the first latent variable was significant according to the permutation test. The first latent variable accounted for $24.9 \%$ of the variation of the dependent variable and $76.7 \%$ of the predictors. $X$ loadings coding the optimum contrast of the predictors exhibited a similar pattern as for the gray matter volume.

In an analysis in which the EDSS was the dependent variable, the first latent variable was significant according to the permutation test $(p<0.001$, explained variance of the independent variable: $18.8 \%$, and of the predictors: $76.8 \%$ ). The $X$ loadings showed that the predictors of EDSS were very similar to those of the gray matter and the brain volume: the radial diffusivity and the mean diffusivity of the lesions had the largest effects on EDSS, irrespective of the distance from the ventricles. Furthermore, the radial diffusivity of the non-lesioned periventricular white matter and the axial diffusivity of the periventricular lesions contributed significantly (Figure 4).

\section{DISCUSSION}

In this diffusion tensor imaging study, we investigated the relationship between the gray matter atrophy and the microstructure of the white matter in four compartments in relapsing-remitting multiple sclerosis. We hypothesized that, 

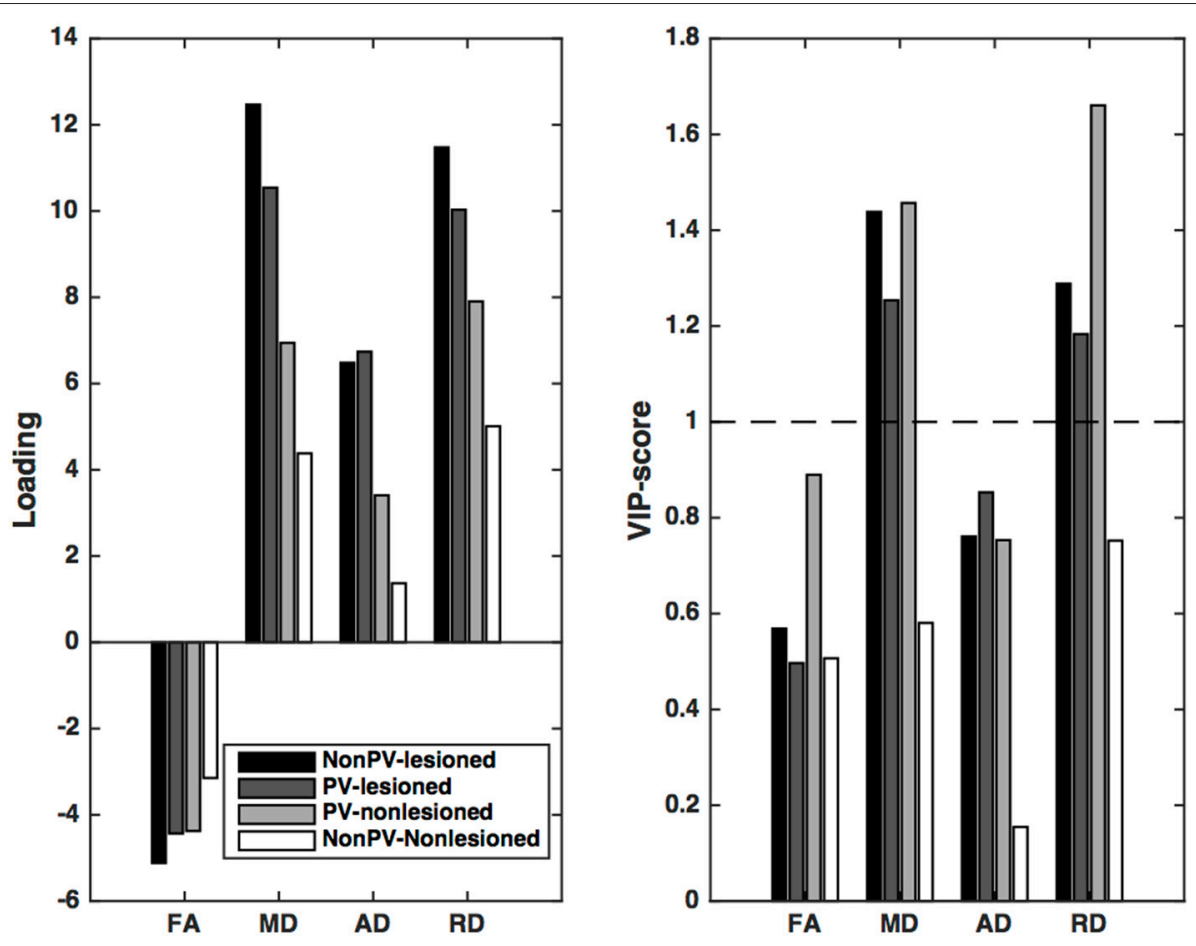

FIGURE 3 | Partial least squares loadings and VIP scores that describe the optimum contrast of the independent variables that predict the gray matter volume. From these loadings and VIP scores, it is conceivable the predominantly the diffusion parameters of the lesions and the non-lesioned periventricular white matter (PV-WM) drive the gray matter atrophy. Of the diffusion parameters, MD and RD, related most significantly to the gray matter atrophy. VIP scores are considered significant if higher than 1.

if the gray matter atrophy was related to axon-loss-like diffusion pattern alterations, that would be an indication of secondary cortical atrophy due to remote axonal transection. Alternatively, if the cortical atrophy correlated with a demyelination-like diffusion pattern, a common pathomechanism could be suspected. Furthermore, if predominantly the periventricular demyelination correlated with the atrophy, common cerebrospinal fluid mediated processes could be suspected. Our model-free, partial least squares analysis supported the second hypothesis, i.e., the gray matter atrophy was related predominantly to the increased mean diffusivity and radial diffusivity of the lesions and the periventricular non-lesioned white matter, a pattern of diffusion parameters that is a putative signature of demyelination. A similar pattern of relationship was found with the disability of the patients. In both cases, the alteration in axial diffusivity, a putative marker of axon loss, contributed less. Importantly, the pathology of the normalappearing white matter did not contribute significantly to the atrophy.

Previous studies have demonstrated that the different patterns of the diffusion parameter alterations may indicate various pathological white matter changes. In mouse models of multiple sclerosis (Song et al., 2005; Velicu et al., 2012), the changes observed in axial diffusivity and radial diffusivity were suggested to relate to axon or myelin damage, respectively. A mouse model study revealed a decreased fractional anisotropy in transected nerves, with the fractional anisotropy returning toward normal with axonal regeneration. Moreover, fractional anisotropy and axial diffusivity correlated significantly with the total number of axons (Lehmann et al., 2010). Three days after induction of ischaemia in the retina, a significant decrease in axial diffusivity was observed in mice without any detectable changes in radial diffusivity, which was consistent with the histological findings of significant axonal degeneration without demyelination. Two days later, consistently with the histological finding of myelin degeneration, the radial diffusivity was increased (Song et al., 2003). Work with a novel mouse model, that combined cuprizone-induced demyelination and experimental autoimmune encephalomyelitis indicated that axonal damage and cellular infiltration led to an alteration in axial diffusivity, whereas primary demyelination after cuprizone treatment was reflected by changes in radial diffusivity, but not in axial diffusivity (Boretius et al., 2012). Moreover, the myelin content in the postmortem human brain prior to and after fixation was predicted by the changes in radial diffusivity, fractional anisotropy and mean diffusivity (Schmierer et al., 2008).

According to the results described above, the diffusion parameter changes found in multiple sclerosis patients reflect widespread demyelination in the white matter. These results are similar to others presented earlier (Cifelli et al., 2002; Fabiano et al., 2003; Inglese et al., 2004; Poonawalla et al., 2008; Dineen et al., 2009; Roosendaal et al., 2009; Raz et al., 2010; Kern et al., 

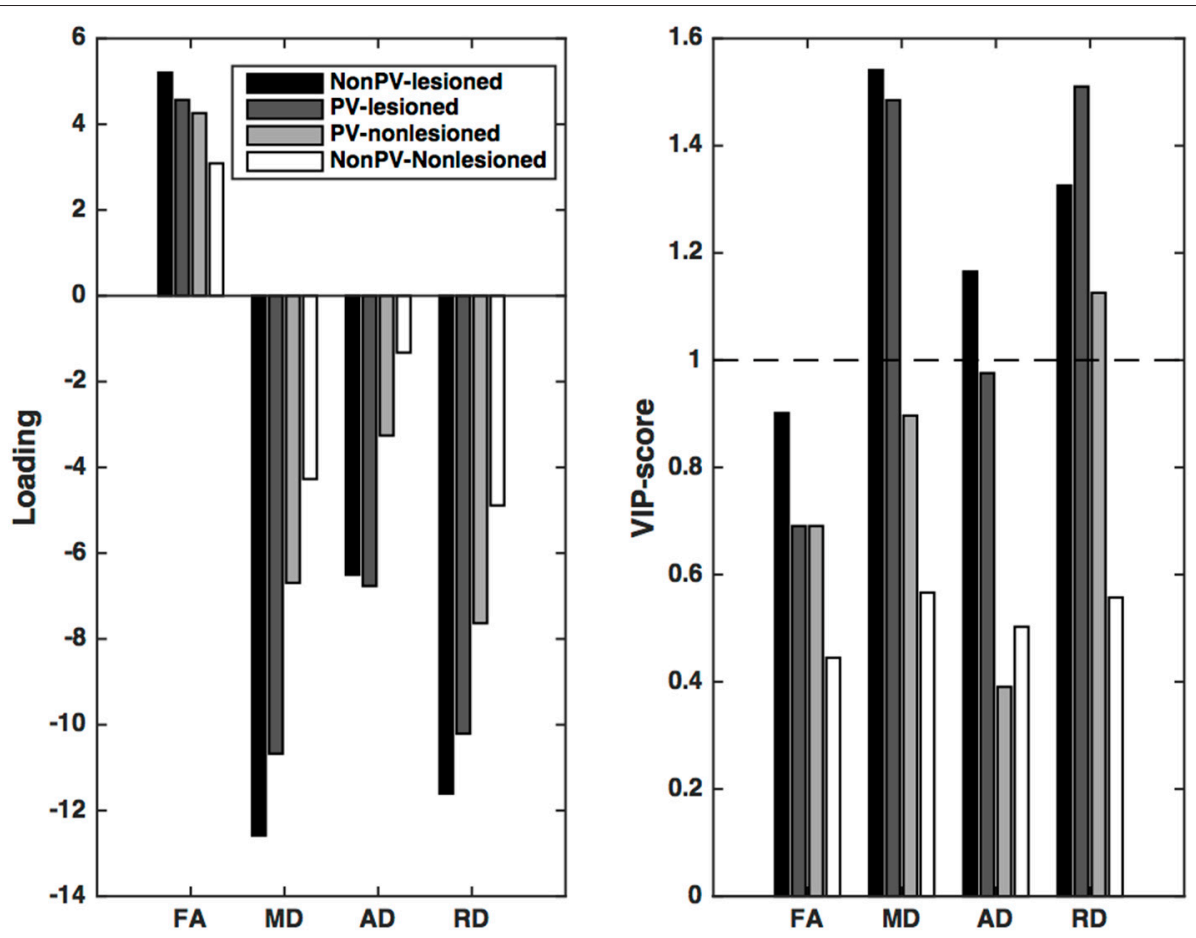

FIGURE 4 | Partial least squares loadings and VIP scores that describe the optimum contrast of the independent variables that predict the disability (EDSS) of the patients. EDSS can be predicted most significantly from the RD and MD of the lesions and the periventricular non-lesioned white matter. A further contribution can be seen from the AD change in the periventricular lesions. VIP scores are considered significant if higher than 1.

2011; Yu et al., 2012). However it is important to point out that we also found a signature of extensive demyelination in the normal appearing white matter, which was only rarely described in former diffusion tensor imaging studies. The high number of diffusion directions used in our study most probably increased the sensitivity of our investigation. A possible histopathological correlate of this change in mean diffusivity might be the lipid abnormality found in the diffusely abnormal white matter (Laule et al., 2013).

More importantly, a pattern of diffusion parameter changes resembling demyelination in the lesions and in the nonlesioned periventricular white matter was a strong predictor of gray matter atrophy. Furthermore, the microstructure of the non-periventricular normal-appearing white matter, even if it had significant demyelination, contributed less to the gray matter pathology. The relatively small contribution of axial diffusivity alterations to the gray matter atrophy, disprove our first hypothesis, that the cortical atrophy is secondary to axonal damage in the white matter. Alternatively, the diffusion measures have only a low sensitivity for axonal damage.

More interestingly, the demyelination-like pattern of diffusion parameters in the non-lesioned periventricular white matter strengthens the hypothesis of Jehna (Jehna et al., 2015) that periventricular demyelination and cortical atrophy are driven by the same process, most probably arising from the nearby Cerebrospinal fluid. Meningeal inflammation, B-cell follicle-like structures, $\mathrm{CD}^{+}$, and $\mathrm{CD} 8^{+}$T-cell infiltrates (Magliozzi et al.,
2010; Howell et al., 2011) were associated with subpial demyelination (Type III lesions) and cortical atrophy. Apart from the demyelination, a gradient of neuronal loss toward the pial surface was observed in the cortex, accompanied by astrocyte loss and, opposite to this gradient, microglia activation (Magliozzi et al., 2010). These findings are consistent with those of in vitro studies (Lisak et al., 2012) and suggest that a non-targeted general immunopathological response mediated by the B-cells and CD8 ${ }^{+}$ T-cells via cytotoxic tissue damage or indirectly through the activation of microglia might be responsible for the cortical pathology. A common pathomechanism behind the cortical demyelination and periventricular lesion is further strengthened by the spatial location of the abnormalities. Subpial lesions are frequently present around deep sulci that often have expanded Virchow-Robin space, a cerebrospinal fluid space with abundant immune cells (Trapp and Nave, 2008). The periventricular white matter has a special feature in contrast with other deep white matter regions, that it is in close proximity to the cerebrospinal fluid. Similarly, the periventricular lesions are often formed around the venules and the Virchow-Robin spaces have been shown to be enlarged in multiple sclerosis (Ge et al., 2005; Wuerfel et al., 2008).

Since the clinical disability and gray matter atrophy are highly correlated, it was expected that the pattern of diffusion parameters best predicting the EDSS would be similar to that of those predicting the gray matter volume. However, one crucial difference must be noted: the axial diffusivity of the 


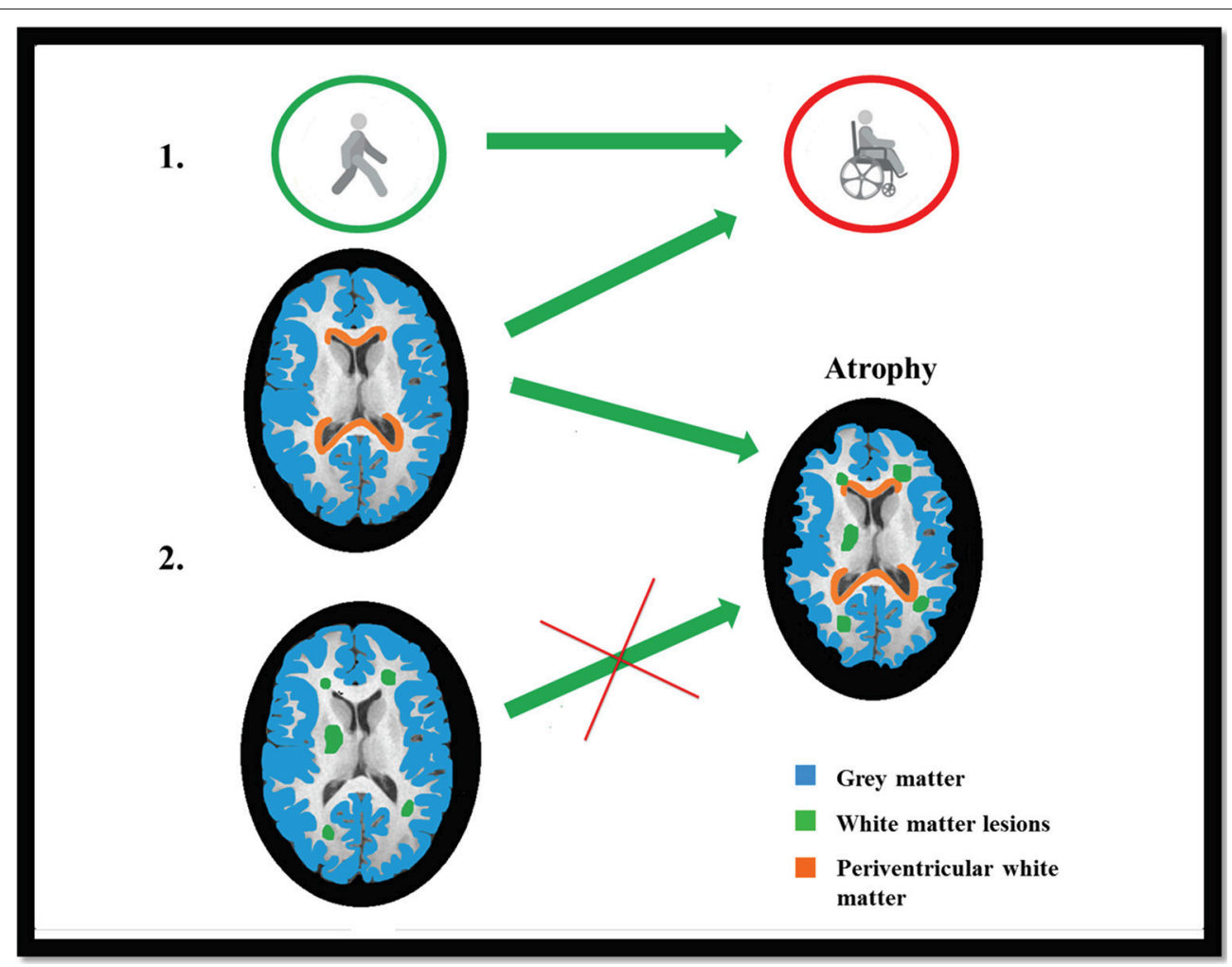

FIGURE 5 | Graphical Presentation: EDSS was best predicted by the radial diffusivity of the lesioned and non-lesioned periventricular white matter and also the axial diffusivity of the lesioned periventricular white matter (Part 1). The gray matter atrophy (marked with blue color) was best predicted by the combination of demyelination-like diffusion parameters (Hypothesis I.), in the lesions and in the non-lesioned periventricular white matter (marked with red color), but not by the axonloss-like diffusion parameters in the NAWM (Hypothesis II; lesions are marked with green color; Part 2).

periventricular lesions, a putative sign of axon damage, also contributed significantly to the disability. This finding confirms earlier results indicating a significant correlation between $\mathrm{N}$ acetyaspartate (a marker of neuronal/axonal integrity) and disability (Llufriu et al., 2014).

Our previous investigation also revealed that the pattern of various diffusion parameters can describe a pathology better than can the individual parameters (Kincses et al., 2013). The partial least squares analysis have a benefit over conventional multiple linear regression analyses as it can identify a pattern of predictors. It is especially useful in settings when the noncollinearity assumption is violated.

\section{CONCLUSIONS}

In our study we found extensive alterations in diffusion parameters in the patients that suggested demyelination in the high lesion burden periventricular white matter and in the normal-appearing white matter. In the patients we found significant brain, gray and white matter atrophy. The partial least squares analysis revealed a combination of demyelinationlike diffusion parameters, in the lesions and in the non-lesioned periventricular white matter which best predicted the gray matter atrophy. Similarly, EDSS was best predicted by the radial diffusivity of the lesions and the non-lesioned periventricular white matter. The periventricular lesion axial diffusivity also contributed significantly to the clinical disability.

The pathology of multiple sclerosis is a heterogeneous process, but our results demonstrate that even spatially remote processes may have common roots. The substance mediating between such processes might be the cerebrospinal fluid. Further studies are needed to reveal the factors that are responsible for the gray and white matter demyelination. We summarized our results in a Graphical presentation (Figure 5).

\section{AUTHOR CONTRIBUTIONS}

The authors concur with the submission of the manuscript and both authors have approved the final version. Everyone who was working on the manuscript is listed between the authors. ET and ZK: Design of the work, interpretation of data for the work, Drafting the work, Final approval of the version to be published, and Agreement to be accountable for all aspects of the work in ensuring that questions related to the accuracy. NS: Interpretation of data for the work, Drafting the work, Final approval of the version to be published, and Agreement to be accountable for all aspects of the work in ensuring that questions related to the accuracy. GC, AK, PF, and TS: Analysis, Revising 
the work critically for important intellectual content, Final approval of the version to be published, and Agreement to be accountable for all aspects of the work in ensuring that questions related to the accuracy. $\mathrm{KB}$ and LV: Substantial contributions to the conception, drafting the work, Final approval of the version to be published, and Agreement to be accountable for all aspects of the work in ensuring that questions related to the accuracy.

\section{REFERENCES}

Abdi, H., and Williams, L. J. (2013). Partial least squares methods: partial least squares correlation and partial least square regression. Methods Mol. Biol. 930, 549-579. doi: 10.1007/978-1-4614-8283-3

Andersson, J. L. R., Jenkinson, M., and Smith, S. (2007). Non-linear Optimisation. (Oxford: FMRIB technical report).

Batista, S., Zivadinov, R., Hoogs, M., Bergsland, N., Heininen-Brown, M., Dwyer, M. G., et al. (2012). Basal ganglia, thalamus and neocortical atrophy predicting slowed cognitive processing in multiple sclerosis. J. Neurol. 259, 139-146. doi: 10.1007/s00415-011-6147-1

Battaglini, M., Jenkinson, M., and De Stefano, N. (2012). Evaluating and reducing the impact of white matter lesions on brain volume measurements. Hum. Brain Mapp. 33, 2062-2071. doi: 10.1002/hbm.21344

Boretius, S., Escher, A., Dallenga, T., Wrzos, C., Tammer, R., Brück, W., et al. (2012). Assessment of lesion pathology in a new animal model of MS by multiparametric MRI and DTI. Neuroimage 59, 2678-2688. doi: 10.1016/j.neuroimage.2011.08.051

Charil, A., Dagher, A., Lerch, J. P., Zijdenbos, A. P., Worsley, K. J., and Evans, A. C. (2007). Focal cortical atrophy in multiple sclerosis: relation to lesion load and disability. Neuroimage 34, 509-517. doi: 10.1016/j.neuroimage.2006.10.006

Cifelli, A., Arridge, M., Jezzard, P., Esiri, M. M., Palace, J., and Matthews, P. M. (2002). Thalamic neurodegeneration in multiple sclerosis. Ann. Neurol. 52, 650-653. doi: 10.1002/ana.10326

De Stefano, N., Stromillo, M. L., Giorgio, A., Bartolozzi, M. L., Battaglini, M., Baldini, M., et al. (2016). Establishing pathological cut-offs of brain atrophy rates in multiple sclerosis. J. Neurol. Neurosurg. Psychiatry 87, 93-99. doi: 10.1136/jnnp-2014-309903

Dineen, R. A., Vilisaar, J., Hlinka, J., Bradshaw, C. M., Morgan, P. S., Constantinescu, C. S., et al. (2009). Disconnection as a mechanism for cognitive dysfunction in multiple sclerosis. Brain 132(Pt 1), 239-249. doi: 10.1093/brain/awn275

Fabiano, A. J., Sharma, J., Weinstock-Guttman, B., Munschauer, F. E. III, Benedict, R. H., Zivadinov, R., et al. (2003). Thalamic involvement in multiple sclerosis: a diffusion-weighted magnetic resonance imaging study. J. Neuroimaging 13, 307-314. doi: 10.1111/j.1552-6569.2003.tb00197.x

Fu, L., Matthews, P. M., De Stefano, N., Worsley, K. J., Narayanan, S., Francis, G. S., et al. (1998). Imaging axonal damage of normal-appearing white matter in multiple sclerosis. Brain 121 (Pt 1), 103-113.

Ge, Y., Law, M., Herbert, J., and Grossman, R. I. (2005). Prominent perivenular spaces in multiple sclerosis as a sign of perivascular inflammation in primary demyelination. AJNR Am. J. Neuroradiol. 26, 2316-2319.

Geurts, J. J., Calabrese, M., Fisher, E., and Rudick, R. A. (2012). Measurement and clinical effect of grey matter pathology in multiple sclerosis. Lancet Neurol. 11, 1082-1092. doi: 10.1016/S1474-4422(12)70230-2

Gilmore, C. P., Donaldson, I., Bö, L., Owens, T., Lowe, J., and Evangelou, N. (2009). Regional variations in the extent and pattern of grey matter demyelination in multiple sclerosis: a comparison between the cerebral cortex, cerebellar cortex, deep grey matter nuclei and the spinal cord. J. Neurol. Neurosurg. Psychiatry 80, 182-187. doi: 10.1136/jnnp.2008.148767

Howell, O. W., Reeves, C. A., Nicholas, R., Carassiti, D., Radotra, B., Gentleman, S. M., et al. (2011). Meningeal inflammation is widespread and linked to cortical pathology in multiple sclerosis. Brain 134 (Pt 9), 2755-2271. doi: 10.1093/brain/awr182

Hua, K., Zhang, J., Wakana, S., Jiang, H., Li, X., Reich, D. S., et al. (2008). Tract probability maps in stereotaxic spaces: analyses of white

\section{ACKNOWLEDGMENTS}

This paper was supported by the "Neuroscience Research Group of the Hungarian Academy of Sciences and University of Szeged," the National Brain Research Program (Grant No. KTIA_13_NAP-A-II/20.) and an EFOP grant (EFOP-3.6.1-162016-00008). NS was supported by the Bolyai Scholarship Program of the Hungarian Academy of Sciences.

matter anatomy and tract-specific quantification. Neuroimage 39, 336-347. doi: 10.1016/j.neuroimage.2007.07.053

Inglese, M., Ge, Y., Filippi, M., Falini, A., Grossman, R. I., and Gonen, O. (2004). Indirect evidence for early widespread gray matter involvement in relapsing-remitting multiple sclerosis. Neuroimage 21, 1825-1829. doi: 10.1016/j.neuroimage.2003.12.008

Jehna, M., Pirpamer, L., Khalil, M., Fuchs, S., Ropele, S., Langkammer, C., et al. (2015). Periventricular lesions correlate with cortical thinning in multiple sclerosis. Ann. Neurol. 78, 530-539. doi: 10.1002/ana.24461

Jenkinson, M., Bannister, P., Brady, M., and Smith, S. (2002). Improved optimization for the robust and accurate linear registration and motion correction of brain images. Neuroimage 17, 825-841. doi: 10.1006/nimg.2002.1132

Jenkinson, M., Beckmann, C. F., Behrens, T. E., Woolrich, M. W., and Smith, S. M. (2012). Fsl. Neuroimage 62, 782-790. doi: 10.1016/j.neuroimage.2011.09.015

Kern, K. C., Sarcona, J., Montag, M., Giesser, B. S., and Sicotte, N. L. (2011). Corpus callosal diffusivity predicts motor impairment in relapsing-remitting multiple sclerosis: a TBSS and tractography study. Neuroimage 55, 1169-1177. doi: 10.1016/j.neuroimage.2010.10.077

Kincses, Z. T., Horínek, D., Szabó, N., Tóth, E., Csete, G., Stepán-Buksakowska, I., et al. (2013). The pattern of diffusion parameter changes in Alzheimer's disease, identified by means of linked independent component analysis. J. Alzheimer's Dis. 36, 119-128. doi: 10.3233/JAD-122431

Kincses, Z. T., Tóth, E., Bankó, N., Veréb, D., Szabó, N., Csete, G., et al. (2014). Grey matter atrophy in patients suffering from multiple sclerosis. Ideggyogy. Sz. 67, 293-300.

Kurtzke, J. F. (1983). Rating neurologic impairment in multiple sclerosis: an expanded disability status scale (EDSS). Neurology 33, 1444-1452. doi: 10.1212/WNL.33.11.1444

Laule, C., Pavlova, V., Leung, E., Zhao, G., MacKay, A. L., Kozlowski, P., et al. (2013). Diffusely abnormal white matter in multiple sclerosis: further histologic studies provide evidence for a primary lipid abnormality with neurodegeneration. J. Neuropathol. Exp. Neurol. 72, 42-52. doi: 10.1097/NEN.0b013e31827bced3

Lehmann, H. C., Zhang, J., Mori, S., and Sheikh, K. A. (2010). Diffusion tensor imaging to assess axonal regeneration in peripheral nerves. Exp. Neurol. 223, 238-244. doi: 10.1016/j.expneurol.2009.10.012

Lisak, R. P., Benjamins, J. A., Nedelkoska, L., Barger, J. L., Ragheb, S., Fan, B., et al. (2012). Secretory products of multiple sclerosis B cells are cytotoxic to oligodendroglia in vitro. J. Neuroimmunol. 246, 85-95. doi: 10.1016/j.jneuroim.2012.02.015

Llufriu, S., Kornak, J., Ratiney, H., Oh, J., Brenneman, D., Cree, B. A., et al. (2014). Magnetic resonance spectroscopy markers of disease progression in multiple sclerosis. JAMA Neurol. 71, 840-847. doi:10.1001/jamaneurol.2014.895

Magliozzi, R., Howell, O. W., Reeves, C., Roncaroli, F., Nicholas, R., Serafini, B., et al. (2010). A Gradient of neuronal loss and meningeal inflammation in multiple sclerosis. Ann. Neurol. 68, 477-493. doi: 10.1002/ana.22230

Polman, C. H., Reingold, S. C., Edan, G., Filippi, M., Hartung, H. P., Kappos, L., et al. (2005). Diagnostic criteria for multiple sclerosis: 2005 revisions to the “McDonald Criteria”. Ann. Neurol. 58, 840-846. doi: 10.1002/ana.20703

Poonawalla, A. H., Hasan, K. M., Gupta, R. K., Ahn, C. W., Nelson, F., Wolinsky, J. S., et al. (2008). Diffusion-tensor MR imaging of cortical lesions in multiple sclerosis: initial findings. Radiology 246, 880-886. doi: 10.1148/radiol.2463070486

Raz, E., Cercignani, M., Sbardella, E., Totaro, P., Pozzilli, C., Bozzali, M., et al. (2010). Clinically isolated syndrome suggestive of multiple sclerosis: voxelwise 
regional investigation of white and gray matter. Radiology 254, 227-234. doi: 10.1148/radiol.2541090817

Roosendaal, S. D., Bendfeldt, K., Vrenken, H., Polman, C. H., Borgwardt, S., Radue, E. W., et al. (2011). Grey matter volume in a large cohort of MS patients: relation to MRI parameters and disability. Multiple sclerosis 17, 1098-1106. doi: 10.1177/1352458511404916

Roosendaal, S. D., Geurts, J. J., Vrenken, H., Hulst, H. E., Cover, K. S., Castelijns, J. A., et al. (2009). Regional DTI differences in multiple sclerosis patients. Neuroimage 44, 1397-1403. doi: 10.1016/j.neuroimage.2008.10.026

Schmierer, K., Wheeler-Kingshott, C. A., Tozer, D. J., Boulby, P. A., Parkes, H. G., Yousry, T. A., et al. (2008). Quantitative magnetic resonance of postmortem multiple sclerosis brain before and after fixation. Magn. Reson. Med. 59, 268-277. doi: 10.1002/mrm.21487

Smith, S. M., Jenkinson, M., Woolrich, M. W., Beckmann, C. F., Behrens, T, E., Johansen-Berg, H., et al. (2004). Advances in functional and structural MR image analysis and implementation as FSL. Neuroimage 23(Suppl. 1), S208-S219. doi: 10.1016/j.neuroimage.2004.07.051

Smith, S. M., Zhang, Y., Jenkinson, M., Chen, J., Matthews, P. M., Federico, A., et al. (2002). Accurate, robust, and automated longitudinal and cross-sectional brain change analysis. Neuroimage 17, 479-489. doi: 10.1006/nimg.2002.1040

Song, S. K., Sun, S. W., Ju, W. K., Lin, S. J., Cross, A. H., and Neufeld, A. H. (2003). Diffusion tensor imaging detects and differentiates axon and myelin degeneration in mouse optic nerve after retinal ischemia. Neuroimage 20, 1714-1722.

Song, S. K., Yoshino, J., Le, T. Q., Lin, S. J., Sun, S. W., Cross, A. H., et al. (2005). Demyelination increases radial diffusivity in corpus callosum of mouse brain. Neuroimage 26, 132-140. doi: 10.1016/j.neuroimage.2005.01.028

Trapp, B. D., and Nave, K. A. (2008). Multiple sclerosis: an immune or neurodegenerative disorder? Annu. Rev. Neurosci. 31, 247-269. doi: 10.1146/annurev.neuro.30.051606.094313

Velicu, I. L., Neagu, M., Dobromir, M., Luca, D., Lupu, N., Chiriac, H., et al. (2012). Structural, magnetic and magnetoelastic behaviour of FeCuNbSiB thin films. Sensor Lett. 10, 902-905. doi: 10.1166/sl.2012.2346

Vrenken, H., Pouwels, P. J., Ropele, S., Knol, D. L., Geurts, J. J., Polman, C. H., et al. (2007). Magnetization transfer ratio measurement in multiple sclerosis normal-appearing brain tissue: limited differences with controls but relationships with clinical and MR measures of disease. Mult. Scler. 13, 708-716. doi: 10.1177/1352458506075521

Wegner, C., Esiri, M. M., Chance, S. A., Palace, J., and Matthews, P. M. (2006). Neocortical neuronal, synaptic, and glial loss in multiple sclerosis. Neurology 67, 960-967. doi: 10.1212/01.wnl.0000237551.26858.39

Wold, S., Johansson, E., and Cocchi, M. (1994). "PLS - Partial Least Squares Projections to Latent Structures," in 3D QSAR in Drug Design Volume 1: Theory Methods and Applications, ed H. Kubinyi (Leiden: ESCOM Science Publishers), 523-550.

Wood, E. T., Ronen, I., Techawiboonwong, A., Jones, C. K., Barker, P. B., Calabresi, P., et al. (2012). Investigating axonal damage in multiple sclerosis by diffusion tensor spectroscopy. J. Neurosci. 32, 6665-6669. doi: 10.1523/JNEUROSCI.0044-12.2012

Wuerfel, J., Haertle, M., Waiczies, H., Tysiak, E., Bechmann, I., Wernecke, K. D., et al. (2008). Perivascular spaces-MRI marker of inflammatory activity in the brain? Brain 131(Pt 9), 2332-2240. doi: 10.1093/brain/awn171

Yu, H. J., Christodoulou, C., Bhise, V., Greenblatt, D., Patel, Y., Serafin, D., et al. (2012). Multiple white matter tract abnormalities underlie cognitive impairment in RRMS. Neuroimage 59, 3713-3722. doi: 10.1016/j.neuroimage.2011.10.053

Zhang, Y., Brady, M., and Smith, S. (2001). Segmentation of brain MR images through a hidden Markov random field model and the expectation-maximization algorithm. IEEE Trans. Med. Imaging 20, 45-57. doi: $10.1109 / 42.906424$

Conflict of Interest Statement: The authors declare that the research was conducted in the absence of any commercial or financial relationships that could be construed as a potential conflict of interest.

Copyright (c) 2017 Tóth, Szabó, Csete, Király, Faragó, Spisák, Bencsik, Vécsei and Kincses. This is an open-access article distributed under the terms of the Creative Commons Attribution License (CC BY). The use, distribution or reproduction in other forums is permitted, provided the original author(s) or licensor are credited and that the original publication in this journal is cited, in accordance with accepted academic practice. No use, distribution or reproduction is permitted which does not comply with these terms. 


\section{OPEN ACCESS}

Edited by:

Jorge Matias-Guiu,

Complutense University of Madrid,

Spain

Reviewed by:

Franca Wagner,

Universitätsspital Bern, Switzerland

Nuria Campora,

Hospital Italiano de Buenos Aires,

Argentina

*Correspondence:

Zsigmond Tamás Kincses

kincses.zsigmond.tamas@ med.u-szeged.hu

Specialty section:

This article was submitted to

Multiple Sclerosis and

Neuroimmunology,

a section of the journal

Frontiers in Neurology

Received: 17 October 2018 Accepted: 18 December 2018

Published: 23 January 2019

Citation:

Tóth E, Faragó P, Király A, Szabó N,

Veréb $D$, Kocsis $K$, Kincses $B$, Sandi $D$, Bencsik $K$, Vécsei $L$ and Kincses ZT (2019) The Contribution of

Various MRI Parameters to Clinical and Cognitive Disability in Multiple Sclerosis. Front. Neurol. 9:1172. doi: 10.3389/fneur.2018.01172

\section{The Contribution of Various MRI Parameters to Clinical and Cognitive Disability in Multiple Sclerosis}

\author{
Eszter Tóth ${ }^{1}$, Péter Faragó ${ }^{1}$, András Király ${ }^{1}$, Nikoletta Szabó ${ }^{1}$, Dániel Veréb ${ }^{1}$, \\ Krisztián Kocsis ${ }^{1}$, Bálint Kincses ${ }^{1}$, Dániel Sandi ${ }^{1}$, Krisztina Bencsik ${ }^{1}$, László Vécsei ${ }^{1,2}$ and \\ Zsigmond Tamás Kincses ${ }^{1,3 *}$
}

${ }^{1}$ Department of Neurology, Albert Szent-Györgyi Clinical Centre, University of Szeged, Szeged, Hungary, ${ }^{2}$ MTA-SZTE Neuroscience Research Group, University of Szeged, Szeged, Hungary, ${ }^{3}$ Department of Radiology, Albert Szent-Györgyi Clinical Centre, University of Szeged, Szeged, Hungary

Next to the disseminated clinical symptoms, cognitive dysfunctions are common features of multiple sclerosis (MS). Over the recent years several different MRI measures became available representing the various features of the pathology, but the contribution to various clinical and cognitive functions is not yet fully understood. In this multiparametric MRI study we set out to identify the set of parameters that best predict the clinical and cognitive disability in MS. High resolution T1 weighted structural and high angular resolution diffusion MRI images were measured in 53 patients with relapsing remitting MS and 53 healthy controls. Clinical disability was inflicted by EDSS and cognitive functions were evaluated with the BICAMS tests. The contribution of lesion load, partial brain, white matter, gray matter and subcortical volumes as well as the diffusion parameters in the area of the lesions and the normal appearing white matter were examined by model free, partial least square (PLS) approach. Significance of the predictors was tested with Variable Importance in the Projection (VIP) score and 1 was used for threshold of significance. The PLS analysis indicated that the axial diffusivity of the NAWM contributed the most to the clinical disability (VIP score: 1.979). For the visuo-spatial working memory the most critical contributor was the size of the bilateral hippocampi (VIP scores: 1.183 and 1.2 left and right respectively). For the verbal memory the best predictors were the size of the right hippocampus (VIP score: 1.972), lesion load (VIP score: 1.274) and the partial brain volume (VIP score: 1.119). In case of the information processing speed the most significant contribution was from the diffusion parameters (fractional anisotropy, mean and radial diffusivity, VIP scores: 1.615, 1.321 respectively) of the normal appearing white matter. Our results indicate that various MRI measurable factors of MS pathology contribute differently to clinical and cognitive disability. These results point out the importance of the volumetry of the subcortical structures and the diffusion measures of the white matter in understanding the disability progression.

Keywords: multiple sclerosis, BICAMS, atrophy, demyelination, cognition 


\section{INTRODUCTION}

Multiple sclerosis (MS) is an inflammatory, demyelinating disease, which affects the central nervous system. Next to the disseminated clinical signs cognitive impairments are frequent symptoms, it can occur in $40-70 \%$ of the patients. Most commonly it affects the information processing speed, the episodic memory, the executive functions, and the visuospatial abilities. There are several psychometric surveys available, but the Brief International Cognitive Assessment for MS (BICAMS) allows a reliable, fast evaluation of the most frequently affected cognitive domains (1-3).

One of the most prominent feature of the disease is the white matter lesions identified on the MRI. The importance of these lesions is unquestionable and hence became cornerstone of the diagnosis (4) and the follow-up of therapeutic efficacy (5). However, the correlation of T2 lesion burden with clinical and cognitive impairment are modest at most, known as the clinio-radiological paradox $(6,7)$. Recently, increasing interest is shown about the gray matter (GM) atrophy, which has become an approach to follow-up of the therapeutic effectiveness $(8,9)$. The fact that it correlates stronger with the clinico-cognitive functioning gives the real importance of the GM $(10,11)$. While lesions and gray matter atrophy are non-specific to the underlying pathology, there are novel methods which better approximate the pathological processes. One of those is diffusion tensor imaging, which non-invasively depicts the diffusion of water in biological tissues. The molecular diffusion is blocked by cellular elements (primarily membranes). This way the diffusion profile of the water depicts the microscopic components of the tissue architecture. It is important to notice, that the axon loss and the demyelination alters the diffusion profile differently. While the axon damage is demonstrated by the alterations in axial diffusivity, the changes of radial diffusivity allude to myelin damage. Diffusion tensor imaging, with appropriate parameters was able to detect widespread alterations of the white matter, even in the non-lesioned, normal appearing white matter (NAWM) (12). These alterations were also correlating with various clinical and cognitive functions $(13,14)$.

Several studies investigated the correlation between various MRI markers and clinical and cognitive dysfunction (14-17), but only a few study investigated the relative importance of these MRI parameters (18-20). Despite the undisputed merit these studies have limitations, as in some of the studies deployed only low number of diffusion directions, only some of the diffusion parameters were used, others did not include all of the subcortical structures separately in the analysis and cognitive domains were evaluated separately only by a few of the investigations.

Moreover, MRI parameters are highly related and that relationship is not trivial (12), conventional linear regression analysis could not unambiguously predict the importance of the variables. The model-free partial least square (PLS) approach, besides handling the problem of collinearity, is able to distinguish a pattern of those parameters that best predicts the variable in question. In the current investigation we set out to identify those MRI parameters, which could predict the clinical disability and
TABLE 1 | Demographic data of the subjects.

\begin{tabular}{lll}
\hline & Healthy & Patients \\
\hline $\mathrm{n}$ & 53 & 53 \\
Age (years; mean $\pm \mathrm{SD}$ ) & $36.06 \pm 11.06$ & $44.34 \pm 11.51$ \\
Sex (male) & 16 & 17 \\
$\begin{array}{l}\text { Education (year } \pm \text { SD) } \\
\text { Disease duration (years; }\end{array}$ & - & $13,71 \pm 2,4$ \\
mean \pm SD) & - & $13.89 \pm 9.02$ \\
EDSS score & - & $1.89 \pm 1.65$ \\
Therapy & - & Interferon beta: 33 \\
& & glatiramer acetate: 20 \\
$\begin{array}{l}\text { Duration of the therapy } \\
\text { (years; mean } \pm \text { SD) }\end{array}$ & - & Interferon beta: $3.89 \pm 3.49$ \\
& & glatiramer acetate: $4.0 \pm$ \\
\end{tabular}

various domains of cognitive dysfunction with the model free PLS approach.

\section{MATERIALS AND METHODS}

\section{Subjects}

The study was carried on 53 patients with relapsing-remitting MS diagnosis and 53 healthy, age-matched controls without history of any neurological or psychiatric diseases. Patients were enrolled from the Multiple Sclerosis Outpatient Clinic at the Department of Neurology. The diagnosis was founded on the 2005 revision of the McDonald criteria (21). The clinical disability was measured on the Kurtzke expanded disability status scale (EDSS) (22). The cognitive performance of patients was measured by Brief international assessment for MS (BICAMS). All patients were on disease-modifying therapy (Table 1). All of our patients were in a stable clinical condition, without relapses or EDSS progression in 6 months before or after the MR scans.

The study was approved by the National Institute of Pharmacy and Nutrition and the Regional Human Biomedical Research Ethics Committee (Ref. No.: 000002/2016/OTIG). All study participant gave their written informed contribution in accordance with the Declaration of Helsinki.

\section{Cognitive Assessment of the Patients}

The Brief International Cognitive Assessment for MS (BICAMS) test is a short form that is a fast, sensitive and specific tool for the determination of the cognitive disability of the patient. The BICAMS test involves 3 separate tests: the symbol digit modalities test (SDMT), the first five recall trials of the California verbal learning test II. (CVLT-II) and the first three recall trials of the brief visuospatial memory test revised (BVMT-R) (23).

In our study we used the validated Hungarian version of the BICAMS test [for details of the validation process see: (2)]. For all subtests of BICAMS the patient's results were compared to the age matched control group of healthy from our earlier validation study (2) more than two standard deviation difference compared to the control database was considered as abnormal. 


\section{Image Acquisition}

MR imaging were carried out on a 1.5T GE Signa Excite HDxt MR scanner. 3D spoiled gradient echo (FSPGR: TE: $4.1 \mathrm{~ms}$, TR: $10.276 \mathrm{~ms}$, matrix: $256 \times 256$, FOV: $25 \times 25 \mathrm{~cm}$, Flip angle: 15 degrees, in-plane resolution: $1 \times 1 \mathrm{~mm}$, slice thickness: $1 \mathrm{~mm}$ ), FLAIR (TE: 133 ms, TR: $6000 \mathrm{~ms}$, TI: $1848 \mathrm{~ms}$, matrix: $256 \times 256$, FOV: $25 \times 25 \mathrm{~cm}$, Flip angle: 90 degrees, in-plane resolution: $1 \times$ $1 \mathrm{~mm}$, slice thickness: $1 \mathrm{~mm}$ ) and 60 direction diffusion-weighted images with 6 non-diffusion-weighted reference volumes (TE: $93.8 \mathrm{~ms}$, TR: $16,000 \mathrm{~ms}$, matrix: $96 \times 96$, FOV: $23 \times 23 \mathrm{~cm}$, Flip angle: 90 degrees, in-plane resolution: $2.4 \times 2.4 \mathrm{~mm}$ slice thickness: $2.4 \mathrm{~mm}$, b: $1,000 \mathrm{~s} / \mathrm{mm}^{2}$, NEX: 2, ASSET) were acquired for all subjects.

\section{Evaluation of Lesion Load}

Lesions were manually segmented on the FLAIR images by ET, and rechecked by ZTK having considerable experience in MS neuroradiology.

\section{Evaluation of Global Atrophy}

The partial brain volume (PBV) was calculated with SIENAX (24), part of FSL $(25,26)$. SIENAX started by extracting brain and skull images from the single whole-head input data (24). Tissuetype segmentation was then carried out (27) in order to calculate the partial volume of brain, the GM and WM.

\section{Volumetric Analysis of the Subcortical Structures}

Image analysis was carried out using tools of FSL (FMRIB Software Library, http://www.fmrib.ox.ac.uk/fsl) (25). To automatically segment the subcortical structures (28), FIRST, a deformable-model-based segmentation/registration tool was used that uses a Bayesian Appearance Model (FMRIB's Integrated Registration Segmentation Toolkit). For the automatic segmentation of structures, shape and intensity variations of subcortical structures were constructed from a training set of 336 images. With preservation of the cross-subject vertex correspondence, surface meshes were obtained with a deformable model. At each vertex a sample was taken from the normalized intensities along the surface normal. Then the vertex location and intensity variation were modeled as a multivariate Gaussian distribution. Finally, maximizing the posterior probability of the shape given the observed intensities, this model was fit to new images $(10,29)$. The result of the segmentation was manually checked and corrected if necessary by the first author. The volume of the segmented subcortical structures were normalized to the head size.

\section{Microstructural Alterations of the White Matter}

Diffusion data were corrected for Eddy currents and movement artifacts by 12 degree-of-freedom affine linear registration to the first non-diffusion-weighted reference image. Diffusion images were processed by using FDT (FMRIB's Diffusion Toolbox part of FSL: www.fmrib.ox.ac.uk/fsl/fdt/). Fractional anisotropy, mean diffusivity $\left[\left(\lambda_{1}+\lambda_{2}+\lambda_{3}\right) / 3\right]$, axial diffusivity $\left(\lambda_{1}\right)$ and radial diffusivity $\left[\left(\lambda_{2}+\lambda_{3}\right) / 2\right]$ to the principal diffusion direction were computed for the whole brain.

The Tract-Based Spatial Statistics (TBSS) method was used to reduce possible errors resulting from misalignment of the images: A non-linear registration tool (FNIRT), which uses a b-spline representation of the registration warp field, aligned all fractional anisotropy images to a $1 \times 1 \times 1 \mathrm{~mm}$ FMRIB58_FA standard space. The data on all patients were brought into the standard space, and the mean fractional anisotropy image was created and then fed into the fractional anisotropy skeletonization program, thresholded at fractional anisotropy $=0.2$ to create a mean fractional anisotropy skeleton that represented the centers of all tracts common to the group. The aligned fractional anisotropy data on each subject were then projected onto this skeleton, which resulted in the $4 \mathrm{D}$ skeletonized fractional anisotropy image.

A voxel-wise alteration of the diffusion parameters, (microstructural integrity index-MII), was calculated for each patient (12), by comparing the value of every voxel with the distribution from the normal subjects in the spatially matching voxel (z-score). To identify a global white matter damage we calculate the averages of these $\mathrm{z}$-scores:

$$
\begin{array}{r}
\overline{X_{n}}=\frac{\sum_{i=1}^{q} X_{n, i}}{q}, \\
\delta_{n}=\frac{\sum_{i=1}^{q}\left(\overline{X_{n}}-X_{n, i}\right)}{q}, \\
Z_{X, n, j}=\frac{X_{n, j}-X_{n}}{\delta_{n}},
\end{array}
$$

where $X$ is the measured diffusion parameter (fractional anisotropy, mean diffusivity, axial diffusivity, and radial diffusivity) in the $\mathrm{n}^{\text {th }}$ voxel in the skeleton. Indices $i$ and $j$ are for controls and patients, respectively.

The average diffusion parameters were calculated for each patient in the lesions and normal appearing white matter: The lesions were projected to the fractional anisotropy skeleton. The manually segmented lesions were brought to the diffusion data space with 6 degree-of-freedom linear registration. Through use of the warp field and the skeleton projections of the TBSS analysis of the fractional anisotropy images, the lesion mask was brought to the skeleton with the FSL tbss_non_fa algorithm. The mask was finally thresholded at 0.5 and binarized to avoid any size increment arising from the interpolation.

\section{Analysis of the Connection Between the MR Parameters and the Clinical and Cognitive Status}

We used partial least square (PLS) regression analysis to estimate the contributions of the various MRI parameters (partial brain volume, normalized gray matter and white matter volume, volume of the subcortical structures, lesion load and the diffusion parameters of the lesions and the normal appearing white matter) to the EDSS and the subscores of the BICAMS test (Figure 1). If 


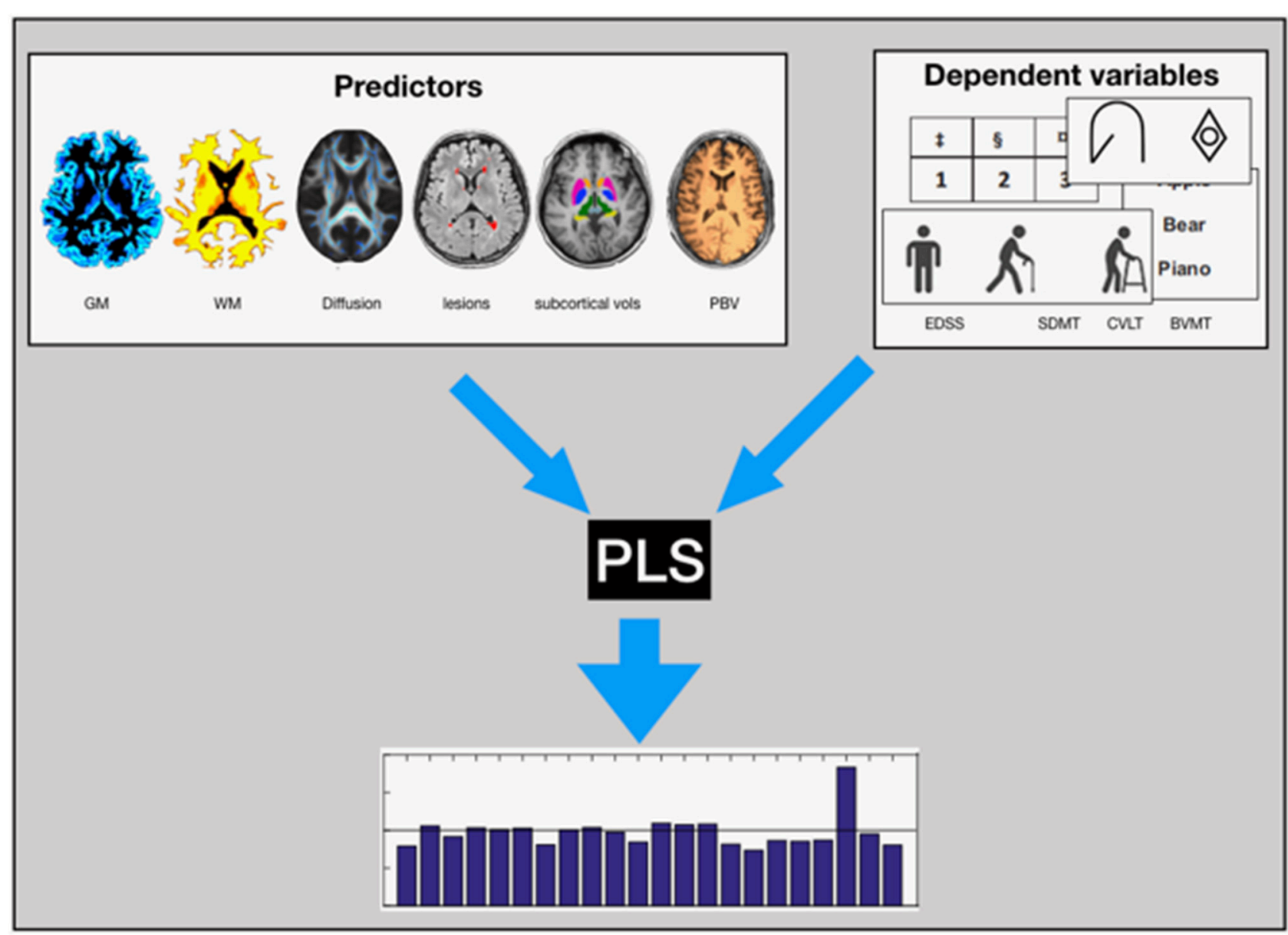

FIGURE 1 | Graphical Presesntation: We used PLS regression analysis to estimate the contributions of the various MRI parameters (GM, WM, the diffusion parameters of the lesions and the normal appearing white matter, the Lesion Load, volume of the subcortical structures, and the PBV) to the EDSS and the subscores of the BICAMS test.

$\mathrm{Y}$ is an $n \times q$ matrix of dependent variables over $\mathrm{n}$ observations and $\mathrm{X}$ is an $n \times p$ matrix of predictors, PLS successively extracts latent variables (factors and loadings) from $\mathrm{X}$ and $\mathrm{Y}$ in such a way that covariance between the factors and loadings is maximized. With this approach, PLS reduces the dimensionality of the data by providing a weighted linear combination of $\mathrm{X}$ variables to form orthogonal components that predicts the dependent variable. In mathematical terms, Partial least squares is a linear decomposition of $\mathrm{X}$ and $\mathrm{Y}$ such that

$$
\begin{aligned}
& \mathrm{X}=\mathrm{TP}^{\mathrm{T}}+\mathrm{E}, \\
& \mathrm{Y}=\mathrm{UQ}^{\mathrm{T}}+\mathrm{F}
\end{aligned}
$$

and the covariance between $\mathrm{T}$ and $\mathrm{U}$ is maximum (30). In the above equations, $\mathrm{T}$ is the $n \times r X$ scores, $U$ is the $n \times r Y$ scores, $P$ is the $p \times r X$ loadings, $Q$ is the $1 \times r Y$ loadings, $\mathrm{E}$, and $\mathrm{F}$ are residuals, and $r$ is the number of extracted latent variables. The statistical inference on the significance of the latent variable was carried out by permutation tests on the singular values of the decomposition. The elements of the dependent variable matrix were randomly permuted 5,000 times and the singular value was recalculated to depict a null distribution. The summary of the importance for the $\mathrm{X}$ loadings was calculated by a Variable Importance in the Projection (VIP) score (31). Since the average of squared Variable Importance in the Projection scores is equal to 1 , the "greater than one" rule was used for the selection of the important variables.

\section{RESULTS}

\section{Clinical, Cognitive, and Imaging Parameters of the Patients}

The patients recruited in our study have mild to moderate disability as measured by EDSS in spite of the relatively long disease duration (Table 1). Out of the 53 patients 18 had cognitive dysfunction on one cognitive test (CVLT: 0, BVMT: 7, SDMT: 9), 8 on two tests (SDMT and BVMT: 7, BVMT and CVLT: 1 ) and 5 on all three tests. 
TABLE 2 | MRI parameters and cognitive scores of the subjects.

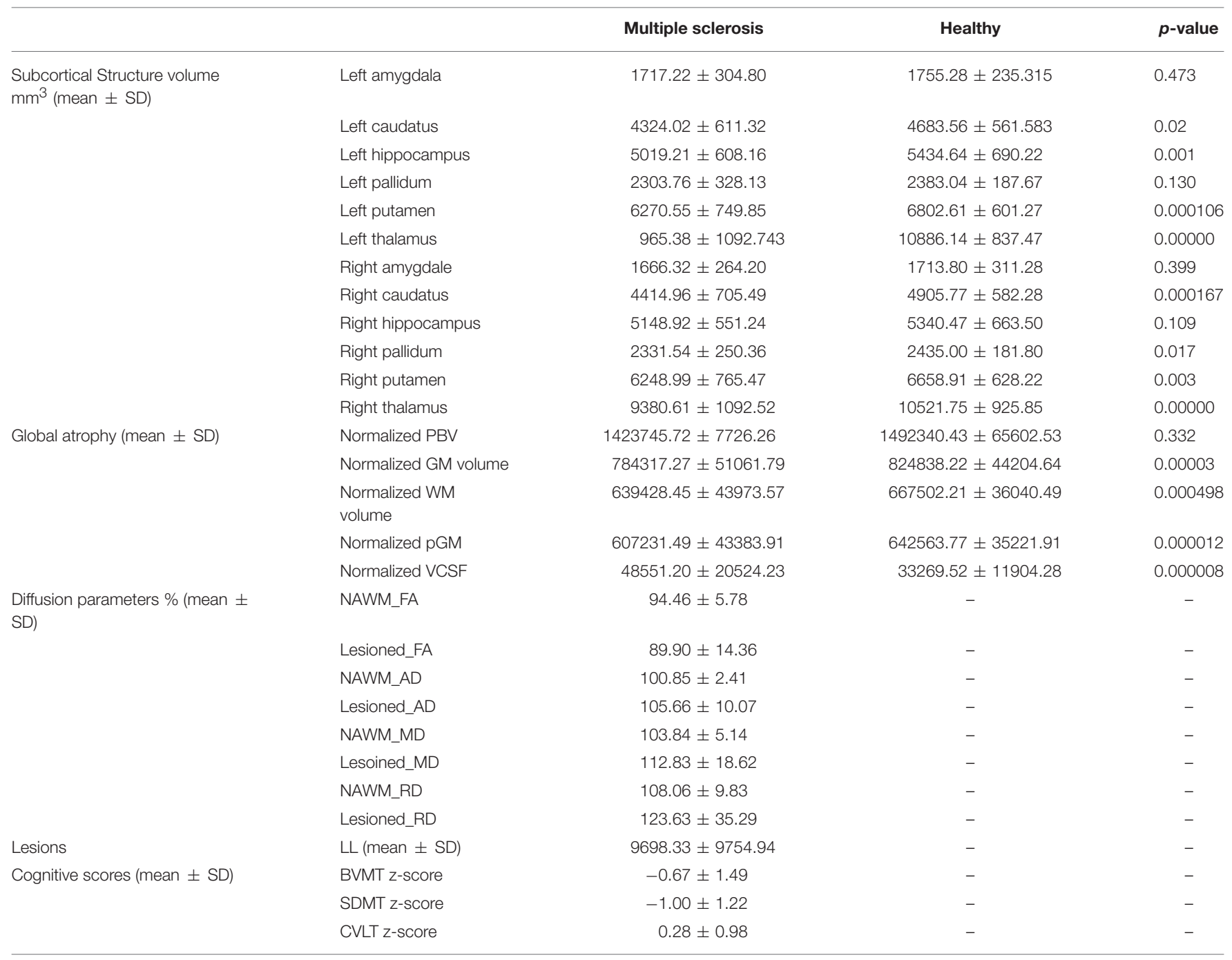

For the measured MRI parameters (partial brain volume, GM and WM volume, volume of the subcortical structures and the diffusion parameters of the white matter) see Table 2.

\section{The Imaging Parameters Influencing Clinical Disability}

In the first PLS analysis, the dependent variable was the EDSS. As the second latent variable interpreted only a small part of the variance of the dependent measure $(<10 \%)$ and the permutation test indicated a non-significant latent variable, only the first latent variable was evaluated. The permutation test showed that the first latent variable was significant $(p<0.001)$ and responsible for $50.67 \%$ of the variation of the dependent variable and $27.08 \%$ of the predictors. The $X$ loadings and the corresponding VIP scores indicated that age (VIP score: 1.72) and the axial diffusivity of the NAWM contributed the most to the clinical disability (VIP score: 1.979) (Figure 2). While far less, but still significant contributor was from the mean diffusivity of the NAWM (VIP score: 1.169), the demyelination features of the lesions $\left(\mathrm{VIP}_{\mathrm{FA}}\right.$ : 1.17, VIP $\mathrm{RD}_{\mathrm{R}}$ : $1.08)$.

\section{The Imaging Parameters Influencing Cognitive Functions}

In these analyses the raw scores from the three subtest of the BICAMS test were used as dependent variables. The first latent variable was evaluated, as the second latent variable was responsible for just a small fraction of the variance of the dependent measure $(<5 \%$ in case of BVMT and CVLT and $10 \%$ in case of SDMT) and the permutation tests indicated non-significant latent variables. The permutation test indicated that the first latent variable was significant $(p<0.001$ for each subtests) and explained for $50.99 \%$ of the variation of the dependent variable and $23.89 \%$ of the predictors in case of the BVMT, for $50.93 \%$ of the variation of the dependent variable and $22.24 \%$ of the predictors in case of the CVLT, for $50.67 \%$ of the variation of the dependent variable and $22.43 \%$ of the predictors in case of the SDMT. 


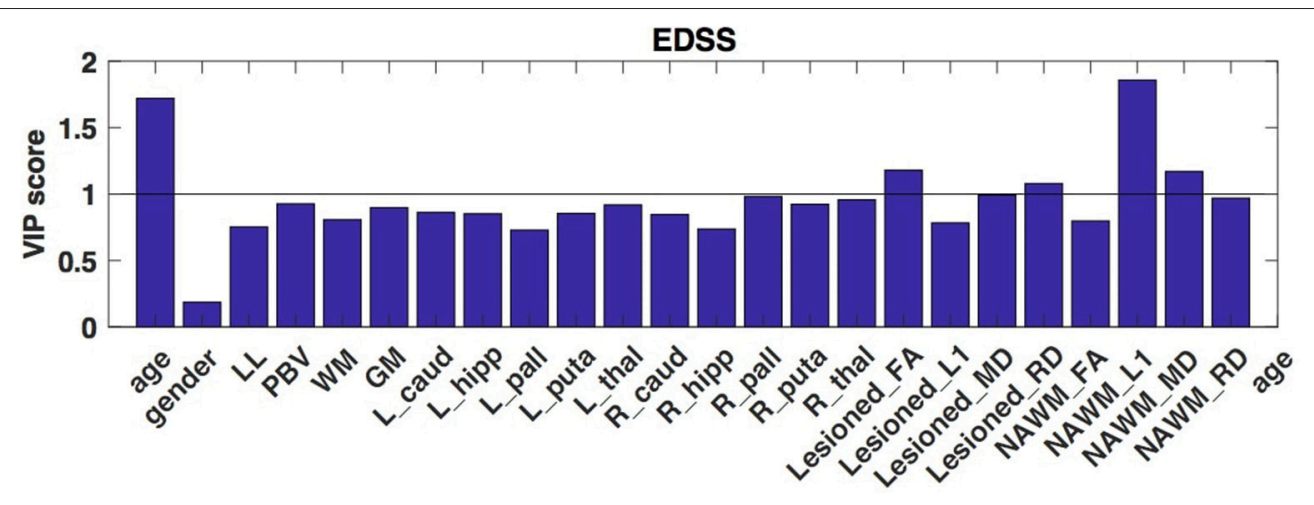

FIGURE 2 | VIP scores of the partial least squares analysis that depict the optimal contrast of the independent variables predicting the clinical disability (EDSS). These VIP scores suggest, that principally the axial diffusivity of the NAWM drives the EDSS. Higher than 1 VIP scores are identified as significant.

Age contributed significantly to all cognitive tests (VIP score: $1.538,1.127$, and 1.296 for BVMT, CVLT, and SDMT, respectively). Gender was significant contributor to CVLT and SDMT (VIP score: 1.356 and 1.345 , respectively).

As regarding the visuo-spatial working memory, the most critical contributor was the size of the bilateral hippocampi (VIP scores: 1.183 and 1.2 left and right, respectively) and the demyelination features of the lesions $\left(\mathrm{VIP}_{\mathrm{FA}}\right.$ score: 1.257, VIP $_{\mathrm{MD}}$ score: 1.008, VIP $\mathrm{RD}_{\mathrm{R}}$ score: 1.158$)$ and the axon loss diffusion features of NAWM (VIP $\mathrm{VA}_{\mathrm{FA}}$ score: $1.125, \mathrm{VIP}_{\mathrm{L} 1}$ score: 1.232) (Figure 3). Lesion load was also a marginally significant contributor (VIP score: 1.031).

For the verbal memory the best predictor was the size of the right hippocampus (VIP score: 1.972), the lesion load (VIP score: 1.274), the partial brain volume (VIP score: 1.119 ) the total white matter volume (VIP score: 1.008), total gray matter volume (VIP score: 1.058), the size of the right caudate (VIP score: 1.152), and the FA of the NAWM (VIP score: 1.012) (Figure 3).

In case of the SDMT test the most significant contribution was from the demyelination-like diffusion parameters of the NAWM (fractional anisotropy and radial diffusivity VIP scores: $1.615,321$, respectively) (Figure 3). The FA, mean and the radial diffusivity of the lesions (VIP scores: 1.289, 1.082, and 1.271, respectively) and the size of the right hippocampus (VIP score: 1.101) also contributed significantly to the performance.

\section{DISCUSSION}

Our model-free analysis of multiparametric MRI data of MS patients revealed complex interplay between the clinical and cognitive disability and various MRI parameters. Clinical disability was best predicted by the axial diffusivity of the NAWM. Cognitive functions were influenced by several factors in the various domains: (i) the most critical MR contributor to the visuo-spatial working memory was the size of the bilateral hippocampi and the demyelination-like diffusion profile of the lesions, and the axon loss of the NAWM; (ii) the best predictor of the verbal memory was the size of the right hippocampus and the brain, gray and white matter volumes, and (iii) information processing speed as measured on the SDMT test was best predicted by the demyelination like diffusion parameter alterations of the white matter.

It is long known that correlation between clinical disability and lesion load is weak $(6,7)$. The correlation of disability with brain atrophy and primarily gray matter atrophy seems to be stronger $(10,32-36)$, however several voxel-wise morphometry studies failed to find correlation of focal gray matter atrophy and disability (37-42). There are conflicting results on the correlation between diffusion metrics and disability. Griffin in a ROI analysis found neither abnormal diffusion parameters in the NAWM nor correlation with disability (43). Filippi et al. (44) found modest correlation between disability and the mean diffusivity of lesions. Hasan found no connection between the fractional anisotropy of the corpus callosum and the disability of patients (45). The anisotropy of the pyramidal tract was correlating with the EDSS in 25 relapsing-remitting MS patients (46). In a whole brain TBSS analysis Onu et al. found widespread differences between controls and MS patients and within these group differences FA correlated with EDSS, hand function and ambulation (47). Ciccarelli and colleagues found connection of the clinical disability with the FA of the supra and infratentorial NAWM. In particularly the FA and $\mathrm{MD}$ of the cerebral peduncles showed a negative correlation with the clinical disability, measured by EDSS (48). Importantly, most of the above mentioned studies limited the analysis to FA. Also the extent of microstructural damage reported was usually far less. Previous studies have demonstrated that the radial and axial diffusivity alterations indicate demyelination and axonal pathology, respectively (49-53). In our previous analysis we showed that the demyeliniation like diffusion parameter changes can be detected in most of investigated white matter skeleton if high number of diffusion directions are investigated (12). Interestingly, our current analysis pointed out, that the clinical disability was best defined by the axial diffusivity of the NAWM.

In recent years cognitive dysfunction in MS become the focus point of research. Patients with multiple sclerosis are usually more concerned about their cognitive impairments, than physical disability, and it has a greater influence on their quality of life (54). Earlier results even suggest that there is an accelerated disease progression in the cognitively impaired patients (55). 

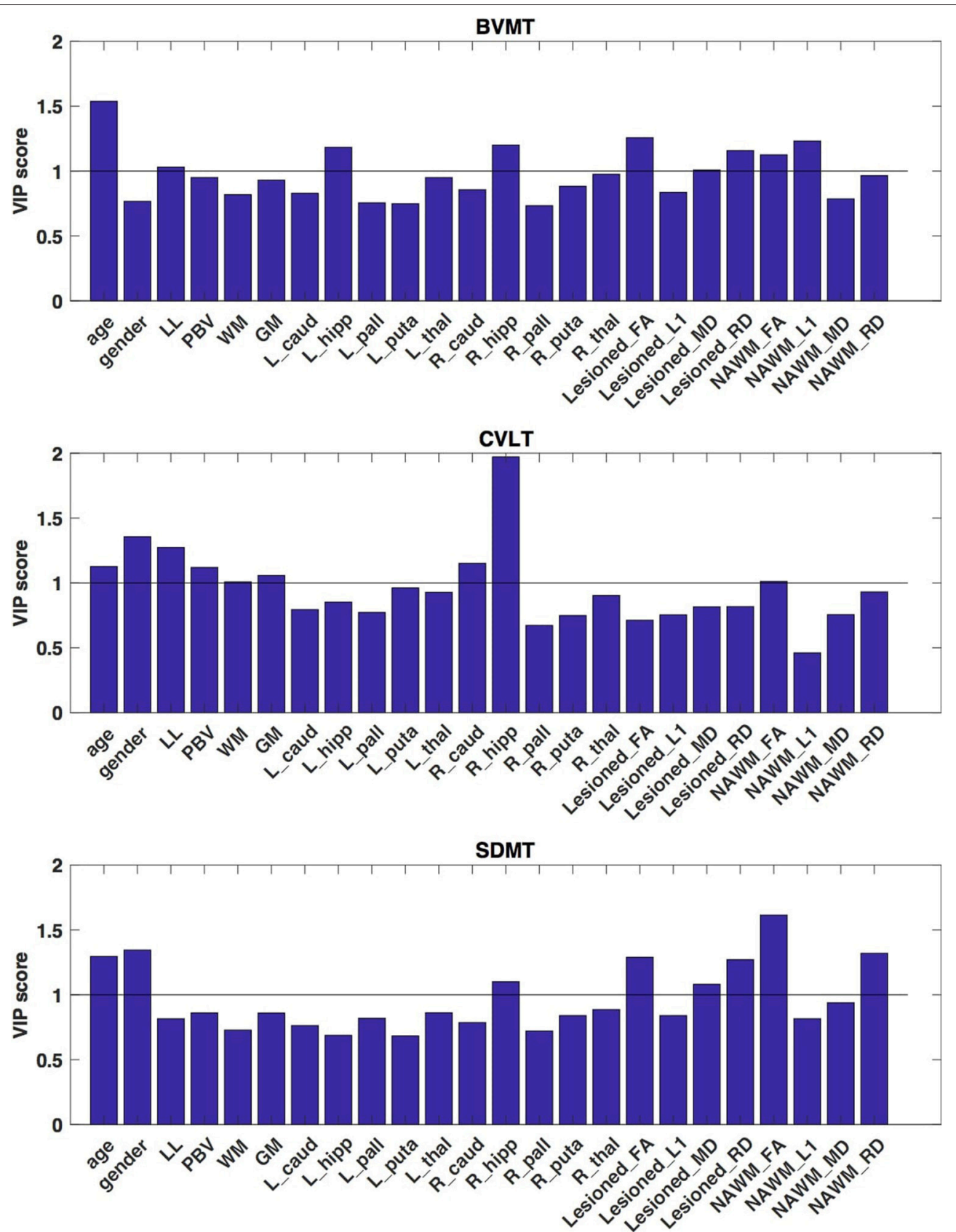

FIGURE 3 | VIP scores of the partial least squares analysis that depict the optimal contrast of the independent variables predicting the cognitive functions. These VIP scores suggest, that for the BVMT the most critical contributor was the size of the bilateral hippocampi, for the CVLT the best predictor was the size of the right hippocampus and the total gray matter volume and in case of the SDMT test the most significant contribution was from the diffusion parameters fractional anisotropy, mean and radial diffusivity of the NAWM. Higher than 1 VIP scores are identified as significant.

Therefore, the research of the structural background of the cognitive dysfunction cannot be overrated. Recently, BICAMS test, a reliable fast tool for cognitive survey become available, but the structural brain abnormality measured with this test was not systematically investigated.

Not only lesion burden, but lesion localization is a weak predictor of cognitive functions (7). There are several studies showing connection between gray matter atrophy and cognitive functions of MS patients. The volume of the thalamus was found to be associated with information processing speed (56), the attention/executive function and also the verbal memory (57). The volume of the putamen correlated with the information processing speed (SDMT test) (11). Hippocampal atrophy also showed a connection to cognitive dysfunction (58-60). In a multicenter study the atrophy of the hippocampus and the deep GM nuclei was found to be the best predictor of cognitive decline 
in MS, while the atrophy developed in the WM was associated with the disability of the patients (61).

The thinning of the different regions of the cortex shows connection with various cognitive functions. While the verbal memory performance showed connection with the cortical thinning in the insula, the visual memory performance correlated to parietal atrophy (62), the reduced verbal fluency was associated to the left-sided, while the impaired figural fluency was related to the right-sided cortical thinning in the anterior cingulate region (63). The auditory information processing speed measured with PASAT shows correlation with the thinning of the orbito-frontal cortex (64).

While the above mentioned studies provide evidence about the relationship of cognitive test and certain MRI measures, only limited number of studies investigated the relative contribution of various structural MRI parameters to clinically relevant set of cognitive test. Our results indicate that the three subtest of the BICAMS is related to the pathology of different brain structures.

The most critical contributor to the visuo-spatial working memory was the size of the bilateral hippocampi. An earlier study investigating the correlation between various cognitive functions and the components of the thalamic-hippocampalprefrontal network found no correlation with the visuo-spatial abilities of the patients and the volume of the hippocampus, but the best predictor of the 7/24 Spatial-Recall Task was the uncinate fasciculus connecting the mediotemporal structures to frontal cortex (57). Other studies found the performance of MS patients on visuospatial memory tests correlated with the diffusion parameters of the fornix, the primary hippocampal efferent $(65,66)$, but not the volume of the hippocampus itself $(65)$. Importantly, the structural abnormality of one structure usually comes along with the other structures connected functionally or structurally (67).

Performance of the verbal memory test was best predicted by the volume of the total gray matter and right hippocampus. Interestingly in the above mentioned study of Dineen on a smaller MS group the volume of the hippocampus did not show correlation with the verbal or the visuo-spatial memory scores (65). Kiy and colleagues found association between the consolidation score of the CVLT test and the right temporal horn volume, an indirect measure of hippocampal atrophy (68). A recent study found correlation between physical activity induced hippocampal viscoelasticity and improvement on CVLT-II test in MS patients (69). Global brain atrophy was found to be correlated with the CVLT long delay recall (52). The learning score of the CVLT-II was correlating with the size of the hippocampus, thalamus, caudate and amygdala, but not with the lesion burden or the brain parenchymal fraction in Benedict's study. According to the linear regression analysis the volume of the caudate predicts the verbal learning ability best (70).

The laterality of the hippocampal atrophy correlating with cognitive performance is also interesting. While in case of the BVMT the both hippocampi were similarly predictors of the cognitive function, in case of the CVLT the right hippocampus was significant predictor but not the left. This later is especially interesting since earlier studies showed that left hippocampal volume was related to verbal while the right to the visuospatial memory (71-73).

Recent study of $\mathrm{Yu}$ found extensive demyelination-like diffusion alterations in the white matter of MS patients spreading well into the NAWM (74). Most of these microstructural alterations correlated with the performance on the SDMT. Importantly out of the three cognitive test SDMT had the largest area of correlation. Another investigation found SDMT performance be correlated with the gray matter fraction and a diffusion measure of the brain parenchyma (18). Interestingly, the authors used a summary statistics for the diffusion metrics similar to our analysis.

Finally, it is important to consider the methods used in the current analysis. There are two important features of our analysis that needs to be considered. (i) We created a clinically feasible, new whole brain summary measure of the diffusion properties, respecting voxel-wise normal variation of the white matter microstructure. This approach is useful, when a large extent of the diffusion parameters are altered, such as in multiple sclerosis (12).

(ii) The contribution of pattern of diffusion parameters to the clinical and cognitive disability was examined by model-free partial least square analysis. If the predictors show high degree of collinearity (like MRI data), the conventional regression analysis might be misleading.

Partial least squares, besides handling the problem of collinearity, is able to distinguish a pattern of those parameters that best predicts the variable in question.

\section{LIMITATIONS}

The main strength of our study is that we have identified the independent contribution of various MRI parameters to the cognitive and clinical disability in MS. Nevertheless, it has to be emphasized that several other quantitative MRI markers were described in multiple sclerosis, such as magnetization transfer imaging, myelin water fraction etc. Including more predictors could possibly give a more through characterization of the dysfunction. Moreover, an important weakness of the approach used in our analysis that we were not considering the spatial distribution of the cortical atrophy. Alternative approaches, such as linked independent component analysis (67) could offer a better characterization of the focal alteration of MRI parameters. It also have to be mentioned that the clinical applicability of theses approach is somewhat limited because of the lengthy data acquisition and processing approaches. However, with advancing MR technology, by establishing the minimum requirements of acquisition parameters (e.g., number of diffusion directions) and improvement of analysis approaches advanced quantitative measures should be available for the clinical practice too.

\section{CONCLUSIONS}

In MS there is a complex pathology of focal lesions and diffuse neuro-glial degeneration affecting the gray matter (cortical and 
subcortical) and also the white matter. These various MRI measurable factors contribute differently to clinical and cognitive disability. Our results indicate that the volumetry of the cortical and subcortical structures and the diffusion measures of the white matter are critical for the understanding the disability progression and these measures should be considered in clinical trials and in the everyday clinical practice.

\section{DATA AVAILABILITY STATEMENT}

All datasets for this study are included in the manuscript and the Supplementary Files.

\section{AUTHOR CONTRIBUTIONS}

ET, NS, and ZK contributed conception and design of the study. $\mathrm{PF}, \mathrm{AK}$, and DS organized the database. $\mathrm{BK}, \mathrm{KK}$, and $\mathrm{DV}$ performed the statistical analysis. ET wrote the first draft of the manuscript. $\mathrm{KB}$ and LV wrote sections of the manuscript. All

\section{REFERENCES}

1. Langdon DW. Cognition in multiple sclerosis. Curr Opin Neurol. (2011) 24:244-9. doi: 10.1097/WCO.0b013e328346a43b

2. Sandi D, Rudisch T, Füvesi J, Fricska-Nagy Z, Huszka H, Biernacki T, et al. The Hungarian validation of the brief international cognitive assessment for multiple sclerosis (BICAMS) battery and the correlation of cognitive impairment with fatigue and quality of life. Mult Scler Relat Disord. (2015) 4:499-504. doi: 10.1016/j.msard.2015.07.006

3. Walker LA, Osman L, Berard JA, Rees LM, Freedman MS, MacLean $\mathrm{H}$, et al. Brief International cognitive assessment for multiple sclerosis (BICAMS): canadian contribution to the international validation project. J Neurol Sci. (2016) 362:147-52. doi: 10.1016/j.jns.2016. 01.040

4. Filippi M, Rocca MA, Ciccarelli O, De Stefano N, Evangelou N, Kappos L, et al. MRI criteria for the diagnosis of multiple sclerosis: MAGNIMS consensus guidelines. Lancet Neurol. (2016) 15:292-303. doi: 10.1016/S1474-4422(15)00393-2

5. Wattjes MP, Rovira À, Miller D, Yousry TA, Sormani MP, de Stefano MP, et al. Evidence-based guidelines: MAGNIMS consensus guidelines on the use of MRI in multiple sclerosis-establishing disease prognosis and monitoring patients. Nat Rev Neurol. (2015) 11:597-606. doi: 10.1038/nrneurol.2015.157

6. Barkhof F. The clinico-radiological paradox in multiple sclerosis revisited. Curr Opin Neurol. (2002) 15:239-45. doi: 10.1097/00019052-200206000-00003

7. Kincses ZT, Ropele S, Jenkinson M, Khalil M, Petrovic K, Loitfelder $\mathrm{M}$, et al. Lesion probability mapping to explain clinical deficits and cognitive performance in multiple sclerosis. Mult Scler. (2011) 17:681-9. doi: 10.1177/1352458510391342

8. Kincses ZT, Tóth E, Bankó N, Veréb D, Szabó N, Csete G, et al. Grey matter atrophy in patients suffering from multiple sclerosis. Ideggyogy Sz. (2014) 67:293-300.

9. De Stefano N, Stromillo ML, Giorgio A, Bartolozzi ML, Battaglini M, Baldini, M. et al. Establishing pathological cut-offs of brain atrophy rates in multiple sclerosis. J Neurol Neurosurg Psychiatry (2015) 87:93-9. doi: 10.1136/jnnp-2014-309903

10. Roosendaal SD, Bendfeldt $\mathrm{K}$, Vrenken $\mathrm{H}$, Polman, $\mathrm{C} \mathrm{H}$, Borgwardt $\mathrm{S}$, Radue EW, et al. Grey matter volume in a large cohort of MS patients: relation to MRI parameters and disability. Mult Scler. (2011) 17:1098-106. doi: 10.1177/1352458511404916

11. Batista S, Zivadinov R, Hoogs M, Bergsland N, Heininen-Brown M, Dwyer $\mathrm{MG}$, et al. Basal ganglia, thalamus, and neocortical atrophy predicting authors contributed to manuscript revision, read, and approved the submitted version.

\section{ACKNOWLEDGMENTS}

The study was supported by: Neuroscience Research Group of the Hungarian Academy of Sciences and the University of Szeged,GINOP-2.3.2-15-2016-00034 grant,EFOP-3.6.1-16-201600008, NAP 2.0 (2017-1.2.1-NKP-2017-00002), National Brain Research Program(KTIA_13_NAP-A-II/20), Bolyai Scholarship Programme of the Hungarian Academy of Sciences, UNKP-173 New National Excellence Program of the Ministry of Human Capacities.

\section{SUPPLEMENTARY MATERIAL}

The Supplementary Material for this article can be found online at: https://www.frontiersin.org/articles/10.3389/fneur. 2018.01172/full\#supplementary-material slowed cognitive processing in multiple sclerosis. J Neurol. (2012) 259:139-46. doi: 10.1007/s00415-011-6147-1

12. Tóth E, Szabó N, Csete G, Király A, Faragó P, Spisák T, et al. Gray matter atrophy is primarily related to demyelination of lesions in multiple sclerosis: a diffusion tensor imaging MRI study. Front Neuroanat. (2017) 11:23. doi: $10.3389 /$ fnana. 2017.00023

13. Hulst HE, Steenwijk MD, Versteeg A, Pouwels PJ, Vrenken H, Uitdehaag $\mathrm{BM}$, et al. Cognitive impairment in MS: impact of white matter integrity, gray matter volume, and lesions. Neurology (2013) 80:1025-32. doi: 10.1212/WNL.0b013e31828726cc

14. Zhang X, Zhang F, Huang D, Wu L, Ma L, Liu H, et al. Contribution of gray and white matter abnormalities to cognitive impairment in multiple sclerosis. Int J Mol Sci. (2016) 18:46. doi: 10.3390/ijms 18010046

15. Filippi M, Rocca MA, Benedict RH, DeLuca J, Geurts JJ, Rombouts SA, et al. The contribution of MRI in assessing cognitive impairment in multiple sclerosis. Neurology (2010) 75:2121-8. doi: 10.1212/WNL.0b013e318200d768

16. Rocca MA, Amato MP, De Stefano N, Enzinger C, Geurts JJ, Penner IK, et al. Clinical and imaging assessment of cognitive dysfunction in multiple sclerosis. Lancet Neurol. (2015) 14:302-17. doi: 10.1016/S1474-4422(14)70250-9

17. Riccitelli GC, Pagani E, Rodegher M, Colombo B, Preziosa P, Falini A, et al. Imaging patterns of gray and white matter abnormalities associated with PASAT and SDMT performance in relapsing-remitting multiple sclerosis. Mult Scler. (2017). doi: 10.1177/1352458517743091. [Epub ahead of print].

18. Benedict RH, Bruce J, Dwyer MG, Weinstock-Guttman B, Tjoa C, Tavazzi E, et al. Diffusion-weighted imaging predicts cognitive impairment in multiple sclerosis. Mult Scler. (2007) 13:722-30. doi: 10.1177/1352458507075592

19. Hulst HE, Gehring K, Uitdehaag BM, Visser LH, Polman CH, Barkhof F, et al. Indicators for cognitive performance and subjective cognitive complaints in multiple sclerosis: a role for advanced $\mathrm{MRI}_{i}{ }^{`}$ Mult Scler. (2014) 20:1131-4. doi: 10.1177/1352458513513969

20. Daams M, Steenwijk MD, Schoonheim MM, Wattjes MP, Balk LJ, Tewarie PK, et al. Multi-parametric structural magnetic resonance imaging in relation to cognitive dysfunction in long-standing multiple sclerosis. Mult Scler. (2016) 22:608-19. doi: $10.1177 / 1352458515596598$

21. Polman CH, Reingold SC, Edan G, Filippi M, Hartung HP, Kappos L, et al. Diagnostic criteria for multiple sclerosis: 2005 revisions to the "McDonald Criteria”. Ann Neurol. (2005) 58:840-6. doi: 10.1002/ana.20703

22. Kurtzke JF. Rating neurologic impairment in multiple sclerosis: an expanded disability status scale (EDSS). Neurology (1983) 33:1444-52. doi: 10.1212/WNL.33.11.1444

23. Langdon DW, Amato MP, Boringa J, Brochet B, Foley F, Fredrikson S, et al. Recommendations for a brief international cognitive assessment 
for multiple sclerosis (BICAMS). Mult Scler. (2012) 18:891-8. doi: $10.1177 / 1352458511431076$

24. Smith SM, Zhang Y, Jenkinson M, Chen J, Matthews PM, Federico A, et al. Accurate, robust, and automated longitudinal and cross-sectional brain change analysis. Neuroimage (2002) 17:479-89. doi: 10.1006/nimg.2002.1040

25. Smith SM, Jenkinson M, Woolrich MW, Beckmann CF, Behrens TE, Johansen-Berg $\mathrm{H}$, et al. Advances in functional and structural MR image analysis and implementation as FSL. Neuroimage (2004) 23 (Suppl. 1):S20819. doi: 10.1016/j.neuroimage.2004.07.051

26. Jenkinson M, Beckmann CF, Behrens TE, Woolrich MW, Smith SM. Fsl. Neuroimage (2012) 62:782-90. doi: 10.1016/j.neuroimage.2011.09.015

27. Zhang Y, Brady M, Smith S. Segmentation of brain MR images through a hidden Markov random field model and the expectation-maximization algorithm. IEEE Trans Med Imaging (2001) 20:45-57. doi: 10.1109/42.906424

28. Patenaude B, Smith SM, Kennedy DN, Jenkinson M. A Bayesian model of shape and appearance for subcortical brain segmentation. Neuroimage (2011) 56:907-22. doi: 10.1016/j.neuroimage.2011.02.046

29. Zarei M, Patenaude B, Damoiseaux J, Morgese C, Smith S, Matthews PM, et al. Combining shape and connectivity analysis: an MRI study of thalamic degeneration in Alzheimer's disease. Neuroimage (2010) 49:1-8. doi: 10.1016/j.neuroimage.2009.09.001

30. Abdi H, Williams LJ. Partial least squares methods: partial least squares correlation and partial least square regression. Methods Mol Biol. (2013) 930:549-79. doi: 10.1007/978-1-62703-059-5_23

31. Wold S, Johansson E, Cocchi M. (1994). PLS - Partial Least Squares Projections to Latent Structures. 3D QSAR in drug design volume 1. In: Kubinyi $\mathrm{H}$, editor. Theory Methods and Applications. Leiden: ESCOM Science Publishers. 523-50.

32. De Stefano N, Matthews PM, Filippi M, Agosta F, De Luca M, Bartolozzi ML, et al. Evidence of early cortical atrophy in MS: relevance to white matter changes and disability. Neurology (2003) 60:1157-62. doi: 10.1212/01.WNL.0000055926.69643.03

33. Amato MP, Bartolozzi ML, Zipoli V, Portaccio E, Mortilla M, Guidi $L$, et al. Neocortical volume decrease in relapsing-remitting MS patients with mild cognitive impairment. Neurology (2004) 63:89-93. doi: 10.1212/01.WNL.0000129544.79539.D5

34. Sanfilipo MP, Benedict RH, Sharma J, Weinstock-Guttman B, Bakshi R. The relationship between whole brain volume and disability in multiple sclerosis: a comparison of normalized gray vs. white matter with misclassification correction. Neuroimage (2005) 26:1068-77. doi: 10.1016/j.neuroimage.2005.03.008

35. Tedeschi G, Lavorgna L, Russo P, Prinster A, Dinacci D, Savettier $\mathrm{G}$, et al. Brain atrophy and lesion load in a large population of patients with multiple sclerosis. Neurology (2005) 65:280-5. doi: 10.1212/01.wnl.0000168837.87351.1f

36. Fisniku LK, Chard DT, Jackson JS, Anderson VM, Altmann DR, Miszkiel $\mathrm{KA}$, et al. Gray matter atrophy is related to long-term disability in multiple sclerosis. Ann Neurol. (2008) 64:247-54. doi: 10.1002/ana.21423

37. Morgen K, Sammer G, Courtney SM, Wolters T, Melchior H, Blecker $\mathrm{CR}$, et al. Evidence for a direct association between cortical atrophy and cognitive impairment in relapsing-remitting MS. Neuroimage (2006) 30:8918. doi: 10.1016/j.neuroimage.2005.10.032

38. Prinster A, Quarantelli M, Orefice G, Lanzillo R, Brunetti A, Mollica $\mathrm{C}$, et al. Grey matter loss in relapsing-remitting multiple sclerosis: a voxel-based morphometry study. Neuroimage (2006) 29:859-67. doi: 10.1016/j.neuroimage.2005.08.034

39. Khaleeli Z, Cercignani M, Audoin B, Ciccarelli O, Miller DH, Thompson, AJ. Localized grey matter damage in early primary progressive multiple sclerosis contributes to disability. Neuroimage (2007) 37:253-61. doi: 10.1016/j.neuroimage.2007.04.056

40. Sastre-Garriga J, Arevalo MJ, Renom M, Alonso J, González I, Galán I, et al. Brain volumetry counterparts of cognitive impairment in patients with multiple sclerosis. J Neurol Sci. (2009) 282:120-4. doi: $10.1016 /$ j.jns.2008.12.019

41. Ceccarelli A, Jackson JS, Tauhid S, Arora A, Gorky J, Dell'Oglio E, et al. The impact of lesion in-painting and registration methods on voxel-based morphometry in detecting regional cerebral gray matter atrophy in multiple sclerosis. AJNR Am J Neuroradiol. (2012) 33:1579-85. doi: 10.3174/ajnr.A3083
42. Cerasa A, Valentino P, Chiriaco C, Pirritano D, Nisticò R, Gioia CM, et al. MR imaging and cognitive correlates of relapsing-remitting multiple sclerosis patients with cerebellar symptoms. J Neurol. (2013) 260:1358-66. doi: 10.1007/s00415-012-6805-y

43. Griffin CM, Chard DT, Ciccarelli O, Kapoor B, Barker GJ, Thompson, A. I. et al. Diffusion tensor imaging in early relapsing-remitting multiple sclerosis. Mult Scler. (2001) 7:290-7. doi: 10.1177/135245850100700504

44. Filippi M, Cercignani M, Inglese M, Horsfield MA, Comi G. Diffusion tensor magnetic resonance imaging in multiple sclerosis. Neurology (2001) 56:30411. doi: 10.1212/WNL.56.3.304

45. Hasan KM, Gupta RK, Santos RM, Wolinsky JS, Narayana PA. Diffusion tensor fractional anisotropy of the normal-appearing seven segments of the corpus callosum in healthy adults and relapsing-remitting multiple sclerosis patients. J Magn Reson Imaging (2005) 21:735-43. doi: 10.1002/jmri.20296

46. Wilson M, Tench CR, Morgan PS, Blumhardt LD. Pyramidal tract mapping by diffusion tensor magnetic resonance imaging in multiple sclerosis: improving correlations with disability. J Neurol Neurosurg Psychiatry (2003) 74:203-7. doi: 10.1136/jnnp.74.2.203

47. Onu M, Roceanu A, Sboto-Frankenstein U, Bendic R, Tarta E, Preoteasa F, et al. Diffusion abnormality maps in demyelinating disease: correlations with clinical scores. Eur J Radiol. (2012) 81:e386-91. doi: 10.1016/j.ejrad.2011.12.014

48. Ciccarelli O, Werring DJ, Wheeler-Kingshott CA, Barker GJ, Parker GJ, Thompson AJ, et al. Investigation of MS normal-appearing brain using diffusion tensor MRI with clinical correlations. Neurology (2001) 56:926-33. doi: 10.1212/WNL.56.7.926

49. Pierpaoli C, Barnett A, Pajevic S, Chen R, Penix LR, Virta A, et al. Water diffusion changes in Wallerian degeneration and their dependence on white matter architecture. Neuroimage (2001) 13(6 Pt 1):1174-85. doi: 10.1006/nimg.2001.0765\$1053811901907657

50. Sun SW, Liang HF, Trinkaus K, Cross AH, Armstrong RC, Song SK. Noninvasive detection of cuprizone induced axonal damage and demyelination in the mouse corpus callosum. Magn Reson Med. (2006) 55:302-8. doi: 10.1002/mrm.20774

51. Kim JH, Budde MD, Liang HF, Klein RS, Russell JH, Cross AH, et al. Detecting axon damage in spinal cord from a mouse model of multiple sclerosis. Neurobiol Dis. (2006) 21:626-32. doi: 10.1016/j.nbd.2005.09.009

52. Sun SW, Liang HF, Cross AH, Song SK. Evolving Wallerian degeneration after transient retinal ischemia in mice characterized by diffusion tensor imaging. NeuroImage (2008) 40:1-10. doi: 10.1016/j.neuroimage.2007. 11.049

53. Zhang J, Jones M, DeBoy CA, Reich DS, Farrell JA, Hoffman PN, et al. Diffusion tensor magnetic resonance imaging of Wallerian degeneration in rat spinal cord after dorsal root axotomy. J Neurosci. (2009) 29:3160-71. doi: 10.1523/JNEUROSCI.3941-08.2009

54. Fricska-Nagy Z, Fuvesi J, Rózsa C, Komoly S, Jakab G, Csépány T, et al. The effects of fatigue, depression and the level of disability on the healthrelated quality of life of glatiramer acetate-treated relapsing-remitting patients with multiple sclerosis in Hungary. Mult Scler Relat Disord. (2016) 7:26-32. doi: 10.1016/j.msard.2016.02.006

55. Sander C, Eling P, Hanken K, Klein J, Kastrup A, Hildebrandt H. The impact of MS-related cognitive fatigue on future brain parenchymal loss and relapse: a 17-month follow-up study. Front Neurol. (2016) 7:155. doi: 10.3389/fneur.2016.00155

56. Koini M, Filippi M, Rocca MA, Yousry T, Ciccarelli O, Tedeschi G, et al. Correlates of executive functions in multiple sclerosis based on structural and functional MR imaging: insights from a multicenter study. Radiology (2016) 280:869-79. doi: 10.1148/radiol.2016151809

57. Kern KC, Gold SM, Lee B, Montag M, Horsfall J, O'Connor MF, et al. Thalamic-hippocampal-prefrontal disruption in relapsing-remitting multiple sclerosis. Neuroimage Clin. (2015) 8:440-7. doi: 10.1016/j.nicl.2014. 12.015

58. Hulst HE, Schoonheim MM, Van Geest Q, Uitdehaag BM, Barkhof F, Geurts JJ. Memory impairment in multiple sclerosis: relevance of hippocampal activation and hippocampal connectivity. Mult Scler. (2015) 21:1705-12. doi: $10.1177 / 1352458514567727$

59. Sacco R, Bisecco A, Corbo D, Della Corte M, d'Ambrosio A, Docimo R, et al. Cognitive impairment and memory disorders in relapsing-remitting multiple 
sclerosis: the role of white matter, gray matter and hippocampus. J Neurol. (2015) 262:1691-7. doi: 10.1007/s00415-015-7763-y

60. Rocca MA, Morelli ME, Amato MP, Moiola L, Ghezzi A, Veggiotti P, et al. Regional hippocampal involvement and cognitive impairment in pediatric multiple sclerosis. Mult Scler. (2016) 22:628-40. doi: $10.1177 / 1352458515598569$

61. Damjanovic D, Valsasina P, Rocca MA, Stromillo ML, Gallo A, Enzinger C, et al. Hippocampal and deep gray matter nuclei atrophy is relevant for explaining cognitive impairment in MS: a multicenter study. AJNR Am J Neuroradiol. (2017) 38:18-24. doi: 10.3174/ajnr.A4952

62. Tillema JM, Hulst HE, Rocca MA, Vrenken H, Steenwijk MD, Damjanovic $\mathrm{D}$, et al. Regional cortical thinning in multiple sclerosis and its relation with cognitive impairment: a multicenter study. Mult Scler. (2016) 22:901-9. doi: $10.1177 / 1352458515607650$

63. Geisseler O, Pflugshaupt T, Bezzola L, Reuter K, Weller D, Schuknecht $\mathrm{B}$, et al. Cortical thinning in the anterior cingulate cortex predicts multiple sclerosis patients' fluency performance in a lateralised manner. Neuroimage Clin. (2016) 10:89-95. doi: 10.1016/j.nicl.2015. 11.008

64. Sbardella E, Petsas N, Tona F, Prosperini L, Raz E, Pace G, et al. Assessing the correlation between grey and white matter damage with motor and cognitive impairment in multiple sclerosis patients. PLoS ONE (2013) 8:e63250. doi: 10.1371/journal.pone.0063250

65. Dineen RA, Bradshaw CM, Constantinescu CS, Auer DP. Extrahippocampal subcortical limbic involvement predicts episodic recall performance in multiple sclerosis. PLoS ONE (2012) 7:e44942. doi: 10.1371/journal.pone.0044942

66. Koenig KA, Sakaie KE, Lowe MJ, Lin J, Stone L, Bermel RA, et al. High spatial and angular resolution diffusion-weighted imaging reveals forniceal damage related to memory impairment. Magn Reson Imaging (2013) 31:695-9. doi: 10.1016/j.mri.2012.10.030

67. Kincses ZT, Horinek D, Szabo N, Toth E, Csete G, Stepan-Buksakowska I, et al. The pattern of diffusion parameter changes in Alzheimer's disease, identified by means of linked independent component analysis. J Alzheimers Dis. (2013) 36:119-28. doi: 10.3233/JAD-122431

68. Kiy G, Lehmann P, Hahn HK, Eling P, Kastrup A, Hildebrandt H. Decreased hippocampal volume, indirectly measured, is associated with depressive symptoms and consolidation deficits in multiple sclerosis. Mult Scler. (2011) 17:1088-97. doi: 10.1177/1352458511403530

69. Sandroff BM, Johnson CL, Motl RW. Exercise training effects on memory and hippocampal viscoelasticity in multiple sclerosis: a novel application of magnetic resonance elastography. Neuroradiology (2017) 59:61-7. doi: 10.1007/s00234-016-1767-x

70. Benedict RH, Ramasamy D, Munschauer F, Weinstock-Guttman B, Zivadinov R. Memory impairment in multiple sclerosis, correlation with deep grey matter and mesial temporal atrophy. J Neurol Neurosurg Psychiatry (2009) 80:201-6. doi: 10.1136/jnnp.2008.148403

71. Shi F, Liu B, Zhou Y, Yu C, Jiang T. Hippocampal volume and asymmetry in mild cognitive impairment and Alzheimer's disease: meta-analyses of MRI studies. Hippocampus (2009) 19:1055-64. doi: 10.1002/hipo.20573

72. Travis SG, Huang Y, Fujiwara E, Radomski A, Olsen F, Carter R, et al. High field structural MRI reveals specific episodic memory correlates in the subfields of the hippocampus. Neuropsychologia (2014) 53:233-45. doi: 10.1016/j.neuropsychologia.2013.11.016

73. Ezzati A, Katz MJ, Zammit AR, Lipton ML, Zimmerman ME, Sliwinski MJ, et al. Differential association of left and right hippocampal volumes with verbal episodic and spatial memory in older adults. Neuropsychologia (2016) 93(Pt B):380-5. doi: 10.1016/j.neuropsychologia.2016.08.016

74. Yu HJ, Christodoulou C, Bhise V, Greenblatt D, Patel Y, Serafin $\mathrm{D}$, et al. Multiple white matter tract abnormalities underlie cognitive impairment in RRMS. Neuroimage (2012) 59:3713-22. doi: 10.1016/j.neuroimage.2011.10.053

Conflict of Interest Statement: The authors declare that the research was conducted in the absence of any commercial or financial relationships that could be construed as a potential conflict of interest.

Copyright @ 2019 Tóth, Faragó, Király, Szabó, Veréb, Kocsis, Kincses, Sandi, Bencsik, Vécsei and Kincses. This is an open-access article distributed under the terms of the Creative Commons Attribution License (CC BY). The use, distribution or reproduction in other forums is permitted, provided the original author(s) and the copyright owner(s) are credited and that the original publication in this journal is cited, in accordance with accepted academic practice. No use, distribution or reproduction is permitted which does not comply with these terms. 